Index of Surface-Water Records to September 30, 1967

Part 12.-Pacific Slope Basins in Washington and Upper Columbia River Basin 



\section{Index of Surface-Water Records to September 30, 1967 Part 12.-Pacific Slope Basins in Washington and Upper Columbia River Basin}

By H. P. Eisenhuth

GEOLOGICAL SURVEY CIRCULAR 582 
United States Department of the Interior STEWART L. UDALL, Secretary

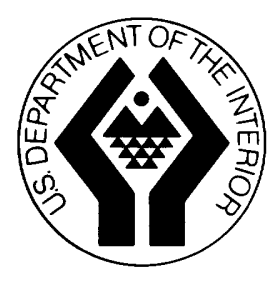

\section{Geological Survey}

William T. Pecora, Director

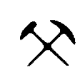




\title{
Index of Surface-Water Records to September 30, 1967
}

\author{
Part 12.-Pacific Slope Basins in Washington and Upper Columbia River Basin
}

\author{
By H. P. Eisenhuth
}

\section{INTRODUCTION}

This report lists the streamflow and reservoir stations in the Pacific slope basins in Washington and upper Columbia River basin for which records have been or are to be published in reports of the Geological Survey for periods through September 30, 1967. It supersedes Geological Survey Circular 512.

Basic data on surface-water supply have been published in an annual series of water-supply papers consisting of several volumes, including one each for the States of Alaska and Hawaii. The area of the other 48 States is divided into 14 parts whose boundaries coincide with certain natural drainage lines. Prior to 1951 , the records for the 48 States were published in 14 volumes, one for each of the parts. From 1951 to 1960, the records for the 48 States were published annually in 18 volumes, there being 2 volumes each for Parts $1,2,3$, and 6 . The boundaries of the various parts are shown on the map in figure 1.

Beginning in 1961, the annual series of water-supply papers on surface-water supply was changed to a 5-year series. Records for the period 1961-65 will be published in a series of water-supply papers using the same 14 part division for the 48 States, but most parts will be further subdivided into two or more volumes. In order to meet interim requirements, beginning in 1961, local offices issue reports annually containing streamflow records for the State or States within the local district.

In addition to the continuous-record gaging stations, this index includes crest-stage and low-flow partial-record stations. A continuous-record station is a gaging station on a stream or reservoir for which the discharge, stage, or contents is published on a daily, weekly, or monthly basis for a continuous period of time. A crest-stage partial-record station is a streamflow station for which only the annual maximum discharge is published over a period of years for use in floodflow analyses. A low-flow partial-record station is a streamflow station for which only discharge measurements made at base flow, when streamflow is primarily from ground-water storage, are published. Measurements are generally collected over a period of five years or more for use in low-flow analyses. Discharge measurements have been made at many sites and published as miscellaneous measurements. Such measurements are not included in this index except those made in earlier years at sites now classified as low-flow partial-record stations.

Explanation of reference marks is given at the end of the index.

An alphabetical list of streams, lakes, and reservoirs is given at the end of this circular.

\section{DOWNSTREAM ORDER}

The stations in this index are listed in the downstream order used in the series of water-supply papers on surfacewater supply of the United States since 1951. Starting at the headwater of each stream, all stations are listed in a downstream direction. Tributary streams are indicated by indention and are inserted between main-stem stations in the order in which they enter the main stream. To indicate the rank of any tributary on which a record is available and the stream to which it is immediately tributary, each indention in the listing of stations represents one rank. A stream name, only, is inserted where necessary for the purpose of showing the proper rank or order of tributaries.

\section{STATION NAMES}

Station names are given in their most recently published form. Parentheses around part of a station name indicate that the enclosed word or words were used in an earlier published name of the station or as an alternate name. Parenthetical explanations are also used to indicate that a stream of a different name is the head of the main stream by use of "(head of River)" and that the name of the main stream has changed by use of "(continuation of River). 


\section{STATION NUMBER}

As an added means of identification, each continuous- and partial-record station has been assigned a station number. The numbers have been assigned in the same downstream order used in this index. In assigning station number, gaps were left to allow for new stations that may be established; hence the numbers are not consecutive. The complete number for each station includes the part number, which is omitted in this index. The number given consists of only the essential digits of the complete number. For example, for a station with the complete number 12-0145.00, the station number shown in this index is 0145 .

\section{DRAINAGE AREA}

The drainage area, in square miles, is the latest figure published or otherwise available at this time.

Under "Periods of record" are three columns. The first column, "Daily or monthly figures," shows the periods of record for continuous-record gaging stations. The dates given are the calendar years in which records began or ended; breaks of less than a year are not shown. For example, if a record began in October 1923, ended in April 1932, began again in March 1933, and ended in September 1944, the period of record would be shown as 1923-44.

The second column, "Annual peaks," shows the period of record for crest-stage partial-record stations. The dates given are the water years for which the annual maximum discharge is available. The water year begins October 1 and ends September 30. In listing the water year, only one date is shown; for example, 1952 stands for the water year October 1, 1951, to September 30, 1952.

The third column, "Low-flow measurements," shows the period of record for low-flow partial-record stations. The dates given are the water years in which base-flow measurements were made at low-flow partial-record stations: breaks of less than two years are not shown. Prior to the 1958 water year, such measurements were published in tables headed "Miscellaneous discharge measurements" or "Discharge measurements at sites other than gaging stations." Many discharge measurements have been made at miscellaneous sites which are not listed in this index because the data collected were not sufficient to qualify the site as a low-flow partial-record station.

A date followed by only a dash shows that the station was continued in operation beyond September 30, 1967. A date followed by a period indicates discontinuance. A date followed by a semicolon indicates a break in the collection of records.

Periods of record for the same continuous-record station published by other agencies are listed only when they are for periods not published in reports of the Geological Survey. These periods are indicated by symbols and footnotes. Records collected by other agencies are included only for stations for which there is some record published in Geological Survey reports. 


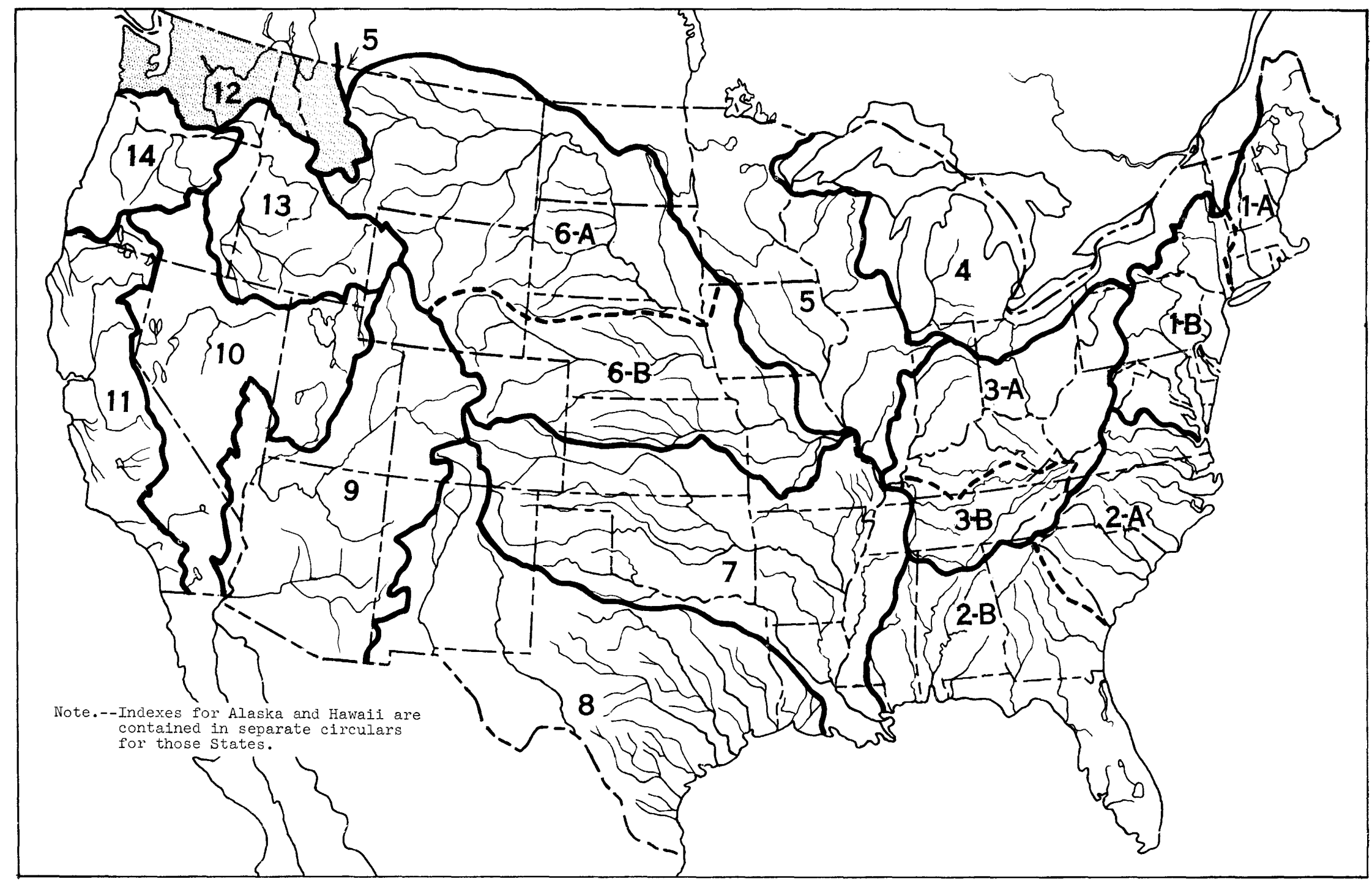

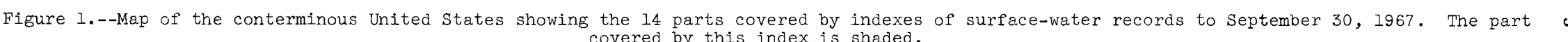




\begin{tabular}{|c|c|c|c|c|c|}
\hline \multirow{2}{*}{ Station name } & \multirow{2}{*}{$\begin{array}{r}\text { Station } \\
\text { number }\end{array}$} & \multirow{2}{*}{$\begin{array}{c}\text { Drainage area } \\
(\mathrm{sq} \mathrm{mi})\end{array}$} & \multicolumn{3}{|c|}{ Periods of record } \\
\hline & & & $\begin{array}{c}\text { Daily or monthly figures } \\
\text { (calendar years) }\end{array}$ & $\begin{array}{l}\text { Annual peaks } \\
\text { (water years) }\end{array}$ & $\begin{array}{c}\text { Low-flow measurements } \\
\text { (water years) }\end{array}$ \\
\hline 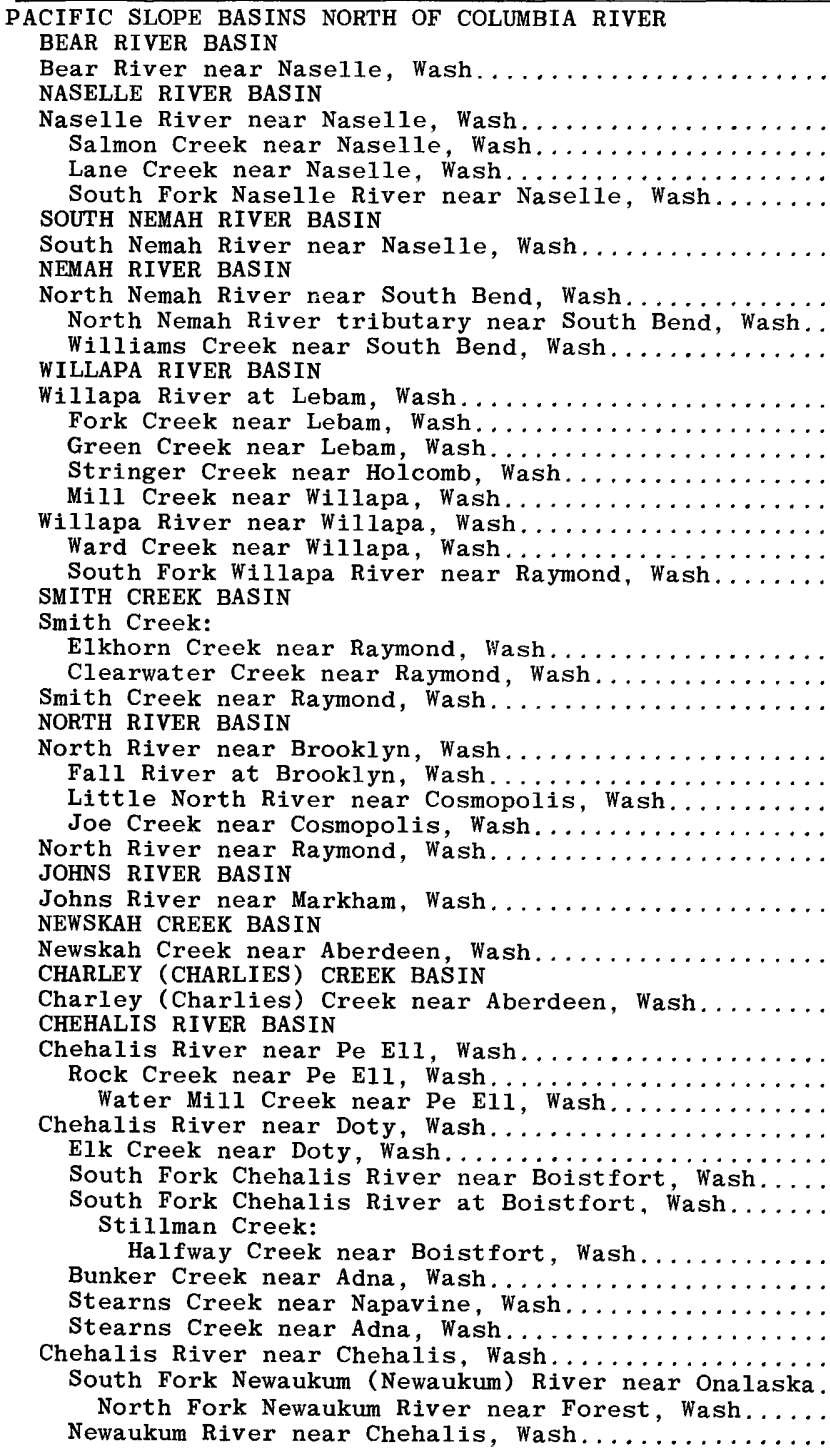 & $\begin{array}{l}0150 \\
0151 \\
0152 \\
\\
0155 \\
0160 \\
0165 \\
0167 \\
0170 \\
\\
0175 \\
\\
0180 \\
0185 \\
\\
0190 \\
0195 \\
0196 \\
0200 \\
0205 \\
0209 \\
0210 \\
\\
0215 \\
02,0 \\
0225 \\
0230 \\
0235 \\
0240 \\
0245 \\
0250\end{array}$ & $\begin{array}{c}11.7 \\
54.8 \\
16.4 \\
2.15 \\
17.9 \\
1.99 \\
18.0 \\
.46 \\
9.43 \\
41.4 \\
20.4 \\
1.79 \\
2.93 \\
23.7 \\
130 \\
19.3 \\
27.8 \\
\\
15.6 \\
3.98 \\
57.7 \\
29.8 \\
41.0 \\
18.6 \\
2.05 \\
219 \\
19.2 \\
7.44 \\
5.93 \\
56.1 \\
14.0 \\
1.98 \\
113 \\
46.7 \\
44.9 \\
48.0 \\
13.7 \\
20.5 \\
16.2 \\
27.1 \\
434 \\
42.4 \\
31.5 \\
155\end{array}$ & 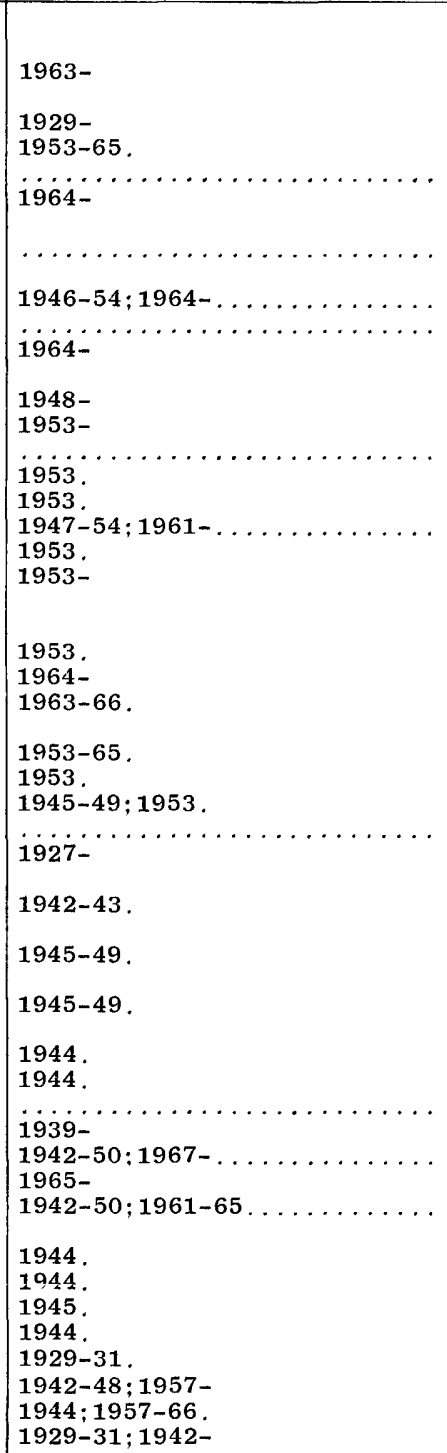 & $1950-$ & \\
\hline
\end{tabular}


Chehalis River at Centralia, Wash...

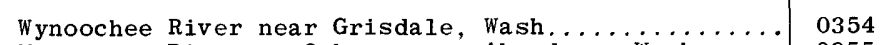
Wynoochee River at Oxbow, near Aberdeen, Wash....... 0355 Wynoochee River above Save Creek, near Aberdeen.... 0360

\begin{tabular}{c|c} 
Wynoochee River near Montesano, Wash..................... & 0365 \\
City of Aberdeen Wynoochee River intake near & 0370 \\
Montesano, Wash.
\end{tabular}

Wynoochee River above Black Creek, near Montesano. Wynoochee River below Black Cr Wishkah River near Wishkah, Wash............... 0380 HOQUIAM RIVER BASIN

Hoquiam River:

West Fork Hoquiam River near Hoquiam, Wash....... 0385

HUMPTULIPS RIVER BASIN

umptulips River:

est Fork Humptulips River:

Gibson Creek near Quinault, Wash $\ldots \ldots \ldots \ldots \ldots \ldots$
Humptulips River near Humptulips, Wash $\ldots \ldots \ldots \ldots \ldots$

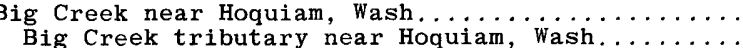
Big Creek tributa
QUINAULT RIVER BASIN

Quinault River:

North Fork Quinault River near Amanda Park, Wash. .

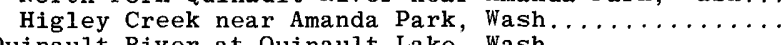

QUEETS RIVER BASIN

ueets River:

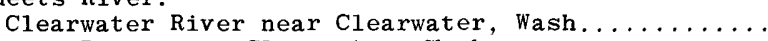

Queets Biver near Clearwater. Wash.......................

HOH RIVER BASIN

Hoh River near Forks (Spruce), wash ..................... 0410

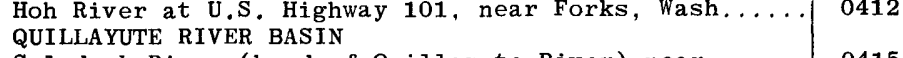

Soleduck River (head of Quillayute River) near

Fairholm, Wash.

0416

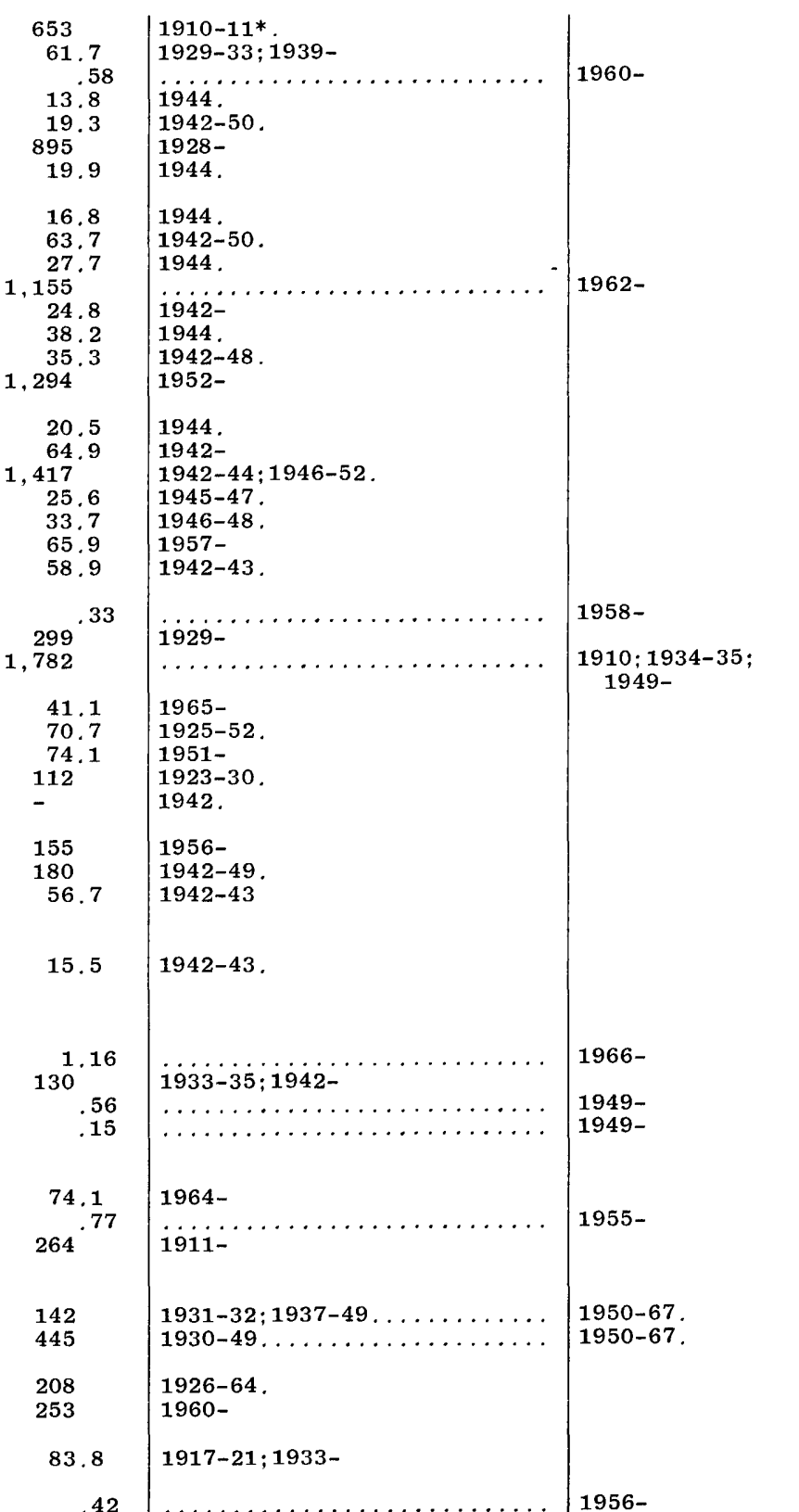




\begin{tabular}{|c|c|c|c|c|c|}
\hline \multirow{2}{*}{ Station name } & \multirow{2}{*}{$\begin{array}{l}\text { Station } \\
\text { number }\end{array}$} & \multirow{2}{*}{$\begin{array}{c}\text { Drainage area } \\
(\text { sq mi) }\end{array}$} & \multicolumn{3}{|c|}{ Periods of record } \\
\hline & & & $\begin{array}{c}\text { Daily or monthly figures } \\
\text { (calendar years) }\end{array}$ & $\begin{array}{l}\text { Annual peaks } \\
\text { (water years) }\end{array}$ & $\begin{array}{l}\text { Low-flow measurements } \\
\text { (water years) }\end{array}$ \\
\hline 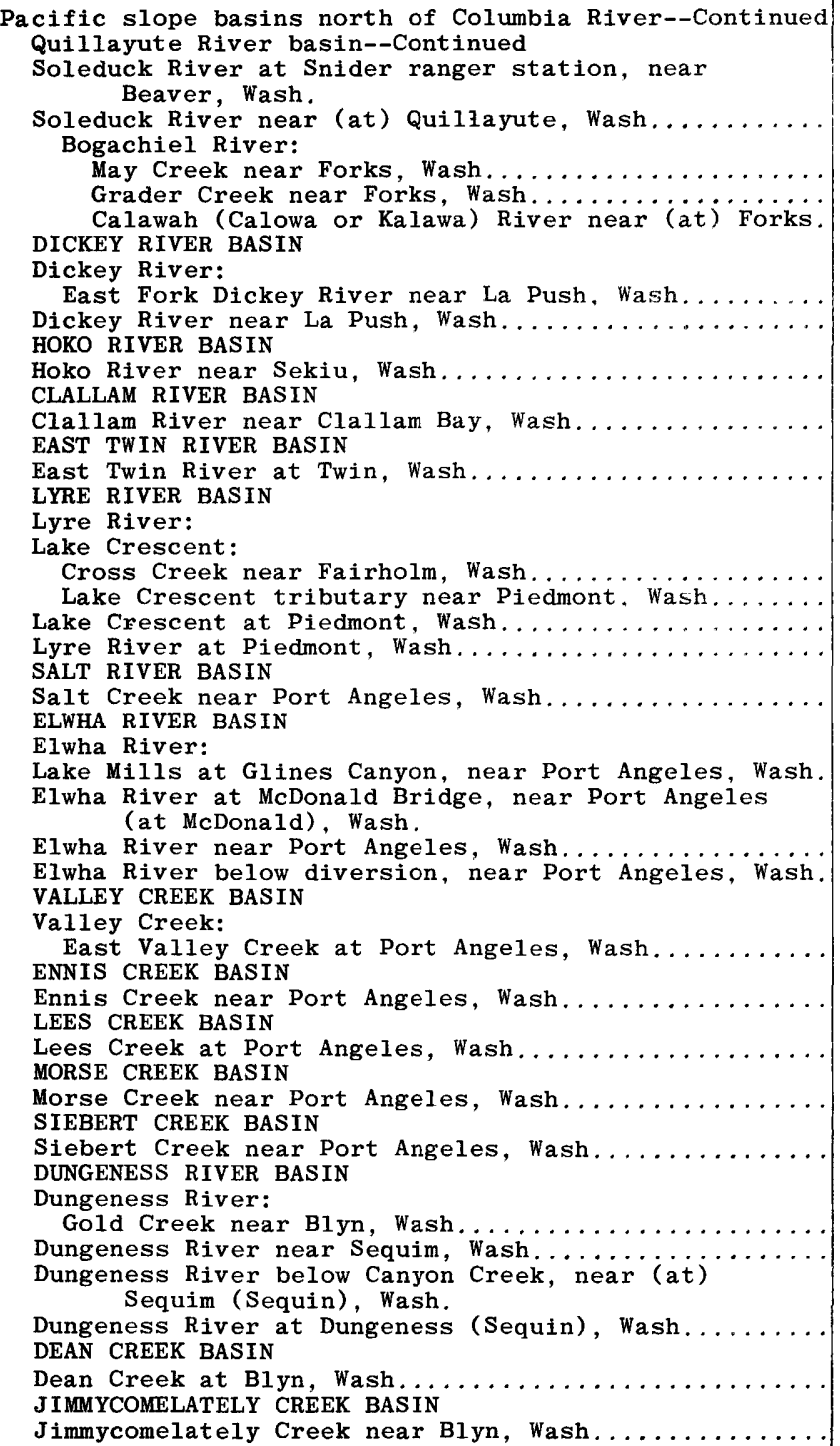 & \begin{tabular}{|l}
$12-$ \\
0420 \\
0425 \\
0427 \\
0429 \\
0430 \\
\\
0430.8 \\
0431 \\
0433 \\
0433.5 \\
0434.3 \\
\\
0434.5 \\
0434.7 \\
0435 \\
0440 \\
0445 \\
\\
0450 \\
0455 \\
0460
\end{tabular} & $\begin{array}{l}219 \\
2.03 \\
1.67 \\
129 \\
\\
39.8 \\
86.3 \\
51.2 \\
137 \\
14.0 \\
\\
\\
.92 \\
.79 \\
48.6 \\
48.6 \\
7.07 \\
\\
245 \\
269 \\
315 \\
318 \\
\\
.69 \\
7.92 \\
4.77 \\
46.6 \\
15.5\end{array}$ & 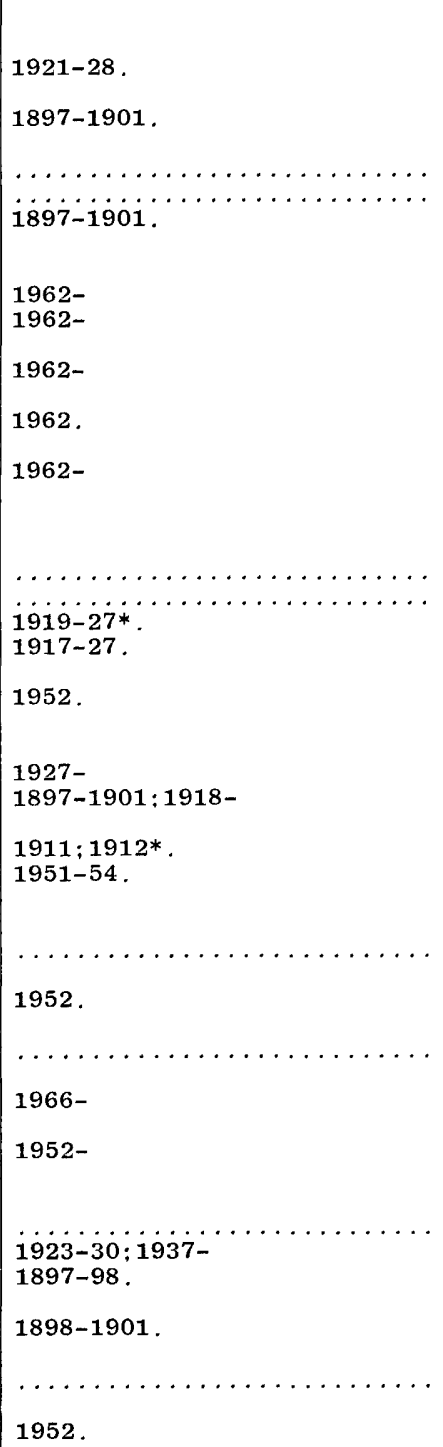 & $\begin{array}{l}1950-56 \\
1956-58\end{array}$ & \\
\hline
\end{tabular}


SALMON CREEK BASIN

Salmon Creek near Maynard, Wash............... 0500

... 0505

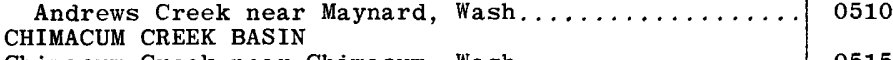

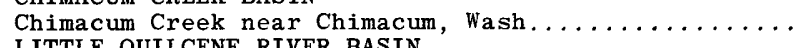

Little Quilcene River near Quilcene, Wash........... 0520

BIG QUILCENE RIVER BASTN

Big Quilcene River:

Penny Creek near Quilcene, Wash............... 0527

Big Quilcene River at (near) Quilcene, Wash......... 0528

DOSEWALLIPS RIVER BASIN

Dosewallips River near Brinnon, Wash............... 0530

Dosewallips River tributary near Brinnon, Wash.... 0534

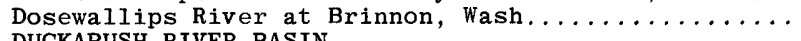

Duckabush River near Brinnon (Duckabush), Wash.....

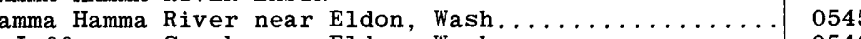

Jefferson Creek near Eldon, Wash.............. 0546

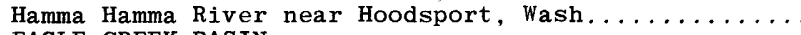

EAGLE CREEK BASIN

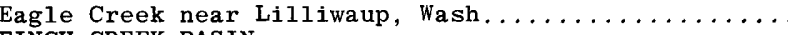

FINCH CREEK BASIN

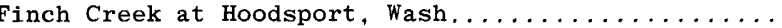

ANNAS BAY BASIN

nnas Bay:

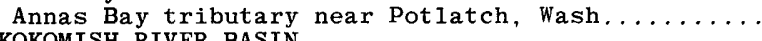

North Fork Skokomish River below Staircase Rapids. near Hoodsport, Wash.

Lake Cushman (Reservoir) near Hoodsport, Wash........ 0570 North Fork Skokomish River near Hoodsport, Wash...... 0575 Deer Meadow Creek near Hoodsport, Wash.......... 0580

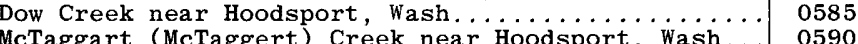
McTaggart (McTaggert) Creek near Hoodsport, Wash... 0590

North Fork Skokomish River near Potlatch, Wash....... 0595 South Fork Skokomish River near Hoodsport, Wash.... 0598 South Fork Skokomish River near Potlatch, Wash..... 0600 South Fork Skokomish River near Union, Wash........ 0605

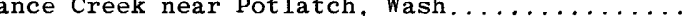
Fir Creek:

Fir Creek tributary near Potlatch, Wash.....

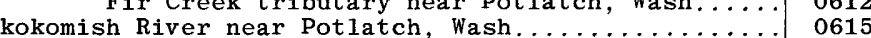

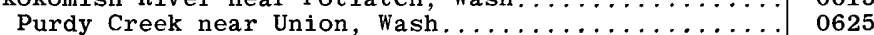

UNION RIVER BASIN

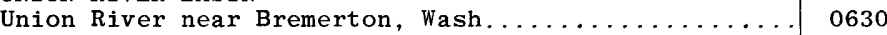

Union River near Belfair, Wash................ 0635

IISSION CREEK

Mission Creek:

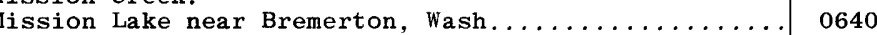

Mission Creek near Bremerton, Wash................ 0645

Mission Creek near Belfair, Wash............... 0650

TAHUYA RIVER BASIN

Tahuya River:

Gold Creek near Bremerton, Wash.............. 0655

Tahiya River (Creek) near Rremerton, wash............. nG6n

Panther Creek:

Panther Lake near Bremerton, Wash.............. 0665

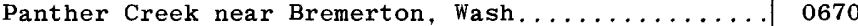

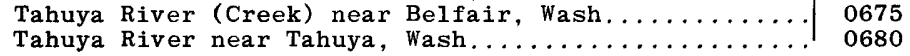

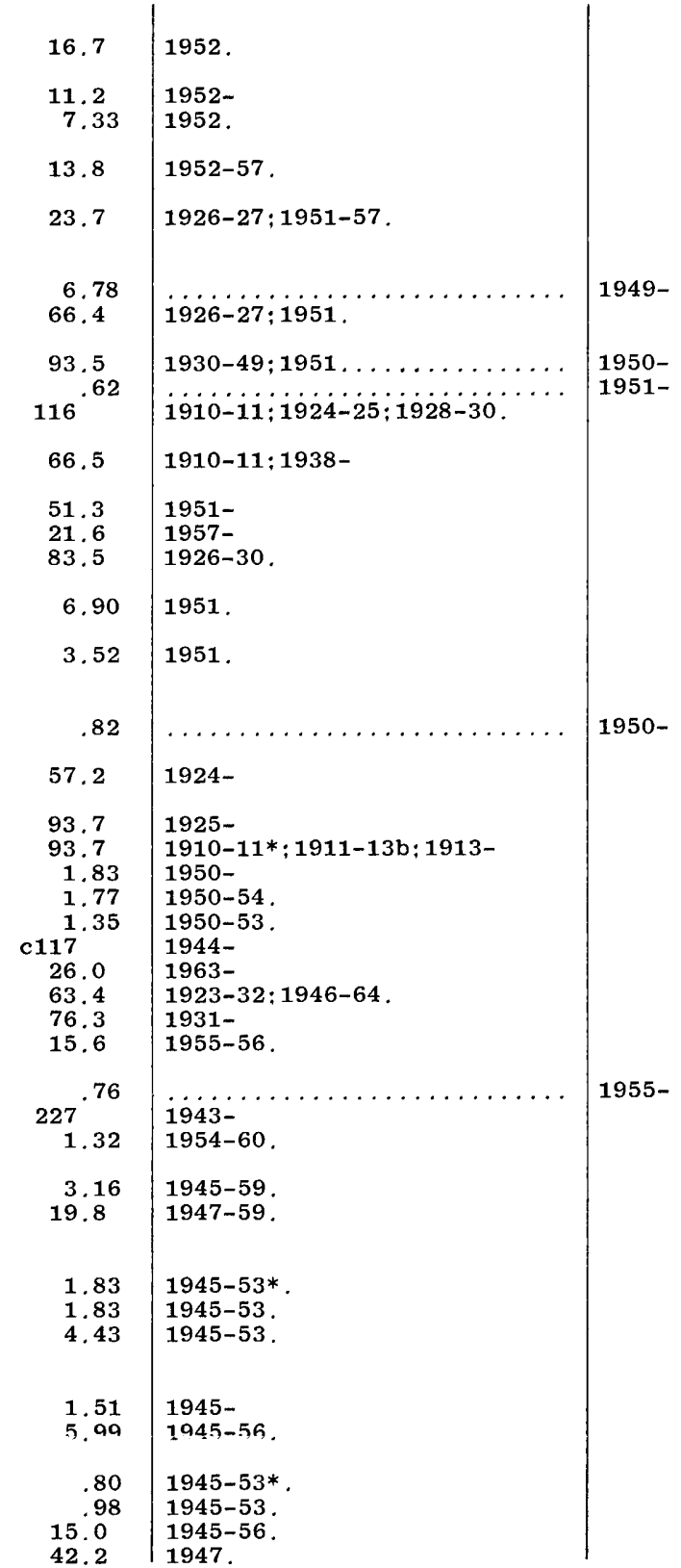


WOODLAND CREEK BASIN

Woodland Creek near Olympia, Wash . . . . . . . . . . MCALLISTER CREEK BASIN

McAllister Creek:

Eaton Creek near Ye1m, Wash................. 0813

McAllister Springs near Olympia, Wash........... 0815

NISQUALLY RIVER BASIN

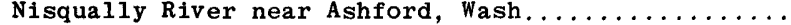

Nisqually River near National, Wash.

Mineral Creek near Mineral, Wash.

East Creek near Elbe, Wash.

Nisqually River near Alder, Wash................

Little Nisqually River near Alder, Wash.

Alder Reservoir at Alder, Wash..............

Tacoma power conduit near La Grande, Wash ..........

Nisqually River (below Little Nisqualiy River) at

(near) La Grande, Wash.

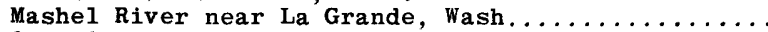

Ohop Creek:

Ohop Lake near Eatonville, Wash.

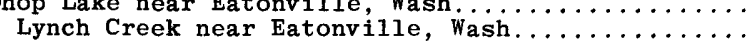

Ohop Creek near Eatonville, Wash.

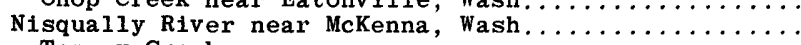

Tanwax Creek:

Tanwax Lake near Kapowsin, Wash $\ldots \ldots \ldots \ldots \ldots \ldots$

Tanwax Creek near McKenna, Wash.

Nisqually River at McKenna, Wash.

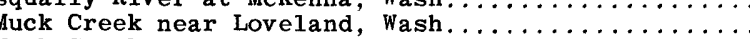

Muck Creek at Roy, Wash.

SEQUALLITCHEW CREEK BASIN

Sequallitchew Creek:

American Lake near Tillicum, Wash.

CHAMBERS CREEK BASIN

Clover Creek (head of Chambers Creek):

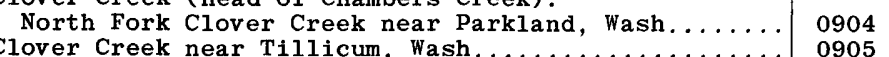

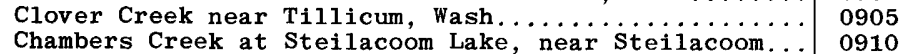

\begin{tabular}{ll|l} 
Chambers Creek at Steilacoom Lake, near Steilacoom... & 0910 \\
Chambers Creek above Flett Creek near Steilacoom..... & 0910
\end{tabular}

Flett Creek at 74th Street, at Tacoma, Wash..........

Flett Creek at Mountain View Memorial Park

$$
\begin{aligned}
& \text { Creek at Mountain } \\
& \text { at Tacoma, Wash. }
\end{aligned}
$$

Flett Creek below Flett Springs, at Tacoma, Wash.

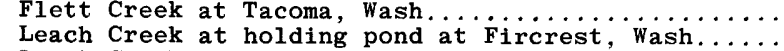

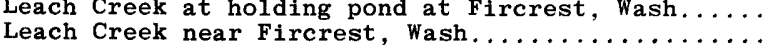
Leach Creek near Fircrest, Wash...

Chambers Creek below Leach Creek, near steilacoom...

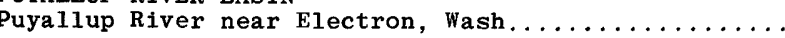

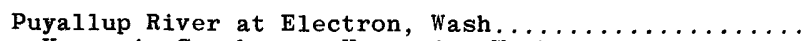

Kapowsin Creek near Kapowsin, Wash.

Puyallup River near Orting, Wash.

Carbon River at Fairfax, Wash.

Carbon River near (at) Fairfax, Wash.

South Prairie Creek near Enumclaw, Wash.

Wilkeson (Gale) Creek at Wilkeson, Wash

Wrie Creek at South Prairie, Wash......

Fennel Creek near Momilin, Wash.

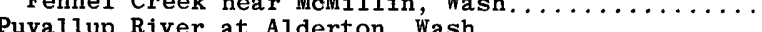




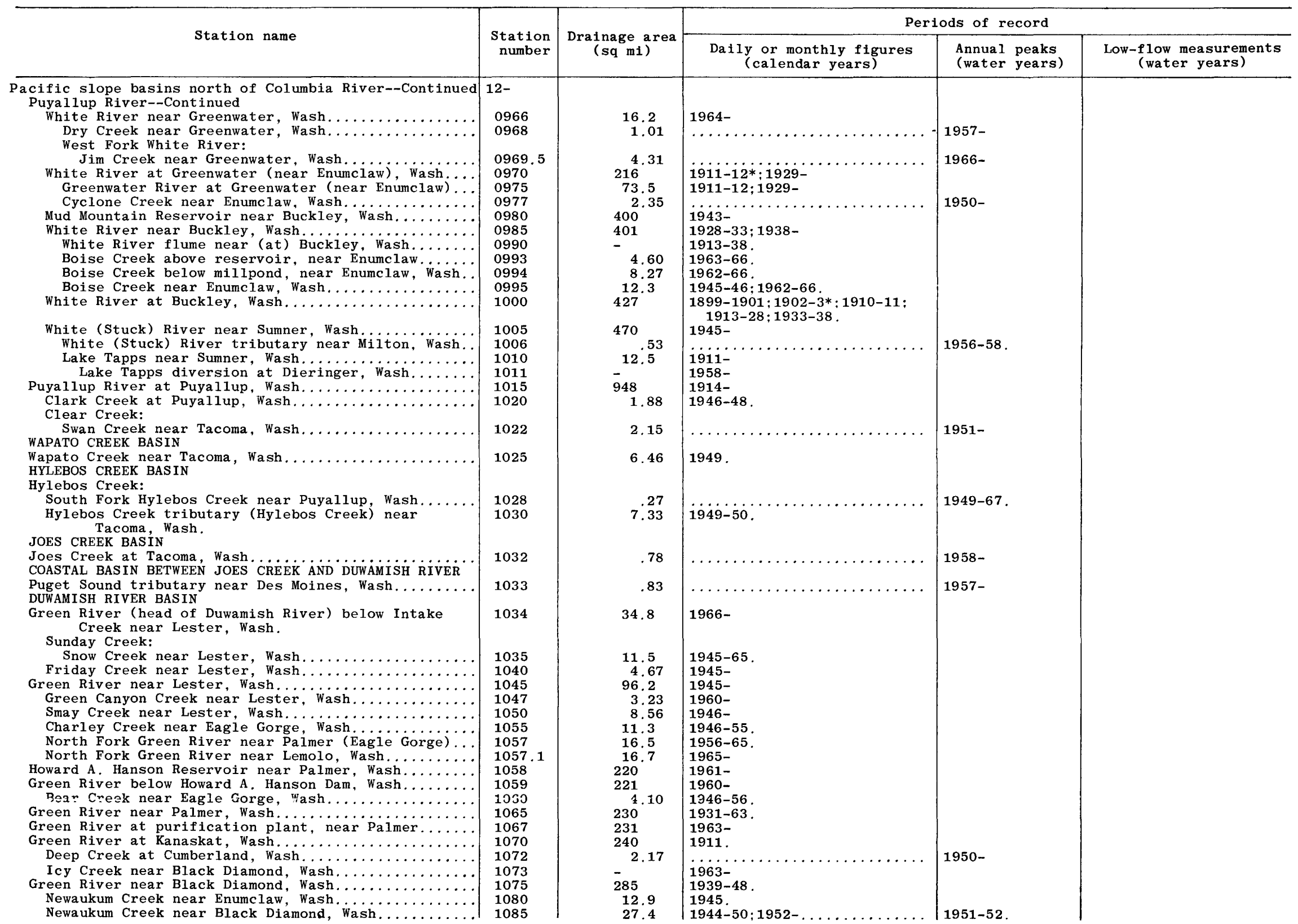


Burns Creek near Black Diamond, Wash........... 1090 Big Soos Creek:

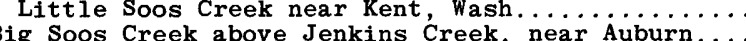
Big Soos Creek above Jenkins Creek, near Auburn..... Covington Creek:

Lake Sawyer near Black Diamond, Wash.

Covington Creek near Black Diamond, Wash......... 1115

..... 1120

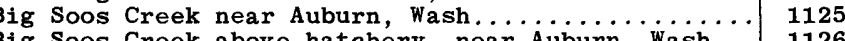

\begin{tabular}{rl|l} 
Big Soos Creek above hatchery, near Auburn, Wash.... & 1126 \\
& 1130
\end{tabular}

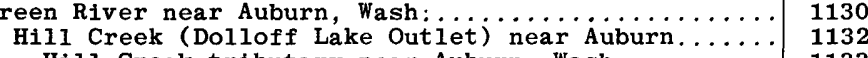

Hill Creek tributary near Auburn, Wash.......... 1133

Green River at Tukwila, Wash.................. 1133.5

North Fork Cedar River near Lester, Wash........... 1135

South Fork Cedar River near Lester, Wash.......... 1140

Cedar River below Bear Creek, near Cedar Falls..... 1145

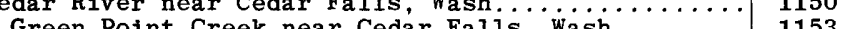

Green Polnt Creek near Cedar Falls, Wash......... 1153

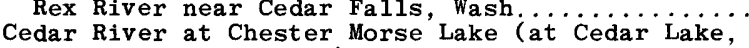
at Vaughn Bridge), near North Bend, Wash.

Canyon Creek near Cedar Falls, Wash........... 116

.... 1165

, Wash...... 1167

Taylor Creek near Selleck, Wash.............. 1170

Cedar River near Landsburg (Seattie, Maple

Valley, Ravensdale), Wash.

Rock Creek diversion near Landsburg (Rock Creek near Landsberg), Wash.

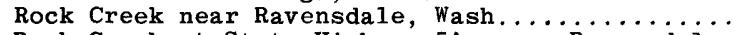
Rock Creek at State Highway 5A, near Ravensdale.

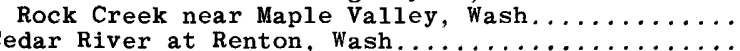

Cour

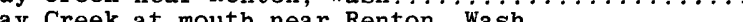

Col Creek near Bellevue, Wash.

Mercer Creek:

North Branch Mercer Creek near Bellevue, Wash....

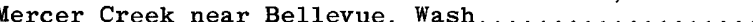

Juanita Creek near Kirkland, Wash. Issaquah, Wash.

East Fork Issaquah Creek near Issaquah, Wash..... Issaquah Creek near mouth, near Issaquah, Wash....... Sammamish Lake:

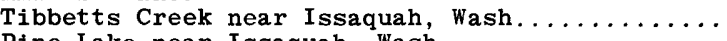

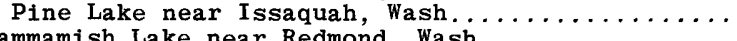
Sammamish River:

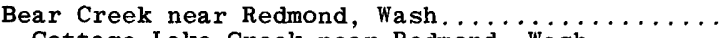
Cottage Lake Creek near Redmond, Wash.......... Evans Creek:

Evans Creek tributary near Redmond, Wash....

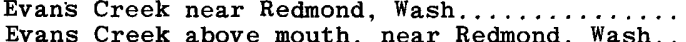
Evans Creek above mouth, near Redmond, Wash... Bear Creek at Redmond, Wash.

Sammamish River near Redmond, Wash.

Bear Creek at Woodinville, Wash. . . . . . . ...... 125

North Creek near Bothell, Wash.............. 1260

\begin{tabular}{|c|c|c|}
\hline 1.73 & 1945 & \\
\hline $\begin{array}{l}6.08 \\
20.9 \\
13.5\end{array}$ & $\begin{array}{l}1945-46 \\
1944-45 \\
1944-45\end{array}$ & \\
\hline $\begin{array}{l}9.77 \\
13.0 \\
21.6 \\
59.2 \\
66.7 \\
399\end{array}$ & $\begin{array}{l}1952-* \\
1953-59 \\
1944-45 \\
1944-56 \\
1960- \\
1936-\end{array}$ & \\
\hline $\begin{aligned} 3.14 \\
440\end{aligned}$ & ig60- & $\begin{array}{l}1949- \\
1959-\end{array}$ \\
\hline $\begin{array}{l}9.30 \\
6.00 \\
25.4 \\
40.7\end{array}$ & $\begin{array}{l}1944-63 \\
1944- \\
1945-63 \\
1945-\end{array}$ & \\
\hline $\begin{array}{l}.89 \\
13.4 \\
78.4\end{array}$ & $\begin{array}{l}1945- \\
1898-99 ; 1902-3 .\end{array}$ & 1957- \\
\hline $\begin{aligned} & .19 \\
& 84.2 \\
& 5.17 \\
& 3.77 \\
& 17.2 \\
& 117\end{aligned}$ & $\begin{array}{l}1945- \\
1914- \\
1956-63 \\
1956-63 \\
1945 ; 1956- \\
1895-\end{array}$ & \\
\hline 11.1 & $1932-48$ & \\
\hline $\begin{array}{c}10.9 \\
11.2 \\
12.6 \\
186 \\
12.5 \\
12.7 \\
6.80\end{array}$ & $\begin{array}{l}1956-58 \\
1956-62 . \\
1945- \\
1901-3 ; 1906-7 ; 1945- \\
1945-50 ; 1955-58 ; 1963-64 . \\
1964- \\
1963-\end{array}$ & \\
\hline $\begin{array}{c}3.05 \\
12.0 \\
6.43 \\
27.0\end{array}$ & $\begin{array}{l}1945 ; 1955- \\
1945 ; 1963- \\
1945-64\end{array}$ & $1949-67$ \\
\hline $\begin{array}{l}8.31 \\
54.7\end{array}$ & $\begin{array}{l}1945 . \\
1963-\end{array}$ & \\
\hline $\begin{array}{r}3.90 \\
1.06 \\
97.7\end{array}$ & $\begin{array}{l}\text { 1963- } \\
1956-* \\
1939-*\end{array}$ & \\
\hline $\begin{array}{l}13.9 \\
10.7\end{array}$ & $\begin{array}{l}1945-49 \\
1945 ; 1955-65\end{array}$ & \\
\hline $\begin{array}{c}2.46 \\
10.9 \\
13.0 \\
48.2 \\
150 \\
157 \\
15.3 \\
24.6\end{array}$ & $\begin{array}{l}1945 . \\
1055- \\
1945-50 ; 1955-58 \\
1939-57 \\
1965- \\
1945 ; 1965- \\
1945-\end{array}$ & 1949- \\
\hline
\end{tabular}




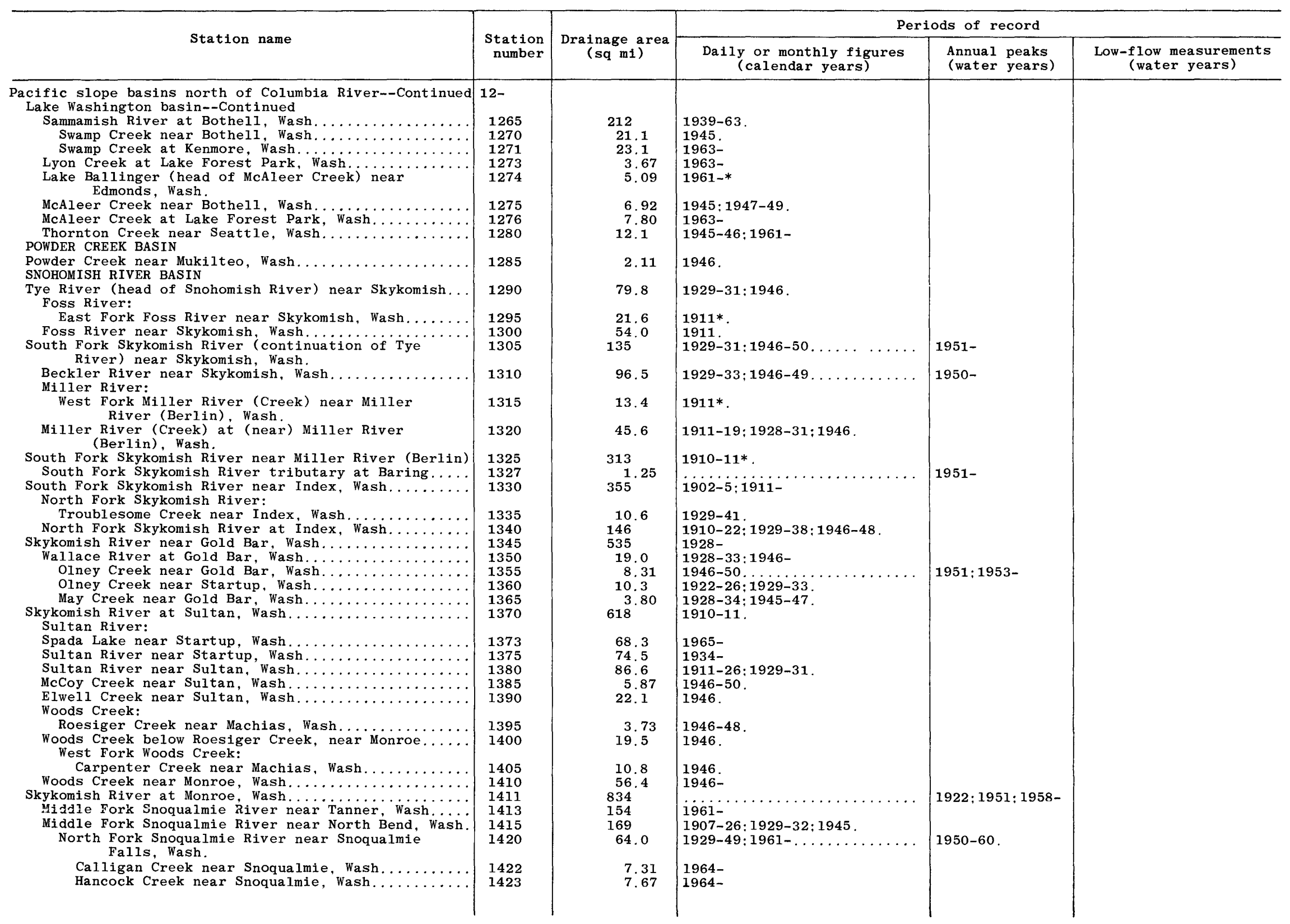


North Fork Snoqualmie River at cable bridge, near North Bend, Wash.

. South Fork Snoqualmie River:

South Fork Snoqualmie River tributary near

South Fork Snoqualmie River tributary No, 2 near North Bend, Wash.

South Fork Snoqualmie River above Alice Creek, near Garcia. Wash.

South Fork Snoqualmie River near Garcia, Wash. . South Fork Snoqualmie River at Edgewick, Wash.

Boxley Creek near Cedar Falls, Wash...

Rattlesmake Lake at Cedar Falls, Wash........ South Fork Snoqualmie River at North Bend, Wash.

Snoqualmie River near Snoqualmie (Snoqualmie Falls)

Beaver Creek near Snoqualmie, Wash.

Tokul Creek near Snoqualmie, Wash...

Raging River near Fall City, Wash

Patterson Creek eight-tenths mile above mouth,

near Fall City (near Fall City), Wash.

Griffin Creek near Carnation (Tolt), Wash......

North Fork Tolt River near Carnation, Wash.....

South Fork Tolt River near Index, Wash. .

South Fork Tolt River at upper station, near Carnation, Wash.

South Fork Tolt River near Carnation, Wash.... South Fork Tolt River tributary near Carnation, Wash.

Tolt River near Carnation (Tolt), Wash........... , Wash.

Snoqualmie River near Carnation (Tolt)

Harris Creek near Tolt, Wash.

Ames Creek near Tolt, Wash.

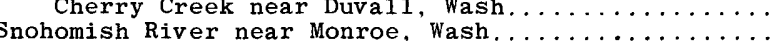

Evans Creek near Snohomish, Wash.............

French Creek near Monroe, Wash...........................

$$
\text { Falls, Wash. }
$$

chuck River near Granite Falls, Wash.

Little Pilchuck Creek near Lake Stevens, Wash... Lake Stevens at Lake Stevens, Wash

Stevens Creek at Lake Stevens, Wash.

Dubuque Creek near Lake Stevens, Wash.

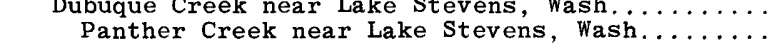

homish River at Snohomish, Wash..

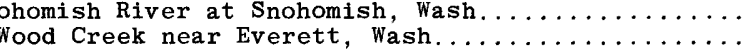

Allen Creek:

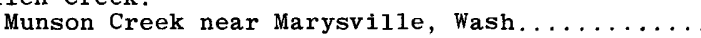

Allen Creek at Marysville, Wash.

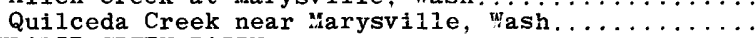

Lake Goodwin (head of Tulalip Creek) near Silvana.

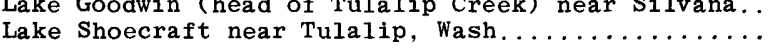

84.5

95.7

.15

.34

41.6

45. 8

65.9

1.86
81.7

375

4.13
32.2
30.6

30.6

15.5
19.9

17.1

39.2
5.34

2.04
8.54

19.7
2.19

81.4

5.58

603

8.39
2.77

19.2
538

4.84

5.53
41.7

54.5

17.0

6.83

14.2

7.19
5.33

1,714

1.89

.97
7.33

7.33
1.5 .4

5.17

6.02
1913-15.

$1907-26 ; 1929-38 ; 1960-$

1951-

1962-

$1960-$

$1910-15$.

$(1945 ; 1953-) *$

$1907-26 ; 1929-38 ; 1945-50$;

$1960-$

898-1900; 1902-4 ; 1905-6* :

$1907-32 ; 1958-$

$1964-67$

1907-14:1929-31;1945 ..... 1959-61.

$1945-50 ; 1963-\ldots \ldots \ldots \ldots \ldots$

1945 .

$1945-$

$1952-63$.

1960-63.

1957-59.

1952-63.

$1928-32$ : $1937-$

1957-63,

$1928-$

1945.

1945-48; 1961-64

$1963-\ldots \ldots \ldots \ldots \ldots \ldots \ldots$

1946 .

1946.

1946.

$1911 ; 1943-57 \ldots \ldots \ldots \ldots \ldots$.

$1946-$

1946-50*.

$1946-50$.

$1946-50$

1946.

$1941-$
$1946-48$

1946.

$1946-$

1953-*

1953-* 


\begin{tabular}{|c|c|c|c|c|c|}
\hline \multirow{2}{*}{ Station name } & \multirow{2}{*}{$\begin{array}{r}\text { Station } \\
\text { number }\end{array}$} & \multirow{2}{*}{$\begin{array}{c}\text { Drainage area } \\
(\mathbf{s q} \mathrm{mi})\end{array}$} & \multicolumn{3}{|c|}{ Periods of record } \\
\hline & & & $\begin{array}{c}\text { Daily or monthly figures } \\
\text { (calendar years) }\end{array}$ & $\begin{array}{l}\text { Annual peaks } \\
\text { (water years) }\end{array}$ & $\begin{array}{l}\text { Low-flow measurements } \\
\text { (water years) }\end{array}$ \\
\hline 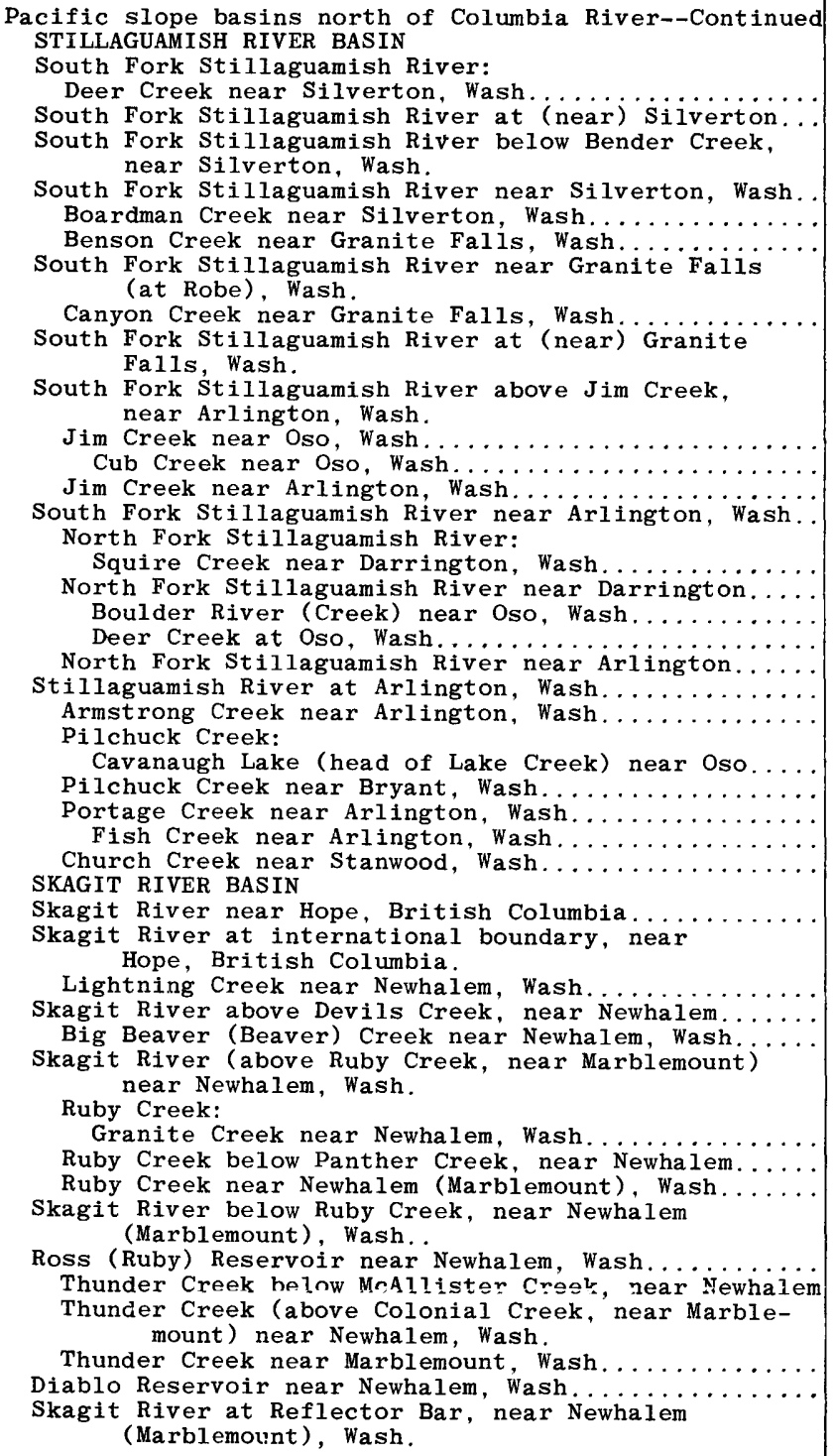 & $\begin{array}{l}1595 \\
1600 \\
1605 \\
1610 \\
1615 \\
1620 \\
1625 \\
1630 \\
1635 \\
1640 \\
1645 \\
1650 \\
1655 \\
1660 \\
1665 \\
1670 \\
1674 \\
1675 \\
1680 \\
1685 \\
1690 \\
1695 \\
1700 \\
1705 \\
1706 \\
1710 \\
1715 \\
1720 \\
1725\end{array}$ & $\begin{array}{c}1.07 \\
37.2 \\
39.6 \\
43.7 \\
9.42 \\
2.16 \\
119 \\
55.3 \\
182 \\
199 \\
\\
10.9 \\
6.44 \\
46.2 \\
251 \\
20.0 \\
82.2 \\
25.6 \\
65.9 \\
262 \\
539 \\
7.33 \\
7.36 \\
52.0 \\
8.97 \\
7.52 \\
7.42 \\
357 \\
381 \\
129 \\
655 \\
63.2 \\
780 \\
\\
71.0 \\
206 \\
210 \\
999 \\
999 \\
91.7 \\
105 \\
58\end{array}$ & $\begin{array}{l}1929-32 . \\
1950 . \\
1910-17 . \\
1950 . \\
1950 . \\
1902-3 * ; 1928- \\
1911-13 * ; 1929-32 ; 1950 . \\
1911 ; 1913-15 . \\
1936-57 . \\
1947-49 . \\
1949-50 . \\
1937-57 \ldots \ldots \ldots \\
1928-36 . \\
1950- \\
1950-57 . \\
1950 . \\
1917-30 ; 1950 . \\
1928- \\
1947-d \\
1950-57 . \\
1950-51 * \\
1929-31 ; 1950- \\
1950 . \\
1950-53 \ldots \ldots \ldots \\
1950 . \\
1915-22 ; 1934-55 . \\
1953-* \\
1943-48 . \\
1940-45 . \\
1940-48 ; 1962- \\
1929-40 . \\
1946-48 . \\
1948-56 ; 1962- \\
1919-20 ; 1928-49 . \\
1908-19 b ; 1919-30 ; 1930-33 b . \\
1940- \\
1957-62 . \\
1930- \\
1919-30 . \\
1929- \\
1908-13 b ; 1913-22 ; 1922-33 b . \\
\end{array}$ & $1966-$ & \\
\hline
\end{tabular}


Stetattle Creek near Newhalem (Marblemount), Wash.

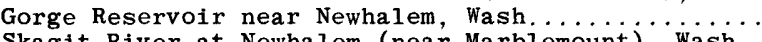
kagit River at Newhalem (near Marblemount), Wash. Newhalem Creek near Newhalem, Wash.

Skagit

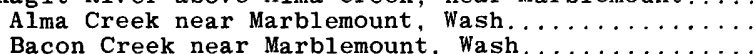
Diobsud Creek near Marblemount wash . . . . . . . . .

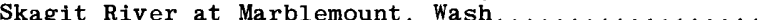
Cascade River:

South Fork Cascade River at South Cascade Glacier near Marblemount (near Marblemount). Wash.

Salix Creek at South Cascade Glacier near Marblemount, Wash.

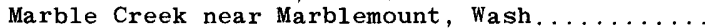
Cascade River near Marblemount, Wash...

Cascade River at Marblemount, Wash...

Clark Creek at Marblemount, Wash.

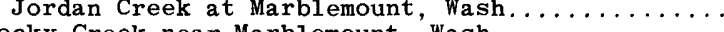

Rocky Creek near

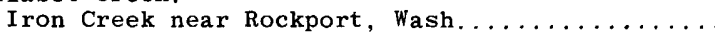

Illabot Creek near Rockport, Wash.

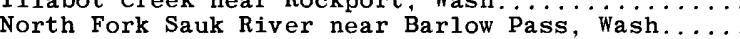
South Fork Sauk River near Barlow Pass, Wash...

Sauk River above Whitechuck River, near Darrington

Whitechuck River near Darrington, Wash.

Sauk River above Clear Creek, near Darrington......

Suiattle River below Lime Creek, near Darringto

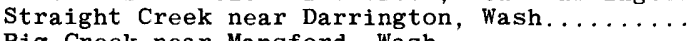
Big Creek near Mansford, Wash.

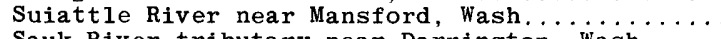
Sauk River tributary near Darrington, Wash.....

Sauk River (at, near Suiattle Crossing) near Sauk. Jackman Creek near Concrete, Wash.............. Baker River:

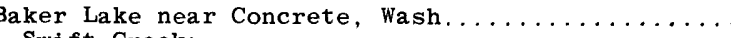
wift Creek:

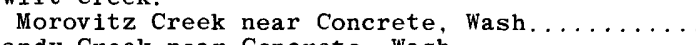

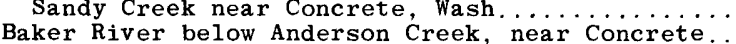
Baker Lake at upper Baker Dam, near Concrete.... Baker Lake at

Sulphur Creek near Concrete, Wash.

Bear Creek near Concrete, Wash

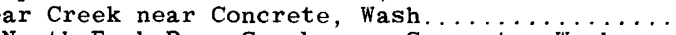

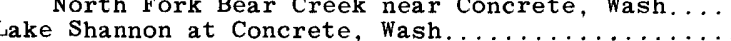
Baker River at Concrete, Wash. .

Skagit River near Concrete, Wash.

Finney Creek near Concrete, Wash.

Grandy Creek near Concrete, Wash.

'Toole Creek near Hamilton, Was

Alder Creek near Hamilton, Wash.......

Day Creek below Day Lake, near Lyman, Wash....

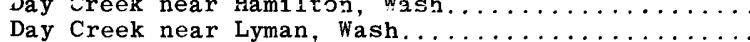

Jones

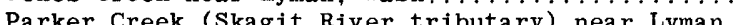

Gili Crek (Skagit River tributa. \begin{tabular}{r|l}
22.0 & $1913-15 ; 1933-$
\end{tabular}

$1960-$

27.9 1908-14:1914-20b; 1920-

$38.7 \quad 1943-4$

$1,274 \quad 1950$

\begin{tabular}{l|l}
8.37 & 1943.
\end{tabular}

\begin{tabular}{l|l}
50.9 & $1943-50$ \\
25.4 & $1943-44$
\end{tabular}

1,381

2.36

$0.078 \quad 1961-$

\begin{tabular}{l|l}
17.1 & $1943-44$. \\
140 & $1909-13$.
\end{tabular}

168

1.42 1944-46.

$12.0 \quad 1943-47$

$10.0 \quad 1943$.

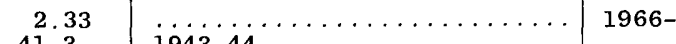

\begin{tabular}{l|l}
41.3 & $1943-44$ \\
76.4 & $1917-20$
\end{tabular}

7. 4

33.

77. 9

259

293

213
4.32

21.0

335

1.11

714
23.9

119

0.55

10.8

211

$1917-21 ; 1928-31$

$1910 *: 1917-22 ; 1928-$

$1910 * ; 1919-21$

$1914-26 ; 1928-32$

1920-21.

$1943-46$.

1938-49.

j9iok:i9ii 1951 -

1943-47.

1910-15*

1966-

1910-25; 1928-31; 1955-59

1959 -

\begin{tabular}{r|r}
8.36 & $1963-$
\end{tabular}

\begin{tabular}{r|r}
11.4 & $1953-54$
\end{tabular}

297 1925-

297

2,737

$51.6 \quad 1924-$

17.4

$5.41 \quad 1943-44$

\begin{tabular}{c|c}
5.41 & $1943-44$ \\
10.7 & $1943-$
\end{tabular}

6.56 1963-

$32.3 \quad 1962-$

\begin{tabular}{c|c}
34.2 & $1943-62$ \\
8.12 & $1943-44$.
\end{tabular}

1.82

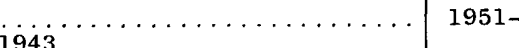




\begin{tabular}{|c|c|c|c|c|c|}
\hline \multirow{2}{*}{ Station name } & \multirow{2}{*}{$\begin{array}{r}\text { Station } \\
\text { number }\end{array}$} & \multirow{2}{*}{$\begin{array}{l}\text { Drainage area } \\
\quad(\mathrm{sq} \mathrm{mi})\end{array}$} & \multicolumn{3}{|c|}{ Periods of record } \\
\hline & & & $\begin{array}{l}\text { Dally or monthly figures } \\
\text { (calendar years) }\end{array}$ & $\begin{array}{l}\text { Annual peaks } \\
\text { (water years) }\end{array}$ & $\begin{array}{l}\text { Low-flow measurements } \\
\text { (water years) }\end{array}$ \\
\hline Pacific slope basins north of Columbia River--Continued & $12-$ & & & & \\
\hline $\begin{array}{l}\text { Skagit River basin--Continued } \\
\text { Cool (Coa1) Creek near Sedro Woolley, Wash........ }\end{array}$ & 1980 & & & & \\
\hline 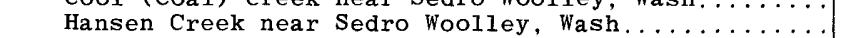 & 1985 & $\begin{array}{l}1.88 \\
9.66\end{array}$ & $\begin{array}{l}1947-50 \\
1943-45\end{array}$ & & \\
\hline Skagit River near Sedro Woolley, Wash........... & 1990 & 3,015 & $1908-24$ & & \\
\hline Nookachamps Creek near Mount Vernon, Wash........ & 1995 & 22.5 & $1943-44$. & & \\
\hline East Fork Nookachamps Creek near Big Lake, Wash. & 1998 & 3.56 & $1961-$ & & \\
\hline East Fork Nookachamps Creek near Clear Lake...... & 2000 & 20.5 & $1943-50 ; 1961-63$. & & \\
\hline $\begin{array}{l}\text { Skagit River near Mount Vernon, Wash................ } \\
\text { Carpenter Creek: }\end{array}$ & 2005 & 3,093 & $1940-$ & & \\
\hline $\begin{array}{l}\text { Carpenter Creek (Skagit River) tributary near } \\
\text { Mount Vernon, Wash. }\end{array}$ & 2007 & 2.58 & & $1949-$ & \\
\hline $\begin{array}{l}\text { SAMISH RIVER BASIN } \\
\text { Samish River: }\end{array}$ & & & & & \\
\hline $\begin{array}{l}\text { Samish River: } \\
\text { Samish Lake (head of Friday Creek): }\end{array}$ & & & & & \\
\hline Lake Creek near Bellingham, Wash....... & 2008 & 2.35 & & $1949-$ & \\
\hline 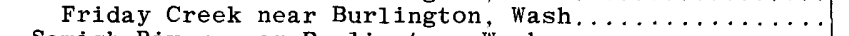 & 2010 & 37.1 & $1943-48$. & 200 & \\
\hline 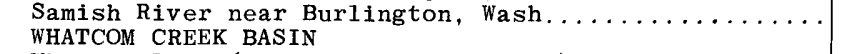 & 2015 & 87.8 & $1943-$ & & \\
\hline Whatcom Lake (head of Whatcom Creek): & & & & & \\
\hline Austin Creek near Bellingham, Wash.. & 2020 & 7.73 & $1948 ; 1954$. & & \\
\hline Whatcom Lake near Bellingham, Wash.... & 2025 & 55.9 & $1913-14 *$ & & \\
\hline 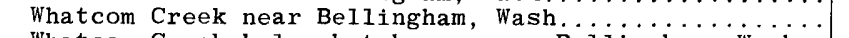 & 2030 & 56.1 & $1910-12 ; 1913-14 *: 1939-46$. & & \\
\hline $\begin{array}{l}\text { Whatcom Creek below hatchery, near Bellingham, Wash.. } \\
\text { SQUALICUM CREEK BASIN }\end{array}$ & 2035 & 56.1 & $1945-56$ & & \\
\hline $\begin{array}{l}\text { Squalicum Creek at Bellingham, Wash....................... } \\
\text { NOOKSACK RIVER BASIN }\end{array}$ & 2040 & 10.9 & $1948 ; 1954$ & & \\
\hline Nooksack River: & & & & & \\
\hline $\begin{array}{l}\text { Nooksack River tributary near Glacier, Wash........ } \\
\text { Nooksack River at Excelsior. Wash. }\end{array}$ & 2044 & 9.15 & & $1956-60: 1962-$ & \\
\hline Nooksack River at Excelsior, Wash. $\ldots \ldots \ldots \ldots \ldots \ldots$ & 2045 & 95.1 & $1920-21$ & & \\
\hline $\begin{array}{l}\text { Nooksack River below (above) Cascade Creek near } \\
\text { Glacier, Wash. }\end{array}$ & 2050 & 105 & $1937-$ & & \\
\hline $\begin{array}{l}\text { Nooksack River (North Fork) near Glacier, Wash....... } \\
\text { Canyon Creek: }\end{array}$ & 2055 & 193 & $1910 * ; 1911 ; 1933-38$ & & \\
\hline 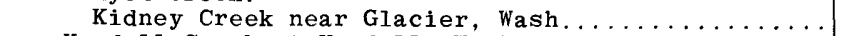 & 2057.5 & 2.66 & & $1966-$ & \\
\hline 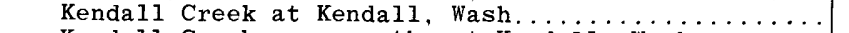 & 2060 & 24.0 & $1948-50$ & & \\
\hline Kendall Creek near mouth, at Kendall, Wash......... & 2065 & 29.2 & 1954. & & \\
\hline 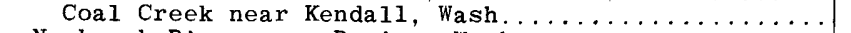 & 2070 & 4.57 & $1948 ; 1954$ & & \\
\hline 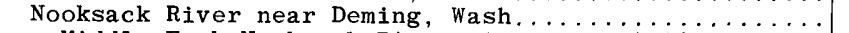 & 2072 & 282 & $1964-$ & & \\
\hline $\begin{array}{l}\text { Middle Fork Nooksack River at ranger station, } \\
\text { near Deming, Wash. }\end{array}$ & 2075 & 25.3 & $1910 *$ & & \\
\hline Middle Fork Nooksack River near Deming, Wash.. & 2080 & 73.3 & $\begin{array}{l}1910-11 * ; 1920-21 ; 1934-35 ; \\
1954 ; 1964-\end{array}$ & & \\
\hline Canyon Creek at Kulshan, Wash $\ldots \ldots \ldots \ldots \ldots$ & 2085 & 8.70 & $1948-54$ & & \\
\hline South Fork Nooksack River near Wickersham, Wash. & 2090 & 103 & $1933-$ & & \\
\hline Skookum Creek near Wickersham, Wash.......... & 2095 & 23.1 & $1948-$ & & \\
\hline South Fork Nooksack River at Saxon Bridge, Wash... & 2100 & 129 & $1920-21 ; 1933-34$ & & \\
\hline 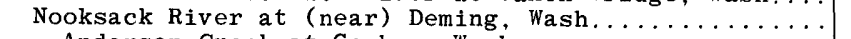 & 2105 & 584 & $1910-11 *: 1935-$ & & \\
\hline Anderson Creek at Goshen, Wash............... & 2110 & 12.9 & $1948 ; 1954$ & & \\
\hline Nooksack River near Lynden, Wash............. & 2115 & 648 & $1944-67$ & & \\
\hline Fishtrap Creek at Lynden, Wash............ & 2120 & 22.3 & $1948-$ & & \\
\hline 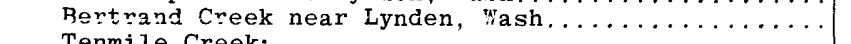 & 2125 & 37.4 & $1948 ; 1954$. & & \\
\hline Tenmile Creek: & & & & & \\
\hline Tenmile Creek tributary No, 1 near Bellingham.... & 2127 & .74 & $\ldots$ & 1949- & \\
\hline & 2128 & & & 1956- & \\
\hline Tenmile Creek near Ferndale, Wash. . . . . . . . . . & 2130 & 25.8 & $1948 ; 1954$ & & \\
\hline 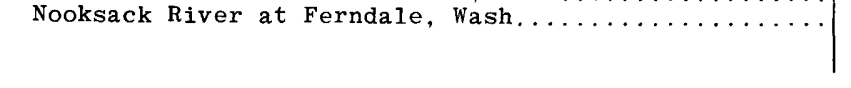 & 2131 & 786 & $1966-\ldots \ldots$ & $\begin{array}{c}1918 ; 1922 ; 1932 ; \\
1935 ; 1946 ; \\
1950-65\end{array}$ & \\
\hline
\end{tabular}


CALIFORNIA CREEK BASIN

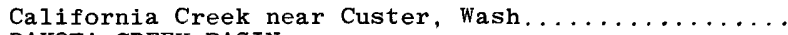
DAKOTA CREEK BASIN

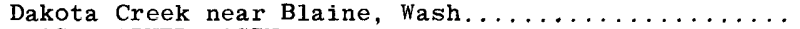
FRASER RIVER BASI

Fraser River:

Chilliwack River near Vedder Crossing, British Columbia.

Slesse Creek near Vedder Crossing, British Columbia.

Vedder River:

Sumas River near Sumas, Wash.

Johnson Creek at Sumas, Wash.............................

Sumas River near Huntingdon, British Columbia.

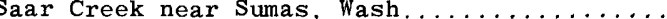
UPPER COLUMBIA RIVER BASIN

COlumbia River:

Kootenay River at Newgate, British Columbia........

ortine Creek (head of Tobacco River) near

$$
\text { Trego, Mont }
$$

Deep Creek near

Grave Creek near Fortine, Mont

Tobacco River near Eureka, Mont...

Konai River near Rexford, Mont...

Kootenai River tributary near Rexford, Mont.

Kootenai River at Warland Bridge, near Libby, Mont.

Little Jackson

Wolf Creek near Libby, Mont

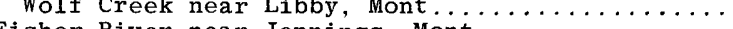

iver near Jennings, Mont

Fisher River near Libby, Mont.

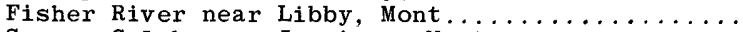

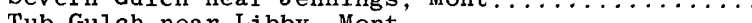
Libby Creek:

Granite Creek:

Shaughnessy Creek near Libby, Mont.........

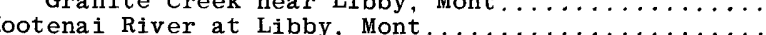
Flower River at Libby, Mont.

Fower crek Lake Creek at Troy, Mont....

Callahan Creek at Troy, Mont.

Whitetail Creek near Yaak, Mont.

Cyclone Creek near Yaak, Mont

Fourth of July Creek near Yaak, Mont.

Yaak River near Troy, Mont. .

Boulder Creek near Leonia, Idaho,

Kootenai River at Katka, Idaho...

Moyie River at Eastport, Idaho (at Kingsgate.

Biver at Snyder. Ida

Moyie River at Eileen, Idaho. .

Kootenai River at Crossport, Idaho.

Kootenai River at Boom Camp, near Bonners Ferry .....

Cow Creek near Bonners Ferry. Idaho.

Kootenai River at (near) Bonners Ferry, Idaho........

Kootenai River near Bonners Ferry, Idaho. \begin{tabular}{l|l}
18.4 & $1948-54$
\end{tabular}

131

$(1923-51 ; 1957-60) f: 1960-$ 1957-60f; 1960-

$1948-50 ; 1954$.

1954 .

1.11

a 11,740

253
860

11,860

2570

656

-

a 12,950

a) 13,000

a13,000
$1930-$

$1946-53 \ldots \ldots \ldots \ldots \ldots \ldots$ 1954: $1958 ; 1960-$

i $1923-24$

$1958-$

$1929-40$.

1959

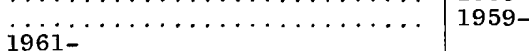

$1961-$

$1967-$

$1950-$

i $967-$

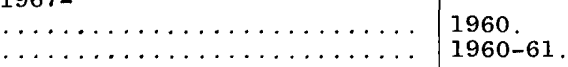

i933. $1936-43 ; 1960 \ldots \ldots \ldots \ldots$.

$1933 ; 1936-43 ; 1960-\ldots \ldots \ldots \ldots .1959$

1910-

1945-57.

$1911-13 ; 1914-16 *$

1960-

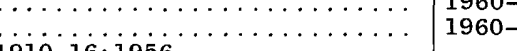

$1928-$

$1928-33$

1915-16f: ( $1914: 1917) * f: 1929$

$1911-16 ; 1919-23$

$1925-$

$1925-27 * f$ : $1927-60 *$

$1928-34$ :
$1904 *: 1905-27 * \mathrm{~d} ; 1928-60$;

$1961-*$

1928-* 


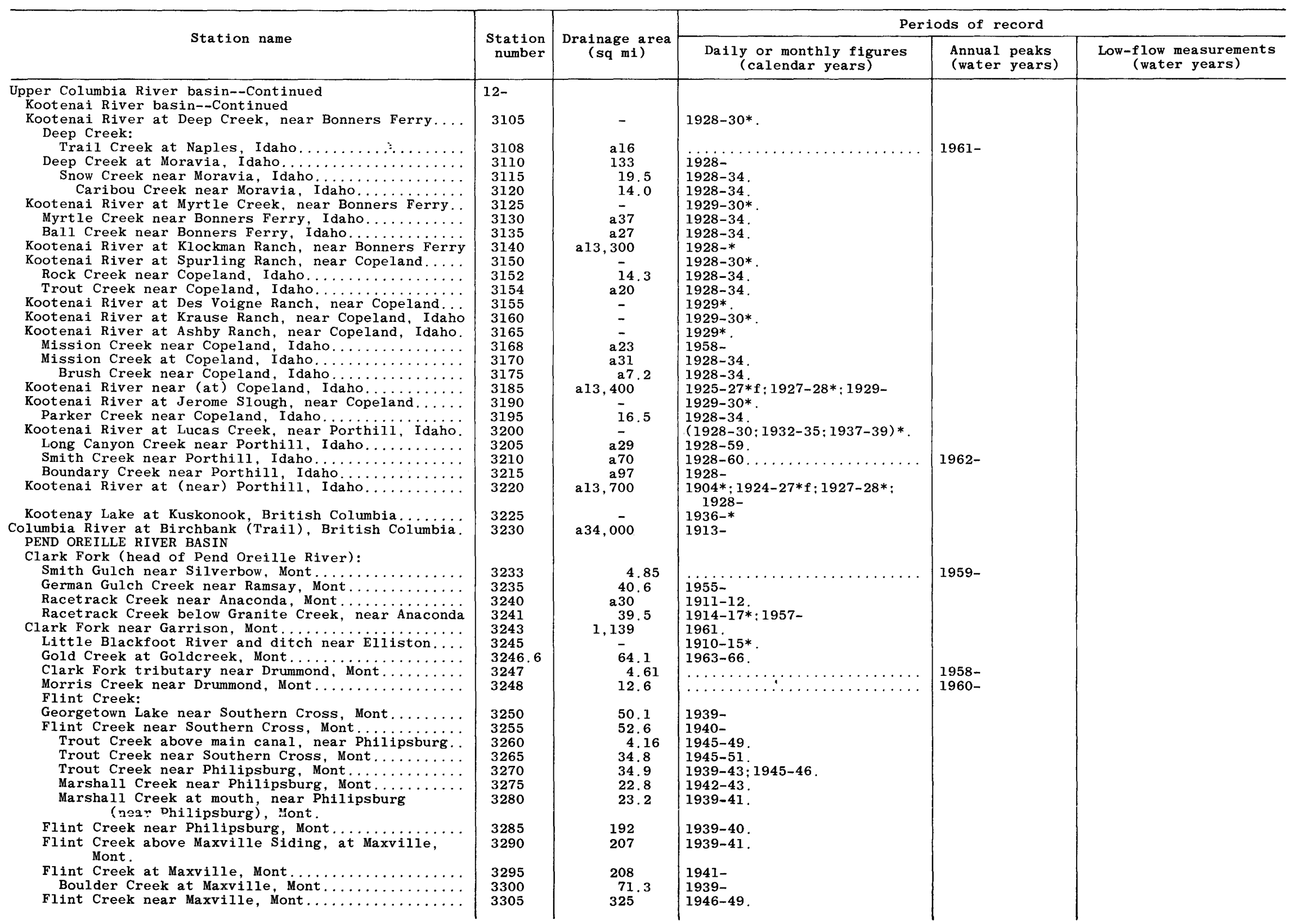


Flint Creek near Hall, Mont

Flint Creek near Drummond, Finards Gulch at Drummond, Mont.

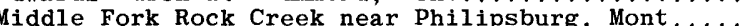
East Fork Rock Creek:

East Fork Rock Creek Reservoir near Philipsburg. East Fork Rock Creek near Philipsburg, Mont..... ock Creek near Quigley, Mont.

Ranch Creek near Quigley, Mont.

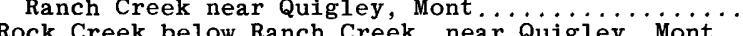

Blackfoot River near Helmville, Mont.

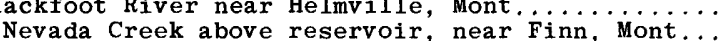

Nevada Creek near Finn, Mont

Nevada Creek Reservoir near Fin $^{2} \ldots \ldots \ldots \ldots \ldots$

Nevada Creek near Helmville, Mont ...............

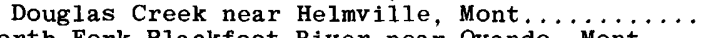

North Fork Blackfoot River near Ovando, Mont....

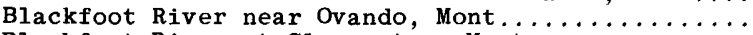

Blackfoot River at Clearwater, Mont.

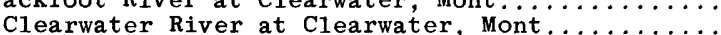

Blackfoot River near Potomac, Mont.............

West Twin Creek near Bonner, Mont.

Blackfoot (Big Blackfoot) River near (at) Bonner.

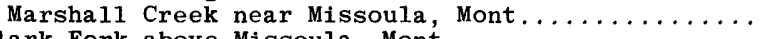

Clark Fork above Missoula, Mont.

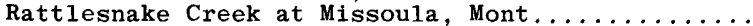

Clark Fork (Missoula River) at Missoula, Mont......

West Fork Bitterroot River

Painted Rocks Lake (West Fork Bitterroot River Reservoir) near Conner, Mont.

West Fork Bitterroot River near Conner, Mont......

West Fork Bitterroot River near Darby, Mont.

East Fork Bitterroot River near Conner, Mont.....

East Fork Bitterroot River at Conner (near

$$
\text { Darby), Mont. }
$$

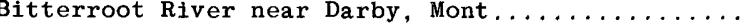

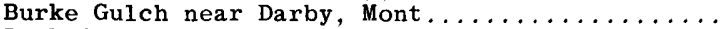
Rock Creek:

Como Lake near Darby, Mont

Rock Creek Canal near Darby, Mont

Camas Creek near Hamilton, Mont.

Skalkaho Creek near Hamilton, Mont.

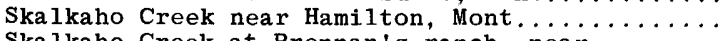
kalkaho Creek at Brennan's ranch, near Hamilton (near Hamilton), Mont.

Blodgett Creek near Corvallis, Mont.

Bitterroot River near Corvallis, Mont.

Wil Creek near Corvallis, Mont.

Writow Creek at Anfinson Ranch, near Corvaiiis. Bear Curr Creek near Victor, Cash Creek near Victor, Mont..

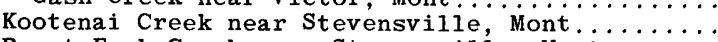
Burnt Fork Creek near Stevensville, Mont........

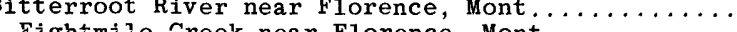
Lolo Creek near Lolo, Mont $\ldots$

Lolo Creek above Sleeman Creek, near

$$
\text { Lolo (near Lolo), Mont }
$$

Hayes Creek near Missoula, Mont.
3310

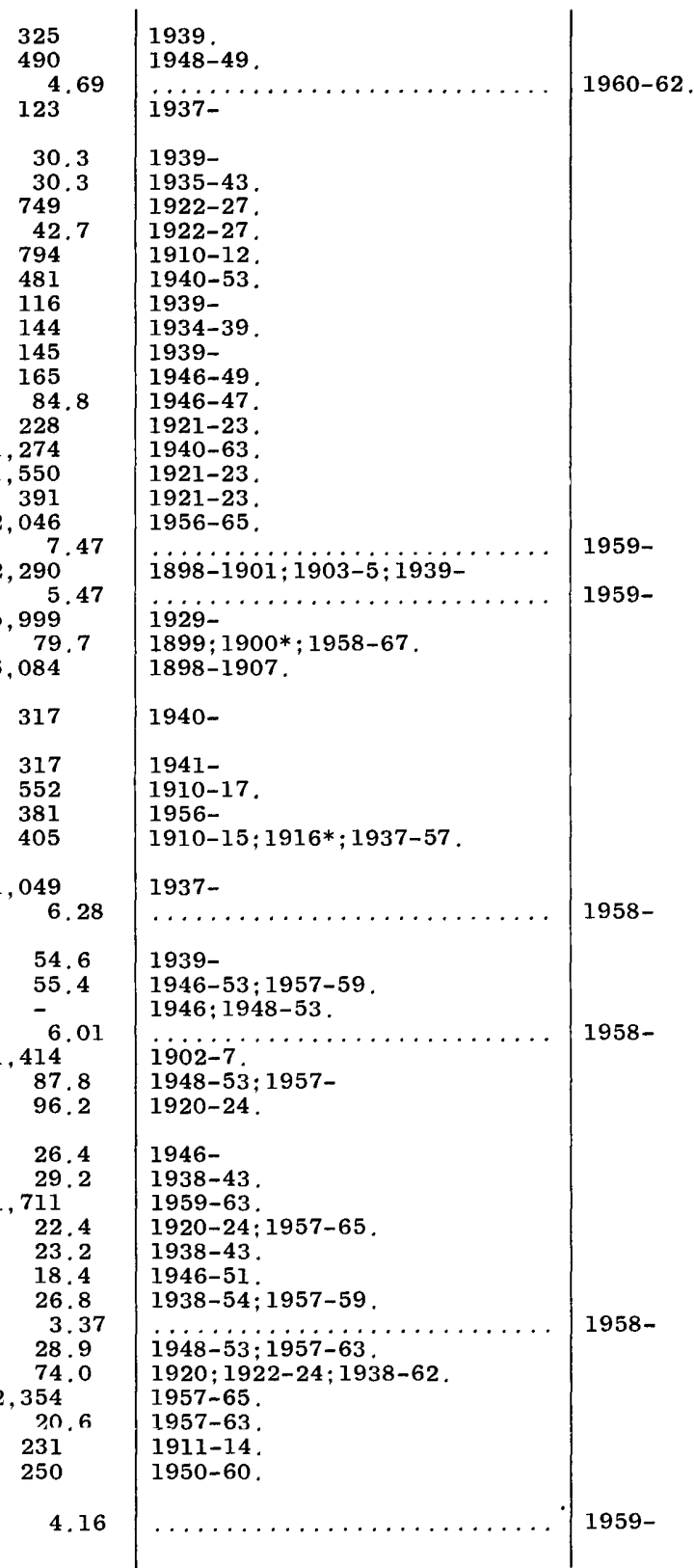




\begin{tabular}{|c|c|c|c|c|c|}
\hline \multirow{2}{*}{ Station name } & \multirow{2}{*}{$\begin{array}{r}\text { Station } \\
\text { number }\end{array}$} & \multirow{2}{*}{$\begin{array}{l}\text { Drainage area } \\
(\mathrm{sq} \mathrm{mi})\end{array}$} & \multicolumn{3}{|c|}{ Periods of record } \\
\hline & & & $\begin{array}{l}\text { Daily or monthly figures } \\
\text { (calendar years) }\end{array}$ & $\begin{array}{l}\text { Annual peaks } \\
\text { (water years) }\end{array}$ & $\begin{array}{c}\text { Low-flow measurements } \\
\text { (water years) }\end{array}$ \\
\hline 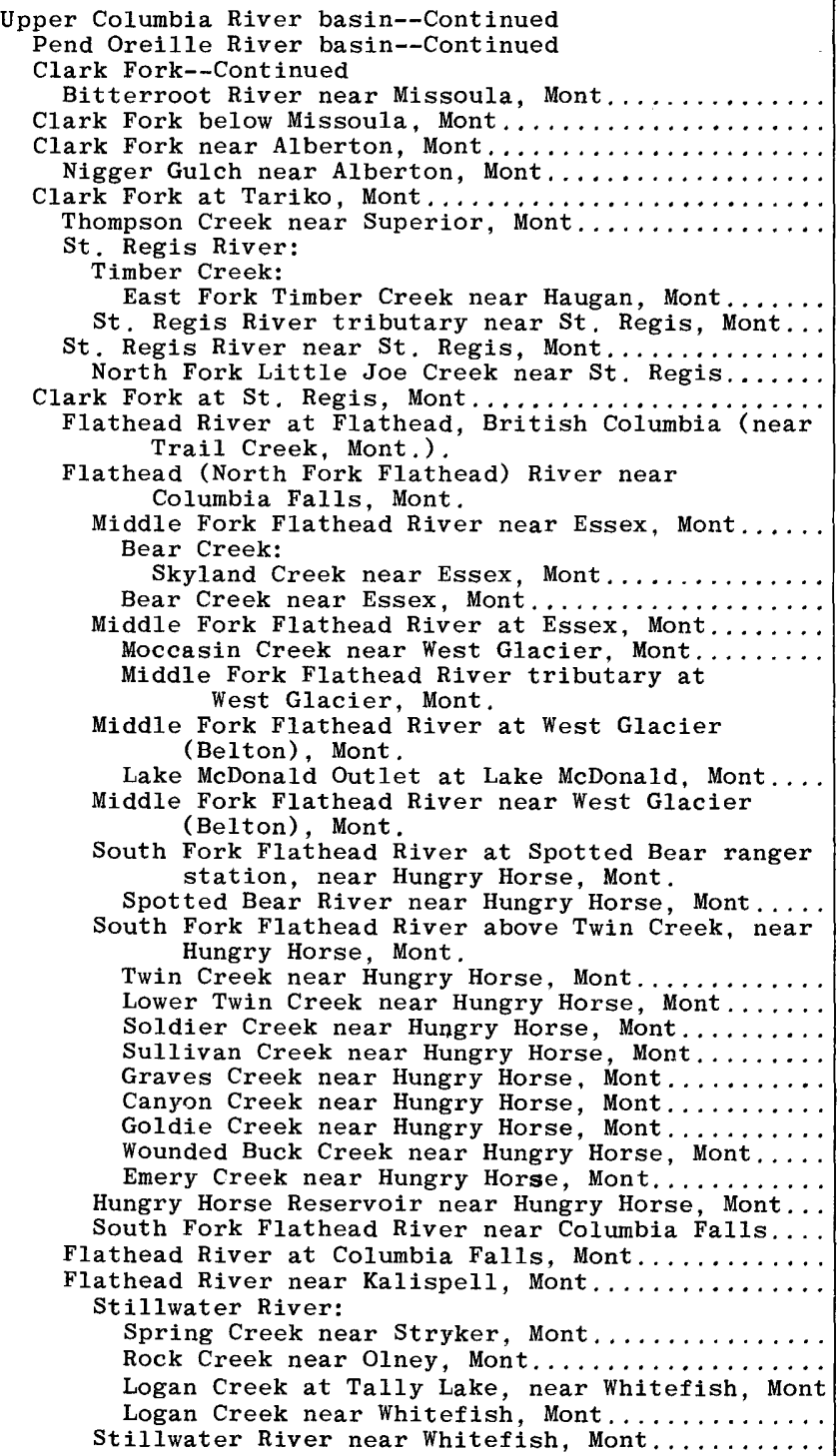 & $\begin{array}{l}3538.5 \\
3539 \\
3540 \\
3541 \\
3545 \\
3550 \\
\\
3555 \\
\\
3557 \\
\\
3560 \\
3565 \\
3570 \\
3573 \\
3574 \\
\\
3575 \\
\\
3580 \\
3585 \\
\\
3590 \\
\\
3595 \\
3598 \\
3600 \\
3605 \\
3606 \\
3610 \\
3615 \\
3616 \\
3617 \\
3618.8 \\
3619.6 \\
3620 \\
3625 \\
3630 \\
3635 \\
\\
3638 \\
3639 \\
3640 \\
3645 \\
3650 \\
\end{array}$ & $\begin{array}{c}2,812 \\
9,003 \\
9,272 \\
8.02 \\
9,882 \\
12.2 \\
\\
2.72 \\
1.16 \\
303 \\
14.7 \\
10,709 \\
2450 \\
1,548 \\
\\
408 \\
8.09 \\
20.7 \\
510 \\
1.97 \\
.10 \\
943 \\
\\
175 \\
1,128 \\
958 \\
\\
184 \\
1,160 \\
47.0 \\
22.4 \\
4.77 \\
71.3 \\
27.0 \\
4.59 \\
3.29 \\
13.6 \\
26.4 \\
1,654 \\
1,663 \\
4,464 \\
- \\
3.86 \\
6.18 \\
183 \\
199 \\
524\end{array}$ & 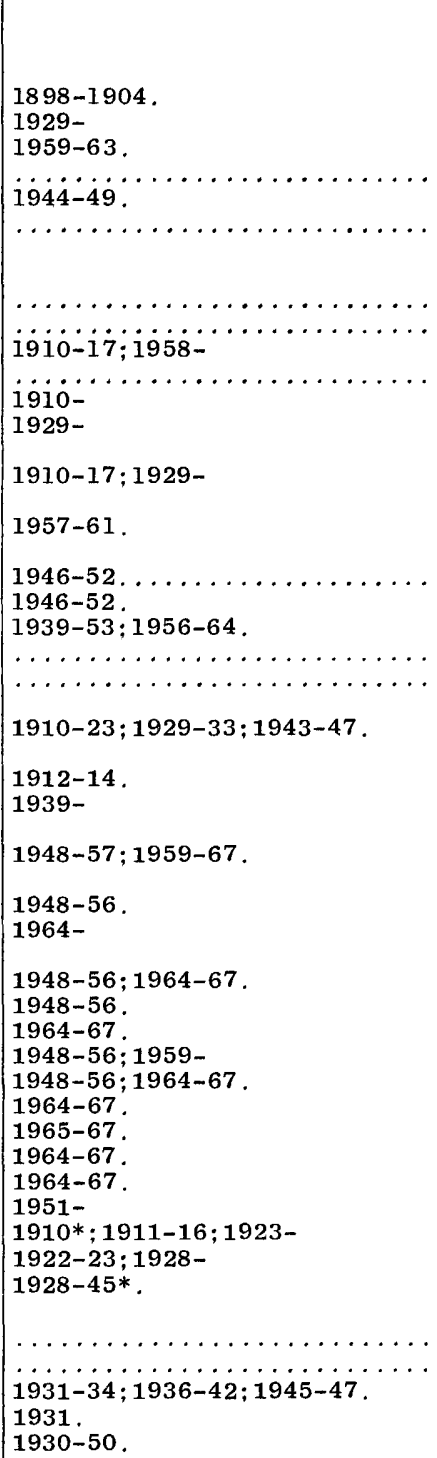 & $\begin{array}{l}1959- \\
1961- \\
1961- \\
1959-61 \\
1960-\end{array}$ & \\
\hline
\end{tabular}


Stillwater River near Kalispe11, Mont

.

Flathead River at Demersville, near Kalispeii, Mont Ashley Creek near Kila, Mont.

Ashley Creek near Kalispell, Mont.

Flathead River at Therriault Ferry Kalispeli .

rathead River at Therriault ,

Swan River

Wan River near Bigfork,

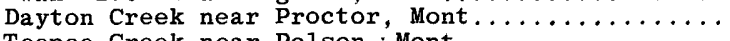

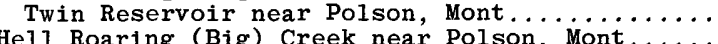

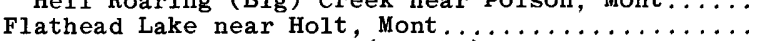

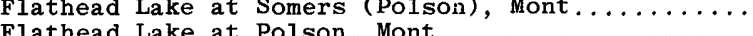

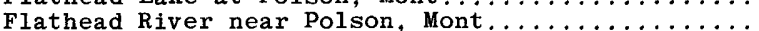

Little Bitterroot River:

Little Bitterroot Lake near Marion, Mont.

Little Bitterroot River near Marion, Mont...

Hubbart Reservoir near Niarada, Mont.

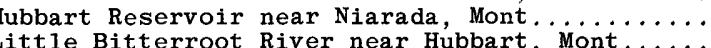

ittle Bitterroot River near Niarada (Dayton)...

Sullivan Creek tributary near Niarada, Mont.

Dry Fork Creek:

Upper Dry Fork Reservoir near Lonepine, Mont... Dry Fork Reservoir near Lonepine, Mont.......... South Fork Garden Creek near Hot Springs, Mont row Creek near Ronan, Mont.

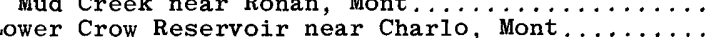
Crow Creek at Lozeau's ranch, near Ronan, Mont... Mission Creek:

Mission Reservoir near St. Ignatius, Mont ........ Dry Creek:

Tabor Reservoir near St. Ignatius, Mont........ Creek near St. Ignatius, Mont . ........

Pablo Reservoir near Pablo, Mont.

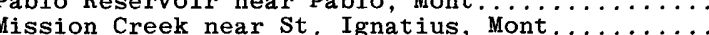
Post Creek:

McDonald Reservoir near Charlo, Mont

Post Creek at Fitzpatrick's ranch, near Ronan (St. Ignatius) (near Ronan), Mont.

Post Creek at Deschamp's ranch, near Ronan....

Post Creek near St. Ignatius, Mont.

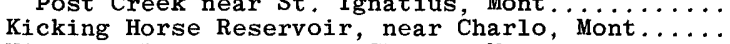

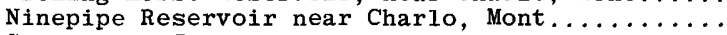

South Fork Jocko River:

Middle Fork Jocko River:

Lower Jocko Lake near Arlee, Mont........... 3805

Middle Fork Jocko River near Jocko, Mont......... 3810

South Fork Jocko River near Jocko, Mont.......... 3815

North Fork Jocko River near Jocko, Mont......... 382

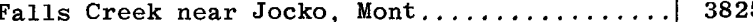

Jocko Rirrer near Josko, Mont .................. 393

Jocko, Mont.

Big Knife Creek near Jocko, Mont........... 3840
44.2

$-$

671

20.9

$-6.41$

$\overline{0} 086$

7,086

7,086
7,096

31.8
31.8

14

114

134
28.0

223.

$-$

8.53

17.8

46.1

30.4

$\overline{139}$

$-$

$-19.5$

74.8

$-$

28.4

29. 7

47.6

-

7.3

14.9

72.3
19.5

19.5
3.57

140

7.16

7.44 1908*;1909-10.

1906-17.

1911-16.

1939-

1939-

1908-16.

$1939-$

$1939-$

1906-11.

1911.

1911-17.

1939-

1940-

1912-16.

$1912-16$.

1912-16.

1912-16.

$1918-19$
$1959-$

$1969-$

1960-67

1939-

$1900 *$.

$1900 * ; 1908-$

$(1900 ; 1908-26$; 1928-41)*

$1907-$

1939-

1910-16.

1909-16

1908-9;19i6-17

$1959-$

1960.

$1959-$ 


\begin{tabular}{|c|c|c|c|c|c|}
\hline \multirow{2}{*}{ Station name } & \multirow[b]{2}{*}{$\begin{array}{r}\text { Station } \\
\text { number }\end{array}$} & \multirow[b]{2}{*}{$\begin{array}{c}\text { Drainage area } \\
(\mathrm{sq} \mathrm{mi})\end{array}$} & \multicolumn{3}{|c|}{ Periods of record } \\
\hline & & & $\begin{array}{l}\text { Daily or monthly figures } \\
\text { (calendar years) }\end{array}$ & $\begin{array}{l}\text { Annual peaks } \\
\text { (water years) }\end{array}$ & $\begin{array}{l}\text { Low-flow measurements } \\
\text { (water years) }\end{array}$ \\
\hline 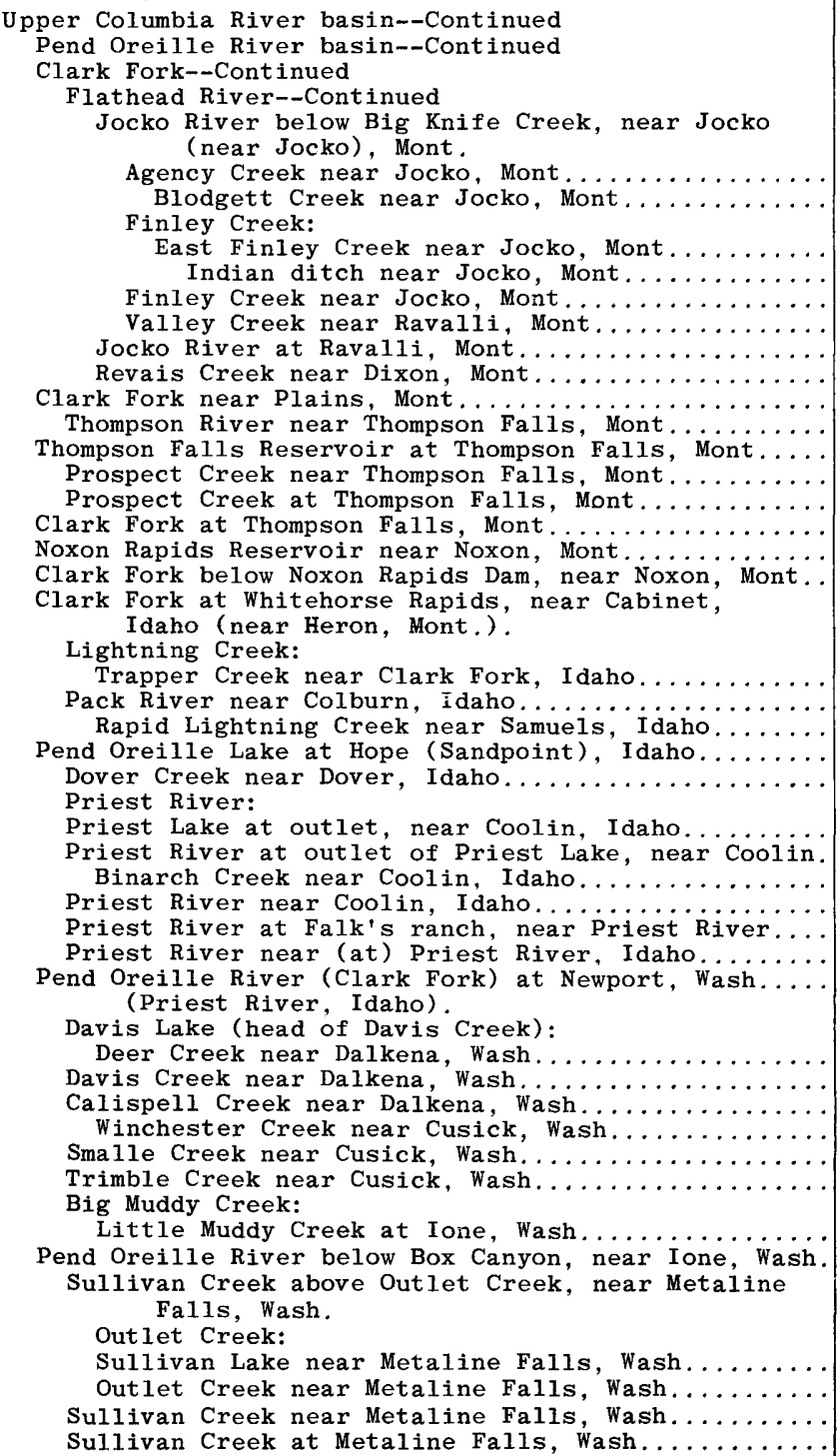 & $\begin{array}{l}3845 \\
\\
3850 \\
3855 \\
3860 \\
3865 \\
3870 \\
3875 \\
3880 \\
3885 \\
3890 \\
3895 \\
3900 \\
3905 \\
3907 \\
3910 \\
3913 \\
3914 \\
3920\end{array}$ & $\begin{array}{c}154 \\
4.00 \\
5.48 \\
5.48 \\
-\quad 36.7 \\
64.1 \\
348 \\
35.0 \\
19,958 \\
642 \\
20,968 \\
145 \\
182 \\
21,113 \\
21,833 \\
21,833 \\
22,067 \\
\\
11.12 \\
124 \\
45.0 \\
\text { a22, 900 } \\
\text { a2. } \\
\\
572 \\
572 \\
10.4 \\
611 \\
792 \\
902 \\
\text { a24, 200 } \\
\end{array}$ & 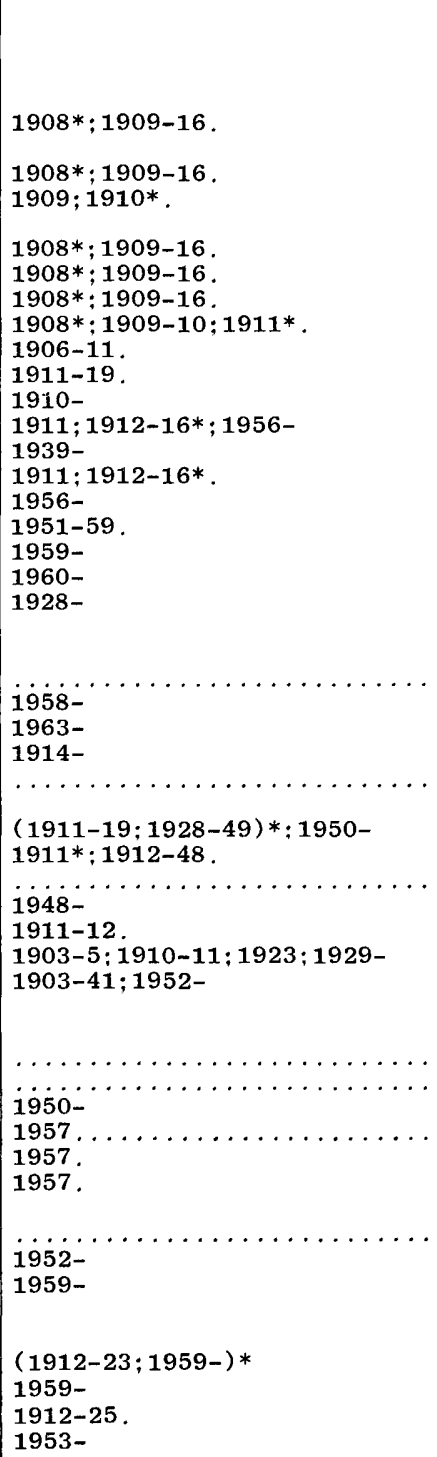 & $\begin{array}{l}1954- \\
1954- \\
1954-\end{array}$ & \\
\hline
\end{tabular}


Pend Oreille River (Clark Fork) (below Z Canyon) near (at) Metaline Falls, Wash.

Pend Oreille River at international boundary.

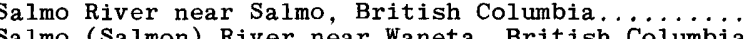

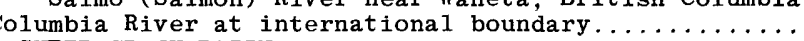

SHEEP CREEK BASIN

Big Sheep Creek (head of Sheep Creek) near Rossland, British Columbia

Sheep Creek near Velvet, Wash.

Sheep Crek near

KETTLE RIVER BASIN

Kettle River:

Myers Creek near Myncaster, British Columbia......

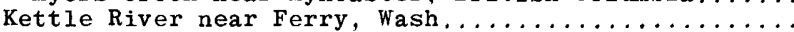

Curlew Creek:

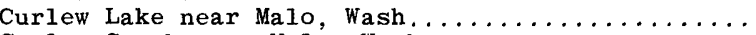

Curlew Creek near Malo, Wash.

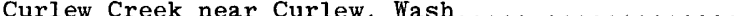

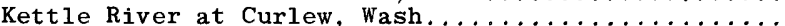

West Deer Creek:

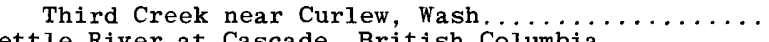

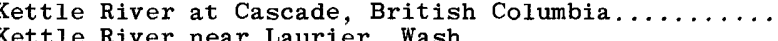

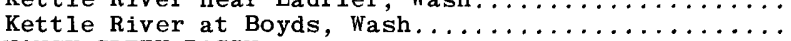
NANCY CREEK BASIN

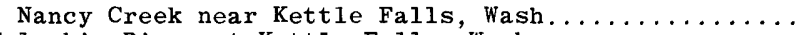

COLVILLE RIVER BASIN

Colville River:

Loon Lake (head of Sheep Creek):

Deer Lake near Loon Lake, Wash.......... 4060

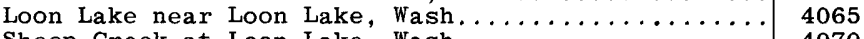

Sheep Creek at Loon Lake, Wash.............. 4070

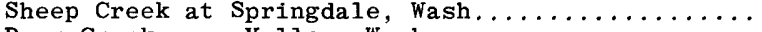

Deer Creek near Valley, Wash

Jumpoff Creek:

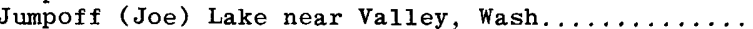

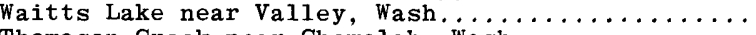

Thomason Creek near Chewelah, Wash

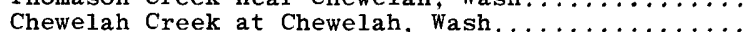

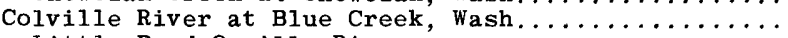

Little Pend Oreille River:

Lake Thomas:

Bighorn Creek (Thomas Lake tributary) near Tiger, Wash.

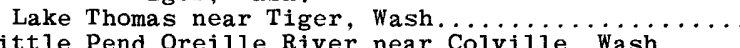
Little Pend Oreille River near Coiviiie, Wash......

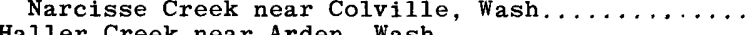

Haller Creek near Arden, Wash.

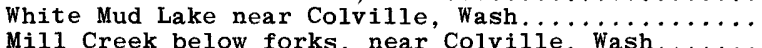

Mil1 Creek below forks, near Colville, Wash........

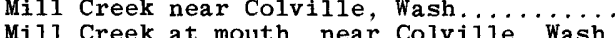

Mill Creek at mouth, near Colville, Wash.................

Colville River at

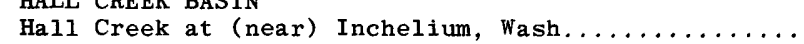

STRANGER CREEK BASIN

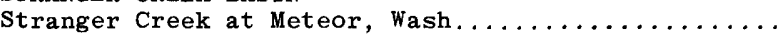

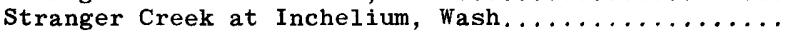

HARVEY CREEK BASIN

Harvey Creek

S.outh Fork Harvey Creek near Cedonia, Wash....... 4106 a25, 200

a25, 200

450

59,700

140

171

225

92.7

a2, 220

65.9

86.7

a2, 640

1.18

a3, 550
a3, 800

a4, 070

11.9

a 64,500

\begin{tabular}{l|l}
18.2 & $1952-*$
\end{tabular}

$37.9 \quad 1950-59$

$48.2 \quad 1953-$

$36.0 \quad 1959$

2.35 1961-*

14.2 1961-*

94.08 i 957 .

428

$1957-$

1922-24 ; 1960-65

1.65

16.3

132

11. 1

37.0
15.3

15.3
67.0

83.0

146

1,007

161

\begin{tabular}{l|l}
50.9 & $1915-29$. \\
82.3 & $1914-17$.
\end{tabular}

.........

$1961-66$

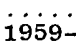

1961-66*

1959.

1939-

1922-

4095

1100

1913-29.

18.1 


\begin{tabular}{|c|c|c|c|c|c|}
\hline \multirow{2}{*}{ Station name } & \multirow{2}{*}{$\begin{array}{r}\text { Station } \\
\text { number }\end{array}$} & \multirow{2}{*}{$\begin{array}{c}\text { Drainage area } \\
(\mathrm{sq} \mathrm{mi})\end{array}$} & \multicolumn{3}{|c|}{ Periods of record } \\
\hline & & & $\begin{array}{c}\text { Dally or monthly figures } \\
\text { (calendar years) }\end{array}$ & $\begin{array}{l}\text { Annual peaks } \\
\text { (water years) }\end{array}$ & $\begin{array}{l}\text { Low-flow measurements } \\
\text { (water years) }\end{array}$ \\
\hline 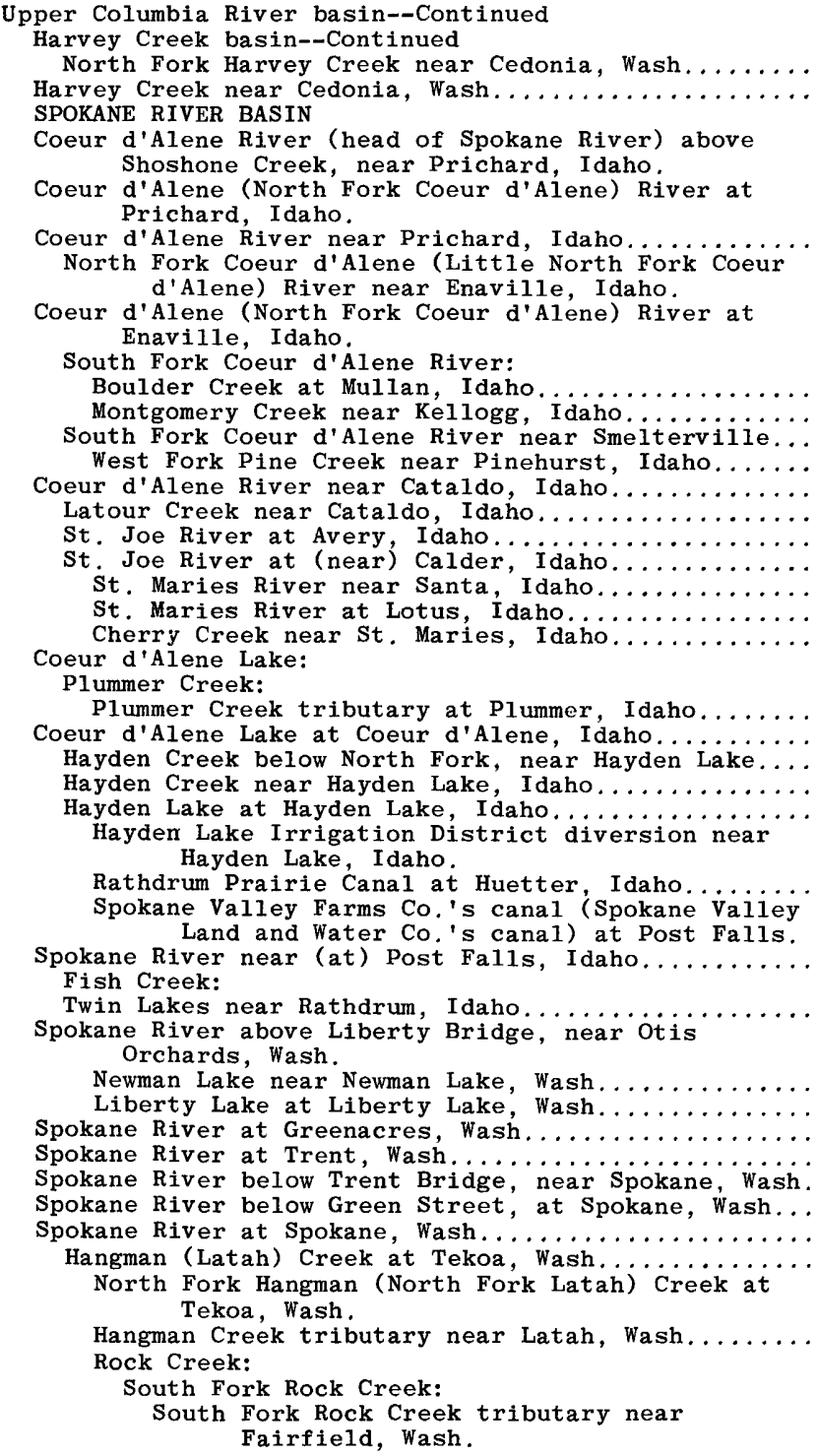 & 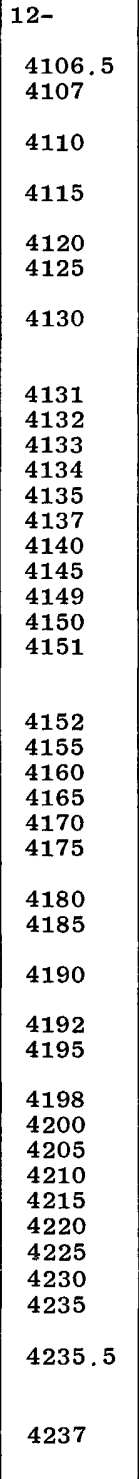 & 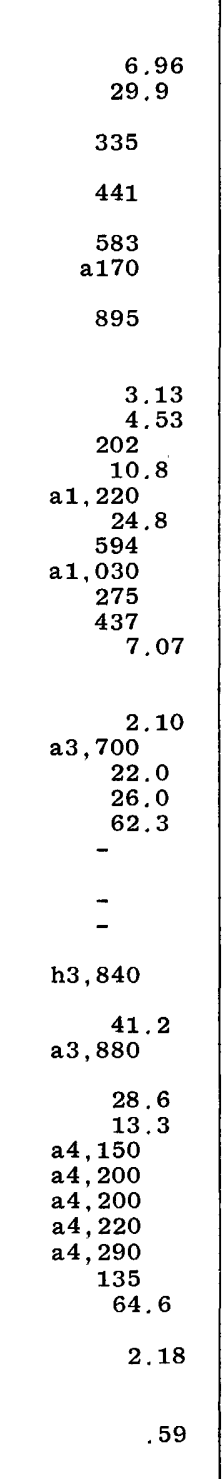 & $\begin{array}{l}1903 \ldots \ldots \ldots \ldots \ldots \ldots \ldots \\
1903-53 ; 1958-59 ; 1965-\ldots \ldots \ldots \\
1948-54 \\
1946-48 . \\
1920-* \\
1945-53 . \\
1945- \\
1911-17 ; 1919-66 . \\
1912- \\
1958- \\
1929- \\
1958-* \\
1950-* \\
1948-52 . \\
1911-13 . \\
1948-54 . \\
1948-52 . \\
1891- \\
1904-5 . \\
1904-5 .\end{array}$ & $\begin{array}{l}1961- \\
1961- \\
1962-65\end{array}$ & \\
\hline
\end{tabular}


Stevens Creek:

. Woran, Wash...... Spokane River above Seven-Mile Bridge, near Spokane. Deep Creek:

Medical Lake at Medical Lake, Wash.

( pokane River below Nine-Mile Dam, near Spokane.....

Little Spokane River at Scotia, Wash.

Little Spokane River at Elk, Wash ......

Diamond Lake (head of West Branch Little Spokane River) near Newport, Wash.

West Branch Little Spokane River:

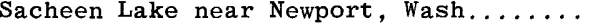

Eloika Lake near E1k, Wash................ 4285

West Branch Little Spokane River near Elk, Wash.

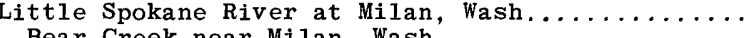

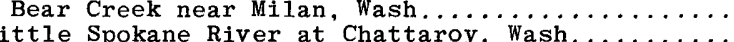

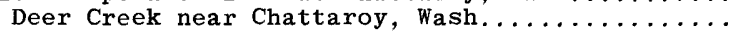

Dragoon Creek:

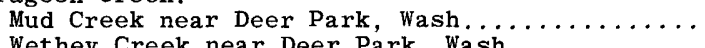

Wethey Creek near Deer Park, Wash....................

Little Spokane River below Dragoon Creek, nea Chattaroy, Wash.

Little Spokane River at Buckeye, Wash.

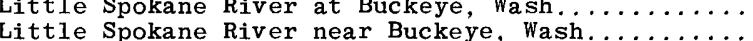

Little Spokane River above Deadman Creek, near Dartford, Wash

Deadman Creek near Mead, Wash

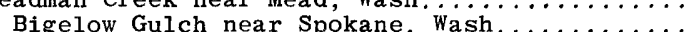

Deadman Creek below U.S. Highway 195, near Mead.

Little Spokane River below Deadman Creek, near Dartford, Wash

Little Spokane River above Wandermere Lake Creek, near Dartford, Wash.

Wandermere Lake Creek near Dartford, Wash.......

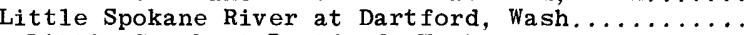

Little Creek at Dartford, Wash........................ e Spokane River bel

Dartford, Wash.
.

Little Spokane River near Dartford, Wash....

Little Spokane River

Little Spokane River near Spokane, Wash.......................

Long Lake at Long Lake, Wash.

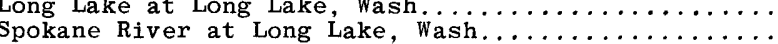

Spring Creek:

Spring Creek tributary near Reardan, Wash....... Spokane River below Little Falls, near Long Lake.... HAWK CREEK BASIN

Hawk Creek at Davenport, Wash $\ldots \ldots \ldots \ldots \ldots \ldots \ldots \ldots$
SANPOIL RIVER BASIN

Sanpoil River:

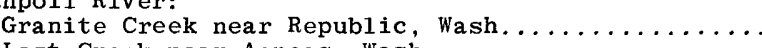
Lost Creek near Aeneas, Wash.

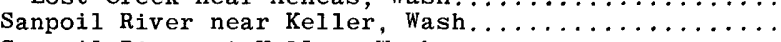

Sanpoil River at Keller, Wash.

Franklin D. Roosevelt Lake:

Feeder Canal at Grand Coulee, Wash.
2.02

1.35
77.3

a 5,200

115.

6.08

33.5

33.
101

104
275

10.5

301.9

31.9
1.83

1.83
12.0

177
511

518

518
523
524

80.3

94.7

31.8
659

660

4.32

4.32
665
11.9

691.9

698

700

701

a6, 020

a 6,020

a6, 340.14

23.2

4.25

$80 . ?$

880

928
$19 \dot{4}$

1948-52.

1953-58*

$1949-50$.

1948 .

1948 -

1953-*

1954-*

igi......

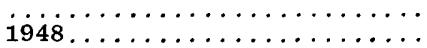

...............................

1948

$1948 . \ldots \ldots \ldots \ldots \ldots \ldots \ldots$

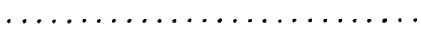

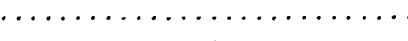

$\ldots \ldots \ldots \ldots \ldots \ldots \ldots \ldots$

$\ldots \ldots \ldots \ldots \ldots \ldots \ldots \ldots$

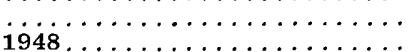

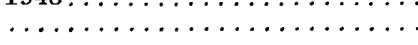

$\ldots \ldots \ldots \ldots \ldots \ldots \ldots \ldots \ldots$

$1929-32 ; 1946-$

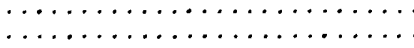

1903-5*: 1948-52.

1911-12*.

1913.

$1913-$

1939-

$1912-40$

$1920-21$

1952-55

1911-17.

1951-
1954-

1962-

1962-

1962-................

1954 -

$\ldots \ldots \ldots$

$\ldots \ldots \ldots \ldots$

$\ldots \ldots \ldots \ldots$

$1950 ; 1962-$

$\ldots \ldots \ldots \ldots$

$\ldots \ldots \ldots \ldots$

...........

$1963-$

...........

.

..

1953 ; 1956-57 ; 1961-

1920-24; 1930-32;

$1947-48 ; 1953-$
1952; 1955-

1948 ; 1952; 1955-

1948 ; 1952; 1955-

1952; 1955-

1948 ; 1952 ; 1955 -

1953-

1952-

1953-

1953-

1953-
1954-

1957 ; 1959 ; $1963-$

1954-

1956-59. 


\begin{tabular}{|c|c|c|c|c|c|}
\hline \multirow{2}{*}{ Station name } & \multirow{2}{*}{$\begin{array}{r}\text { Station } \\
\text { number }\end{array}$} & \multirow{2}{*}{$\begin{array}{l}\text { Drainage area } \\
(\mathrm{sq} \mathrm{mi})\end{array}$} & \multicolumn{3}{|c|}{ Periods of record } \\
\hline & & & $\begin{array}{c}\text { Daily or monthly figures } \\
\text { (calendar years) }\end{array}$ & $\begin{array}{l}\text { Annual peaks } \\
\text { (water years) }\end{array}$ & $\begin{array}{c}\text { Low-flow measurements } \\
\text { (water years) }\end{array}$ \\
\hline 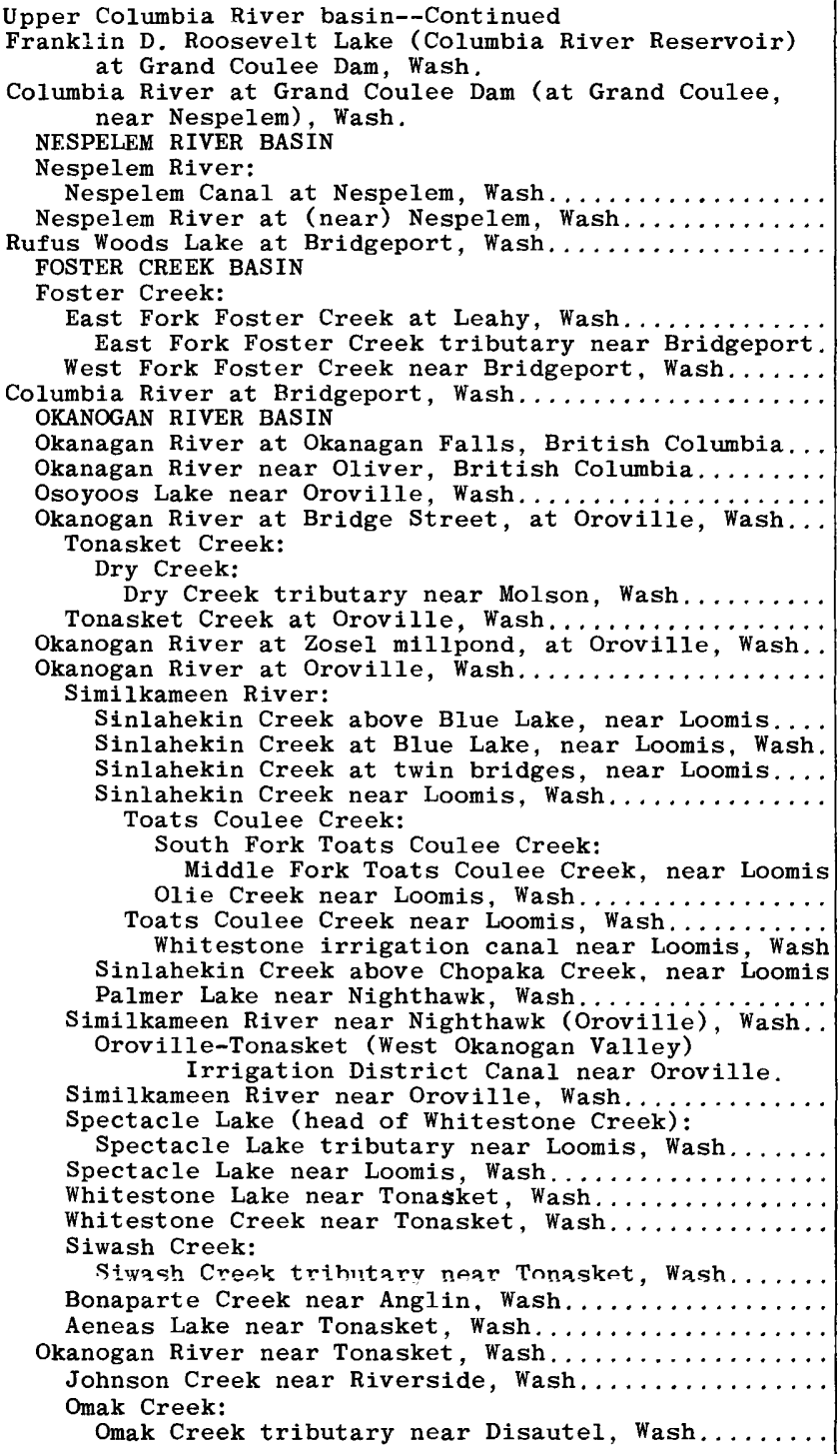 & $\begin{array}{l}4417 \\
4418 \\
4420 \\
4422 \\
4423 \\
4424 \\
4425 \\
4430 \\
\\
4435 \\
\\
4437 \\
4438 \\
4440 \\
4441 \\
\\
4444 \\
4445 \\
\mathbf{4 4 4 7} \\
\mathbf{4 4 5 0} \\
\mathbf{4 4 5 5} \\
\\
4458\end{array}$ & $\begin{array}{c}1.68 \\
60.0 \\
\text { a3, } 210 \\
\text { a3,210 } \\
41.7 \\
42.9 \\
75.5 \\
86.6 \\
\\
17.1 \\
1.42 \\
130 \\
-56 \\
256 \\
293 \\
\text { a3,550 } \\
- \\
\text { a3, } 580 \\
4.59 \\
17.2 \\
52.3 \\
55.4 \\
.66 \\
\text { a110 } \\
32.4 \\
\text { a } 7,280 \\
73.3 \\
4.12\end{array}$ & 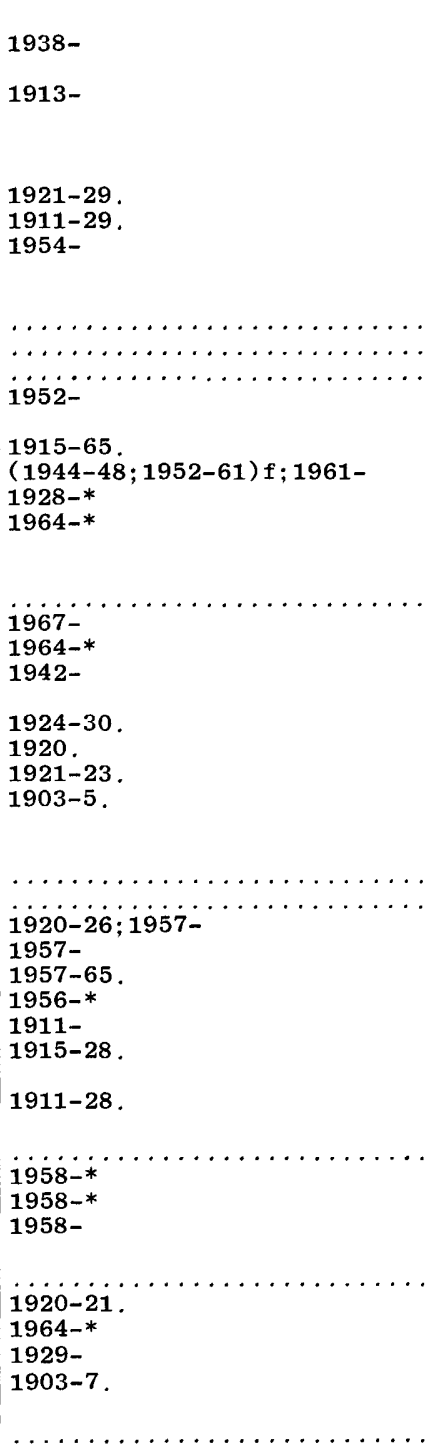 & $1957 ; 1959-$ & \\
\hline
\end{tabular}


Okanogan River at Okanogan, Wash.

Salmon Creek mear Conconully (Okar

(Okanogan), Wash...... 4465

Comeonuly (Okalott), Wash................ 4470

Okanon

. 447

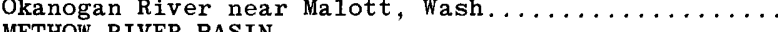

Methow River:

Early Winters Creek:

Pine Creek near Mazama, Wash.

Chewack Creek:

near Winthrop, Wash.

ightmile Creek:

Ortell Creek near Winthrop, Wash.

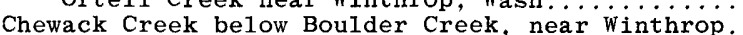

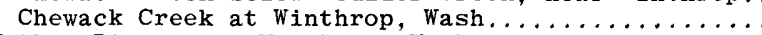

Williams Creek near Twisp, Wash

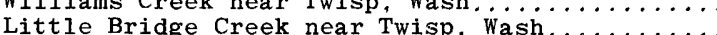

Twisp River at Twisp, Wash . . . . . . . . . . .

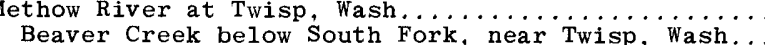

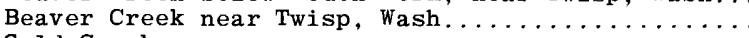
Gold Creek:

outh Fork Gold Creek:

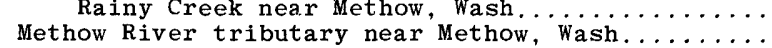
thow River near Pateros, Wash.

Methow River at Pateros, Wash.

Columbia River below Wells Dam, Wa CHELAN RIVER BASIN

Stehekin River (head of Chelan River) at Stehekin... Lake Chelan:

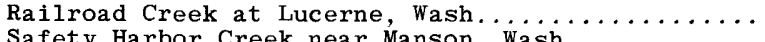
Safety Harbor Creek near Manson, Wash..

Grade Creek near Manson, Wash

Gold Creek near Manson, Wash.

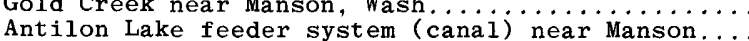

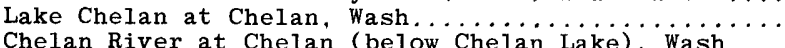

Chelan River at Chelan (below Chelan Lake), Wash....

ENTIAT RIVER BASIN

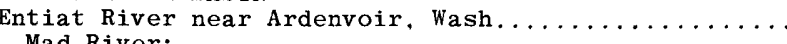

Mad River:

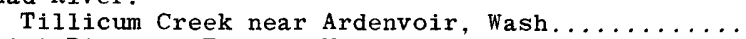

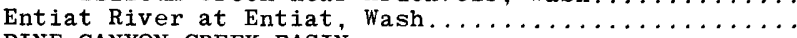
PINE CANYON CREEK BASIN

Pine Canyon Creek near Waterville, Wash ................... RIVER

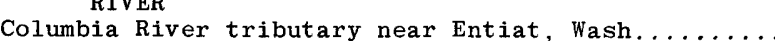

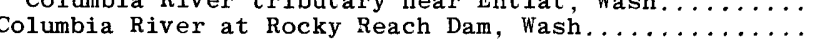
WENATCHEE RIVER BASIN

White River (head of Wenatchee River) near Plain (Chiwaukum), ivash.

Little Wenatchee River:
Little Wenatchee River tributary near Telma, Wash

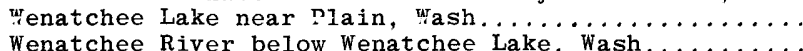

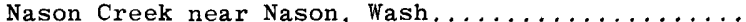

$1911-25 ; 1925-29 b$ $1910-22$

a8, 100

a8, 220

4510

4515

4516

4516.2

517

4525

4528

4528.8

4530

4535

4536
4537

4537

4540

4542.9

4515

4550

4555

1903-10; 1911-12*

1958-67.

4.63

3.80

4.05

465
525

525
1,007

3.15

16.

1,301

62.0
68.1

8.51

1,772

1,792

a86, 100

344

64.8

7.85

8.45
6.30

924

203

7.15

419

11.1

$287,800^{.77} 1960-$

150

1.02

273
273

84.8

1932-

1932-58.

1911.

1911-13*.

1960-

1903-20.

1967-

19-15; 1926-

1910-13; 1926-57.

961-

1903-

1957-

$1910-25 ; 1951-58$.

1959

\begin{tabular}{l|l}
$\overline{9} 24$ & $1958-$ \\
924 & $1897-99 ; 1905 ; 1910) * ; 1911-$
\end{tabular}

1959-

$1967-$

1957-

1966-

$1966-$

1966-

$1954-$

1966- 


\begin{tabular}{|c|c|c|c|c|c|}
\hline \multirow{2}{*}{ Station name } & \multirow[b]{2}{*}{$\begin{array}{r}\text { Station } \\
\text { number }\end{array}$} & \multirow[b]{2}{*}{$\begin{array}{l}\text { Drainage area } \\
\qquad(\mathrm{sq} \mathrm{mi})\end{array}$} & \multicolumn{3}{|c|}{ Periods of record } \\
\hline & & & $\begin{array}{c}\text { Daily or monthly figures } \\
\text { (calendar years) }\end{array}$ & $\begin{array}{l}\text { Annual peaks } \\
\text { (water years) }\end{array}$ & $\begin{array}{c}\text { Low-flow measurements } \\
\text { (water years) }\end{array}$ \\
\hline 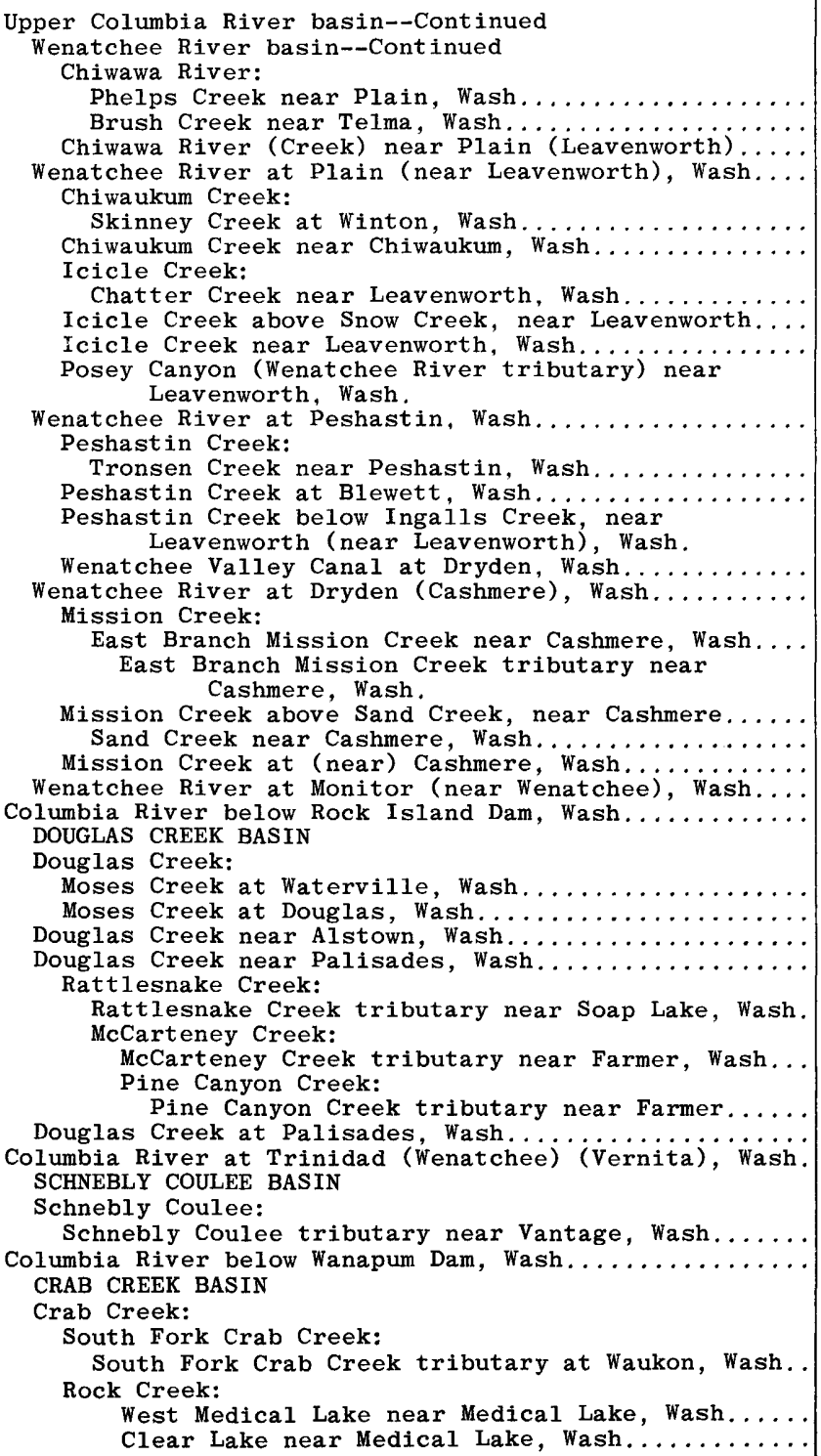 & $\begin{array}{l}4560 \\
4563 \\
4565 \\
4570 \\
4573 \\
4575 \\
4579 \\
4580 \\
4585 \\
4589 \\
4590 \\
4594 \\
4595 \\
4600 \\
4605 \\
4610 \\
\\
4611 \\
4612\end{array}$ & $\begin{array}{c}16.4 \\
3.34 \\
172 \\
591 \\
2.55 \\
47.8 \\
2.25 \\
193 \\
211 \\
1.36 \\
\text { a1, } 000 \\
3.96 \\
38.3 \\
97.2 \\
\\
-155 \\
1, \\
15.4 \\
2.49 \\
39.8 \\
18.6 \\
81.2 \\
1,301 \\
\text { a89, } 400\end{array}$ & 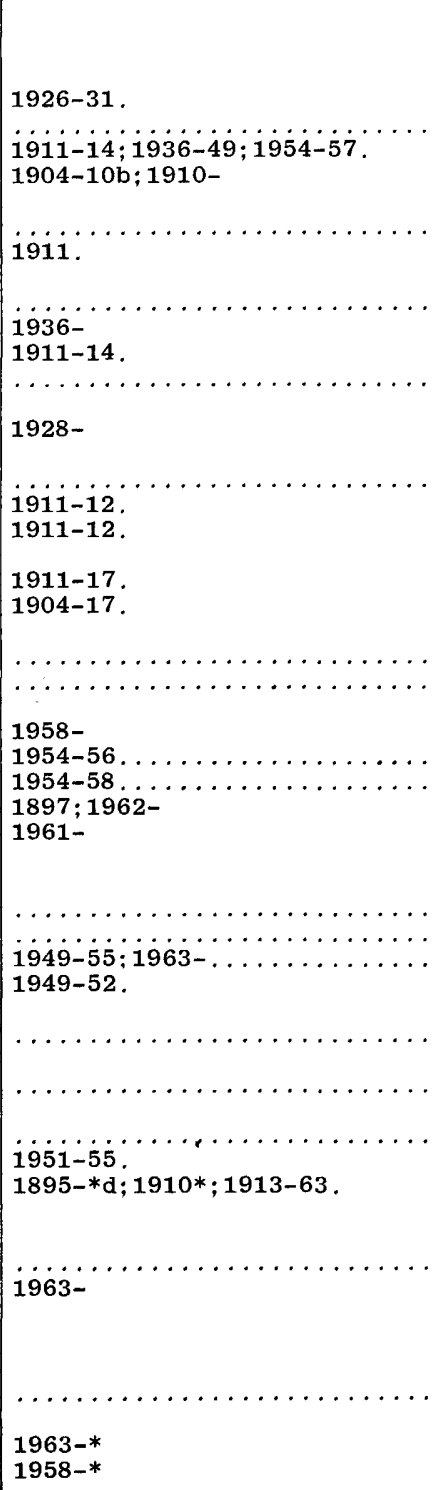 & $\begin{array}{l} \\
1954- \\
1955 ; 1957- \\
1956-60 \\
1959 ; 1961- \\
1960 ; 1962- \\
1960 ; 1962-\end{array}$ & \\
\hline
\end{tabular}


Coal Creek at Mohler, Wash

Connawai Creek tributary near Govan, Wash.......

Wilson Creek near Almira

Broadax Draw Creek:

Broadax Draw Creek tributary near Wilbur....

Grand Coulee tributary near Coulee City, Wash...

Park Creek (continuation of Grand Coulee) near Coulee City, Wash.

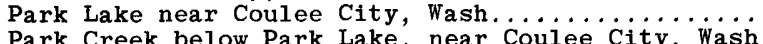

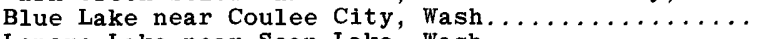
Lenore Lake near Soap Lake, Wash.

Soap Lake near Soap Lake, Wash.

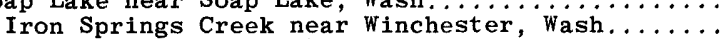

Rocky Ford (Upper Crab) Creek near Ephrata, Wash..

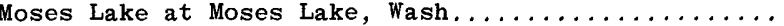
Crab Creek:

Lind Coulee:

\section{Paha Coulee:}

Paha Coulee tributary near Ritzville, Wash....

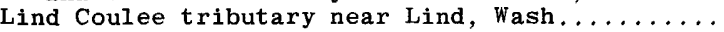

Weber Coulee:

Farrier Coulee near Schrag, Wash. .............

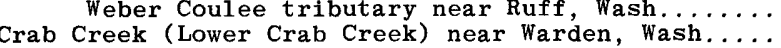

Crab Creek near Smyrna, Wash

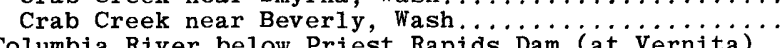

Columbia River below Priest Rapids Dam (at vernita)

(at Trinidad), Wash.

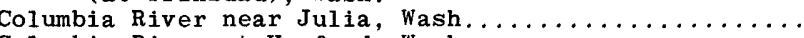

Columbia River at Hanford, Wash.

SCOOTENEY RESERVOIR BASIN

Scooteney Reservoir:

Kansas No. 2 (Scooteney Reservoir tributary) near Cunningham, Wash.

YAKIMA RIVER BASIN

Yakima River:

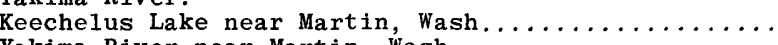

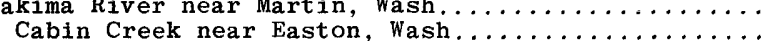

Cabin Creek near

Kachess River:

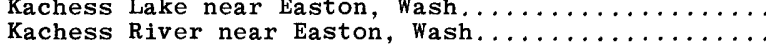

Kittitas Canal at Easton, Wash. . . . . . . . . .

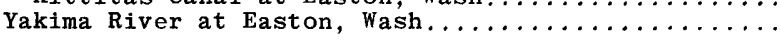

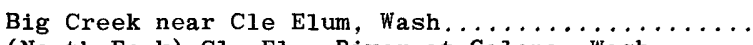

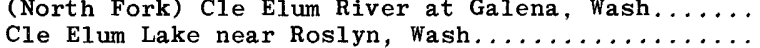

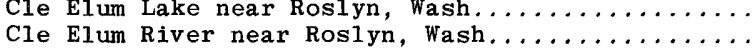

Yakima River at Cle Elum, Wash.

Teanaway River below Forks, near cle Elum, Wash...

Teanaway River near Cle Elum (Clealum), Wash.....

Swauk Creek:

Hovey Creek near Cle Elum, Wash.

4680

4685

4690

4695

4700

4703

4705
4710

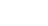

4711

4712

4712.7

4713

4715

4725
4726

4728

4730

4735

4737

4740

4745

4760

4765

4775

4775
4780

4780
4785

4790

4795
4800

4800
4805

4807

\begin{tabular}{|c|c|c|}
\hline $1,042.7$ & $\begin{array}{l}1963- \\
1942-\end{array}$ & \\
\hline $\mathrm{a} 200^{.25}$ & ig6i. $\cdots \cdots \cdots \cdots \cdots \cdots \cdots \cdots$ & 1958- \\
\hline $\begin{aligned} & 1.12 \\
& 1,767 \\
& 12, 765 \\
& i 2,228\end{aligned}$ & $\begin{array}{l}1951- \\
1904 * \\
1909-12 . \\
1942-\end{array}$ & $1955-$ \\
\hline $\mathrm{a2} .7$ & $1922-45 \ldots \ldots \ldots \ldots \ldots \ldots$ & $1959-$ \\
\hline $\begin{array}{c}\mathbf{j} 317 \\
\mathbf{j} 317 \\
\mathbf{j} 334 \\
\mathbf{j} 367 \\
\mathbf{j} 413 \\
1.57 \\
\mathrm{k} 458 \\
\mathrm{~m} 3,080\end{array}$ & $\begin{array}{l}1938-* \\
1945- \\
1938-* \\
(1936 ; 1938-) * \\
(1936 ; 1938-) * \\
1909-11 ; 1942-\ldots \ldots \ldots \ldots \ldots \\
(1909-14 ; 1936-) *\end{array}$ & 1959- \\
\hline $\begin{array}{r}8.52 \\
.21\end{array}$ & 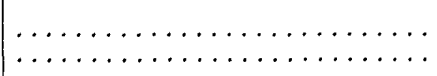 & $\begin{array}{l}1962- \\
1956 ; 1961-\end{array}$ \\
\hline $\begin{array}{l}42.0 \\
m 4,470 \\
m 4,781 \\
m 4,842 \\
96,000\end{array}$ & $\begin{array}{l}1963- \\
1909-12 ; 1942-65 \ldots \ldots \ldots \ldots \\
\text { 1942-59. } \\
\text { 1959- } \\
1917-\end{array}$ & $1959-$ \\
\hline$\overline{-}$ & $\begin{array}{l}1905 * \\
1910 *\end{array}$ & \\
\hline 6.06 & & $1955-$ \\
\hline $\begin{array}{l}54.7 \\
54.7 \\
29.3\end{array}$ & $\begin{array}{l}1906- \\
1903- \\
1909-11\end{array}$ & \\
\hline $\begin{array}{l}- \\
\overline{203} \\
203 \\
495 \\
172 \\
200\end{array}$ & $\begin{array}{l}1905- \\
1903- \\
1930-\mathrm{n} \\
1904 ; 1910-15 ; 1941-50 ; \\
\quad 1950-53 \mathrm{~b} \\
1909 * \\
(1907 ; 1911) * \\
1906- \\
1903- \\
1906- \\
1911-12 \\
1909-14 ; 1946-52\end{array}$ & \\
\hline 2.65 & & 1955- \\
\hline
\end{tabular}




\begin{tabular}{|c|c|c|c|c|c|}
\hline \multirow{2}{*}{ Station name } & \multirow{2}{*}{$\begin{array}{r}\text { Station } \\
\text { number }\end{array}$} & \multirow{2}{*}{$\begin{array}{l}\text { Drainage area } \\
(\mathbf{s q} \mathrm{mi})\end{array}$} & \multicolumn{3}{|c|}{ Periods of record } \\
\hline & & & $\begin{array}{c}\text { Daily or monthly figures } \\
\text { (calendar years) }\end{array}$ & $\begin{array}{l}\text { Annual peaks } \\
\text { (water years) }\end{array}$ & $\begin{array}{l}\text { Low-flow measurements } \\
\text { (water years) }\end{array}$ \\
\hline 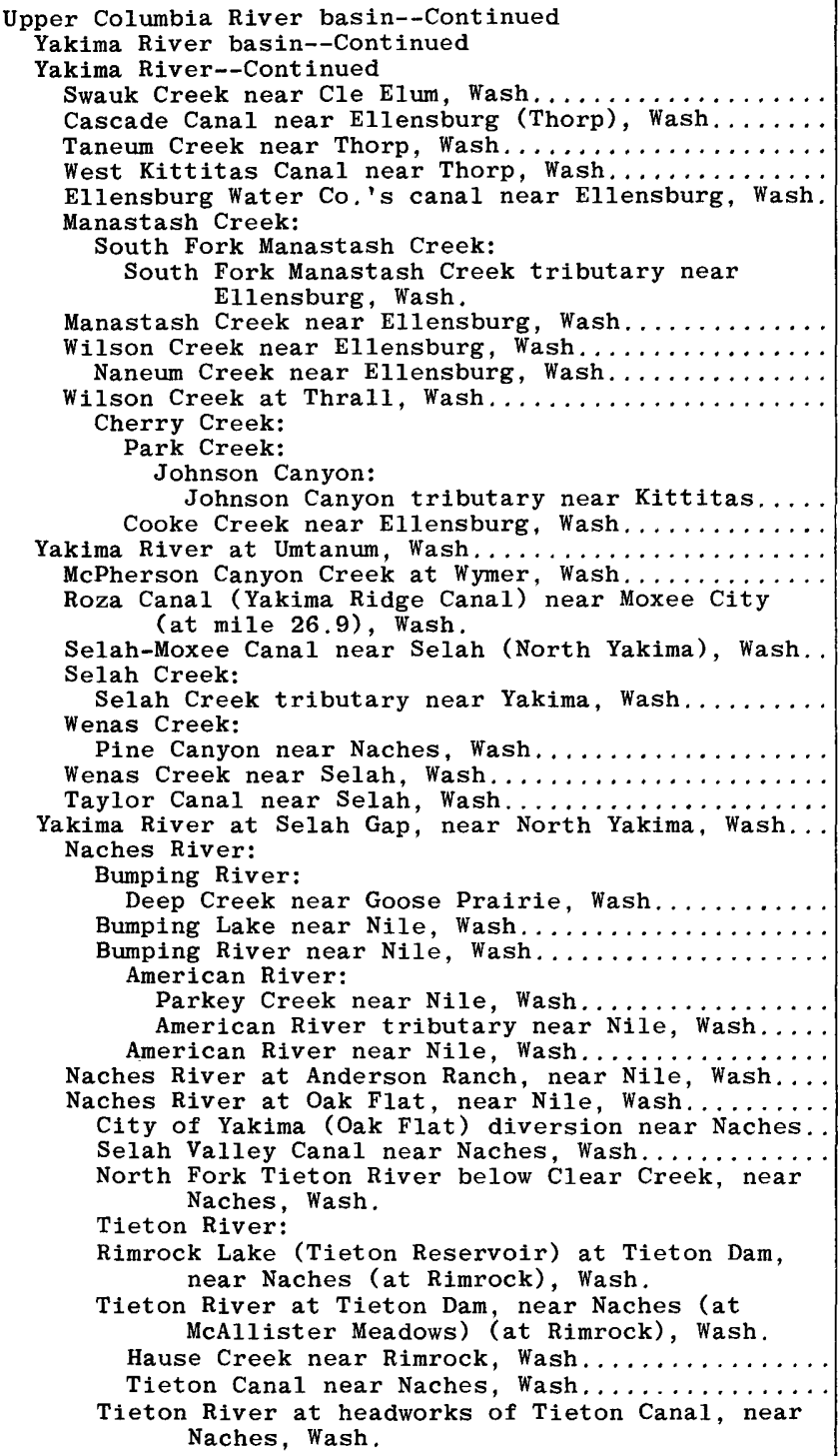 & $\begin{array}{l}4842 \\
4843 \\
4845 \\
4846 \\
4850 \\
\\
4855 \\
\\
4857 \\
\\
4859 \\
4860 \\
4865 \\
4870\end{array}$ & 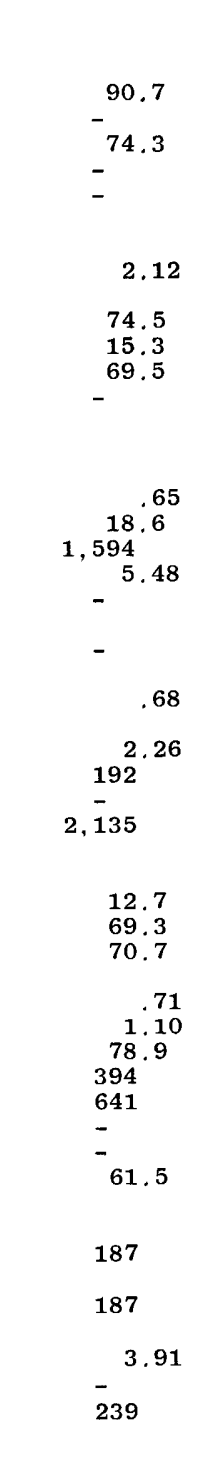 & $\begin{array}{l}1906 ; 1909- \\
1906 ; 1909- \\
\ldots \ldots \ldots \ldots \ldots \ldots \ldots \ldots \ldots \ldots \\
1909-15 ; 1939 \ldots \ldots \ldots \ldots \ldots \\
1909-14 . \\
1904-17 . \\
1929-q \\
1904 ; 1909-14 ; 1920-q \\
1914-15 . \\
1925- \\
1908-12 ; 1914 ; 1918-21 ; 1925- \\
191 \ldots \ldots \ldots \ldots \ldots \ldots \ldots \\
1906-\end{array}$ & $\begin{array}{l}1966- \\
1955-57 . \\
1955-\end{array}$ & \\
\hline
\end{tabular}


Tieton River above and below Oak Creek, near Natches (near North Yakima, near Natches, and at (obb's ranch), Wash

Wapatox Canal near Naches (North Yakima), Wash.

Naches River below Tieton River, near Naches, Wash.

Naches Canal Co. (Gleed) Canal near Naches, Wash.

Yakima Valley (Congdon) Canal near Naches, Wash..

Naches-Cowiche Canal near North Yakima, Wash .....

North Yakima power canal near North Yakima, Wash.

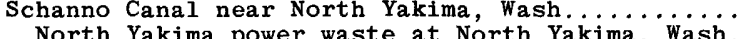

North Yakima power waste at North Yakima, Wash.

North Yakima Milling Co, waste at North Yakima.

Id Union Canal near North Yakima, Wash.

Naches Avenue Union Canal at North Yakima.......... Naches River near North Yakima, Wash

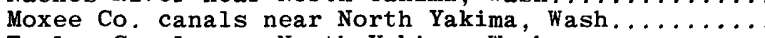

Fowler Canal near North Yakima, Wash.

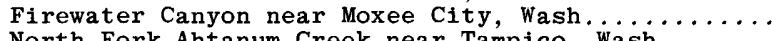

orth Fork Ahtanum Creek near Tampico, Wash..

South Fork Ahtanum Creek at Conrad Ranch, near Tampico, Wash.

South Fork Ahtanum Creek near Tampico, Wash.

Ahtanum Creek at The Narrows, near Tampico, Wash... Ahtanum Creek at Union Gap (near Yakima), Wash....

Yakima River at Union Gap (near Yakima), Wash.......

New Reservation Canal near (at) Parker (Yakima).... Old Reservation Canal near (at) Parker (Wapato).

Sunnyside Canal near Parker (Yakima) (Wapato).

Yakima River near Parker (Wapato), Wash.

Topperish Creek at Alfalfa, Wash.......

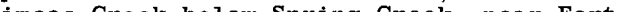
Simcoe (near Fort Simcoe), Wash

Toppenish Creek near White Swan (Wapato), Wash.....

Toppenish Creek tributary near Toppenish, Wash...

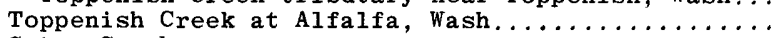

Shinando Creek tributary near Goldendale, Wash.

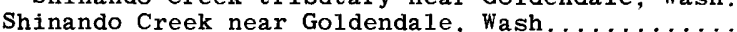

Satus Creek tributary near Toppenish, wash..........

Satus Creek near Toppenish, Wash

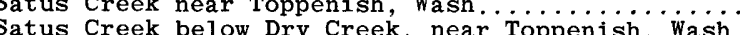
Yakima River tributary near Sunnyside, Wash.......

Yakima River near Mabton, Wash.

Yakima River near Prosser, Wash.

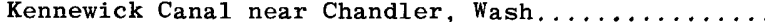

Snipes Creek:

Snipes Creek tributary near Benton City, Wash.... Kiona Canal near Kiona, Wash $\ldots \ldots \ldots \ldots \ldots \ldots \ldots$

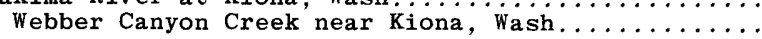
Cold Creek:

Cold Creek tributary near Priest Rapids, Wash...

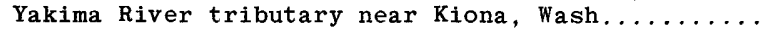

Kennewick Canal near Kiona (Richland)

$$
\text { (Kennewick), Wash. }
$$

Lower Yakima Canal near Kiona, Wash............

Yakima River near Richland, Wash............... 512
$1904 ; 1905 * ; 1909-14 ; 1916-q$ $1905 ; 1908-$

$1904 ; 1905^{*} ; 1909-11$.

$1904 ; 1905 * ; 1909-11$.

$1904 ; 1905 * ; 1909-11$

$1904 ; 1905 * ; 1910$.

$1904 ; 1905 * ; 1909-11$.

1909-12.

1909-12.

1904 ; 1905*; 1909-11.

1910 .

1893-95*; 1896-1915.

1904; 1905*; 1909-11.

1904;1905*; 1909-11.

$1907-$

1915-

$28.5 \quad 1907 * ; 1908-14$

119

$1908-13 ; 1960$

904; 1907-8; 1909*; 1910-14 ;

$3,652 \quad \begin{gathered}1951-53 ; 1960- \\ (1893-94 ; 1895-96) * ; 1896-1914 \text {; }\end{gathered}$ $1963-64$; 1967

1904-

$\overline{-}$

$3, \overline{6} 60$

1904;1903*; 1906

5040

5045

505

5060

5065

5070

5075

5076

5076.5

5076.6

5080

5085

5088

5090

5095

5096

5098

5100

5105

5106.2

5107

120

$1904-6 ; 1913-33$ $\overline{122}$

370

1.24
625

1908

1912-23.

1909-24

1909-11; 1912*.

…............... 1955-

.28

8.54

271

1.91

5,400
5,453

5.18

$5, \overline{6} 15$

2.88

3.35

.................. 1955-

$\ldots \ldots \ldots \ldots \ldots \ldots$ 1953;1956:1961

1908-13

1913-24.

1954

$1956-r$

1904 (1905; $1908-9) *: 1910$ -

1895*;1896-1915;1933- $\ldots \ldots \ldots \ldots \ldots \ldots \ldots \ldots$ 1955-

1967

1904;1905*:1910-11......

- $1905 * ; 1910-11$

6,155

1906 ; 1907-8*; 1909-11. 


\begin{tabular}{|c|c|c|c|c|c|}
\hline \multirow{2}{*}{ Station name } & \multirow{2}{*}{$\begin{array}{r}\text { Station } \\
\text { number }\end{array}$} & \multirow{2}{*}{$\begin{array}{l}\text { Drainage area } \\
(\mathbf{s q} \mathrm{mi})\end{array}$} & \multicolumn{3}{|c|}{ Periods of record } \\
\hline & & & $\begin{array}{l}\text { Daily or monthly figures } \\
\text { (calendar years) }\end{array}$ & $\begin{array}{l}\text { Annual peaks } \\
\text { (water years) }\end{array}$ & $\begin{array}{l}\text { Low-flow measurements } \\
\text { (water years) }\end{array}$ \\
\hline 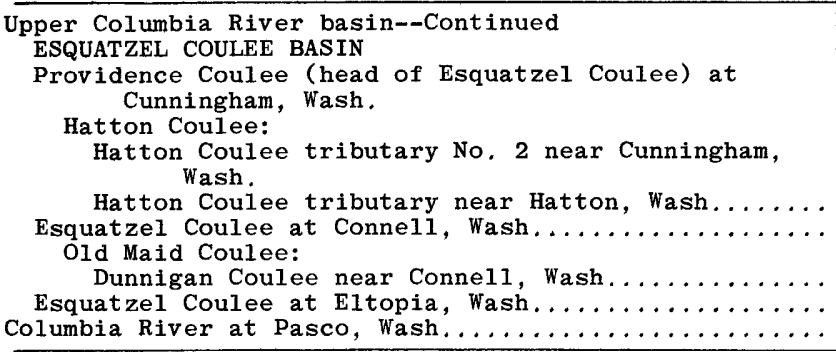 & \begin{tabular}{|l}
$12-$ \\
5125 \\
5126 \\
5127 \\
5130 \\
5133 \\
5135 \\
5140
\end{tabular} & $\begin{array}{c}27.8 \\
2.44 \\
3.71 \\
234 \\
27.1 \\
5551 \\
104,000\end{array}$ & 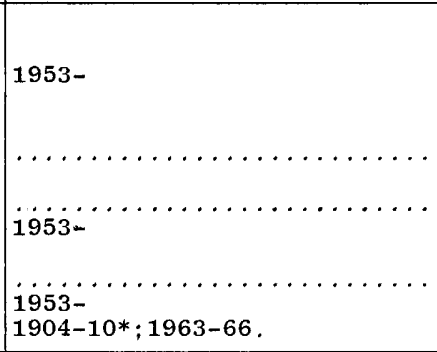 & $\begin{array}{l}1961- \\
1956- \\
1956 ; 1963-\end{array}$ & \\
\hline
\end{tabular}

* Gage heights, or gage heights and discharge measurements only.

a Approximately.

In water-supply bulletins of State of Washington.

c Includes $99 \mathrm{sq} \mathrm{mi}$ above Cushman Dam No. 2 which is normally noncontributing.

In reports of U.S. Weather Bureau.

Creek and $10.75 \mathrm{sq} \mathrm{mi}$ from Rocky Creek for greater part of year

In reports of Department of Northern Affairs and National Resources, Canada.

Fragmentary gage-height records at Coolin, published as part of the records for Priest River at outlet of Priest Lake, at Coolin.

h Approximately, about $122 \mathrm{sq} m i$ in the vicinity of Hayden Lake is noncontributing.

$1219 \mathrm{sq} \mathrm{mi}$ in the vicinity of Long Lake Reservoir is probably non

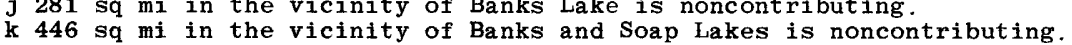

m 665 sq $\mathrm{mi}$ is noncontributing.

m 665 sq mi is noncontributing

p Published with

q Published with station 4940. Naches River below Tieton River, near Naches.

$r$ Yearly diversion only published with station 5105. Yakima River at Kiona.

$\mathrm{s} 168 \mathrm{sq} \mathrm{mi}$ in the vicinity of Sulphur Lake is noncontributing. 
Page

Aeneas Lake, Wash.

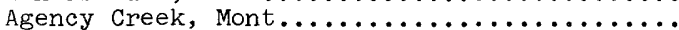

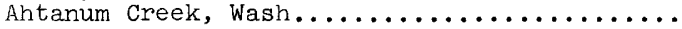

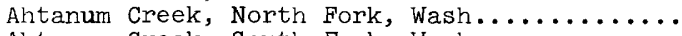

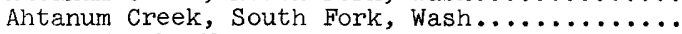

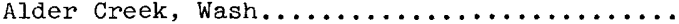

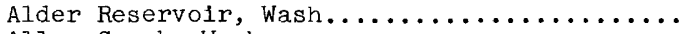

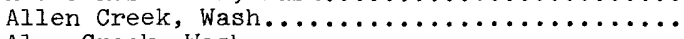

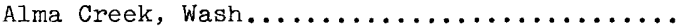

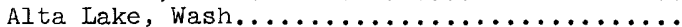

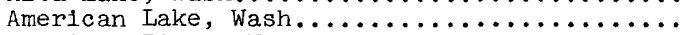

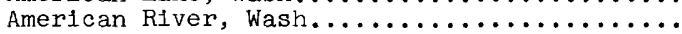

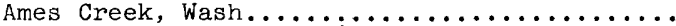

Anderson Creek, Wash. (tributary to Nooksack

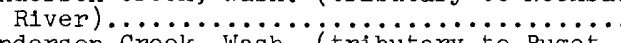

Anderson Creek, Wash. (tributary to Puget

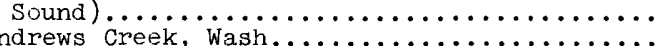

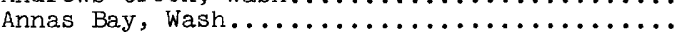

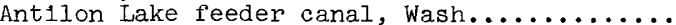

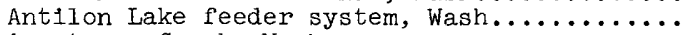

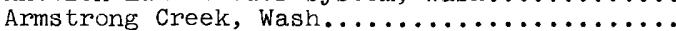

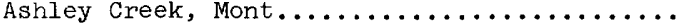

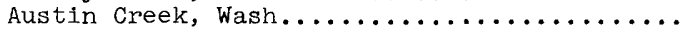

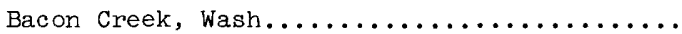

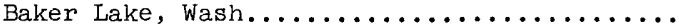

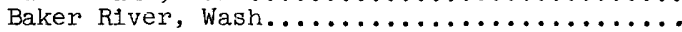

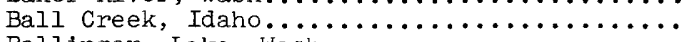

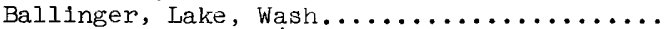

Bear Creek, Mont. (tributary to Bitterroot

River) .......... (tributary to Middie Fork

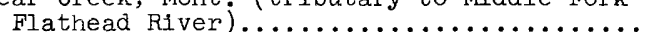

Bear Creek, Wash. (tributary to Green River).

Bear Creek, Wash. (tributary to Lake Shannonj

Bear Creek, Wash. (tributary to Little

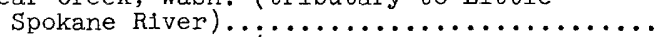

Bear Creek, Wash. (tributary to Sammamish

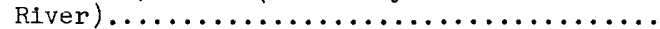

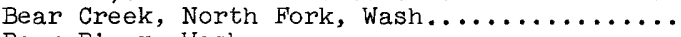

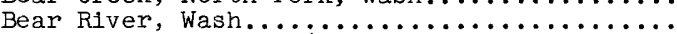

Beaver Creek, Wash. (tributary to Puget

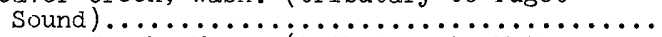

Beaver Creek, Wash. (tributary to Methow

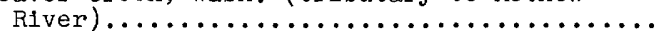

Beaver Creek, wash. (tributary to skagit

River $\ldots \ldots \ldots \ldots \ldots \ldots \ldots \ldots \ldots \ldots \ldots \ldots \ldots$

Beaver Creek, Wash. (tributary to Tokul

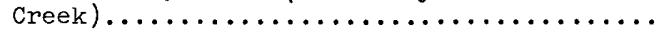

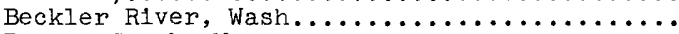

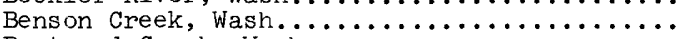

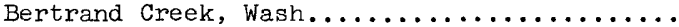

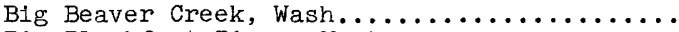

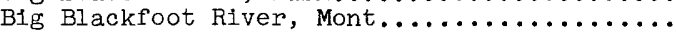

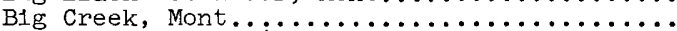

Big Creek, Wash. (tributary to Humptuiips

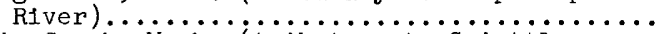

Big Creek, wash. (tributary to suiatile

R1ver).................................. (tributary to Yakima River)

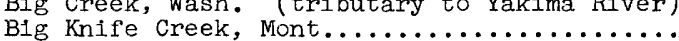

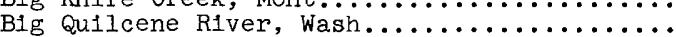

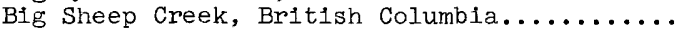

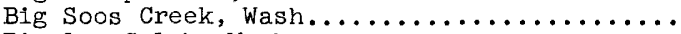

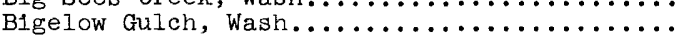

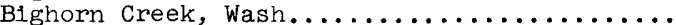

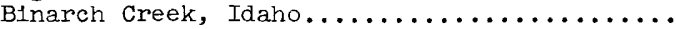

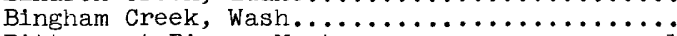

B1tterroot River, Mont......................... 20

Bitterroot River, East Fork, Mont............. 19

B1tterroot River, West Fork, Mont............ 19

Bitterroot River, West Fork, Reservoir, Mont.

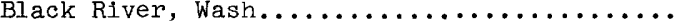

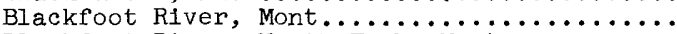

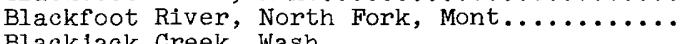

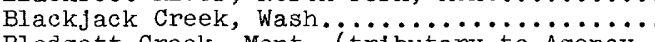

Blodgett Creek, Mont. (tributary to Agency

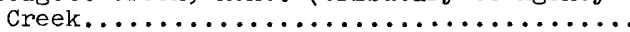

26 Blodgett Creek, Mont. (tributary to

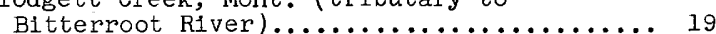

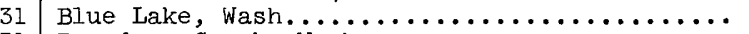

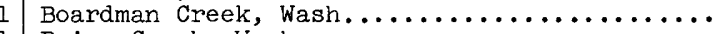

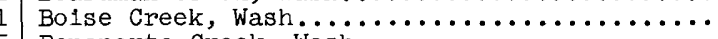

Boulder Creek, Idaho (tributary to Kootenai

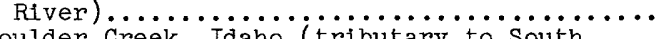

Boulder Creek, Idaho (tributary to South

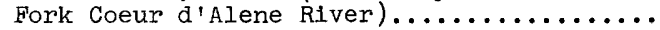

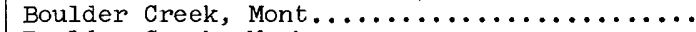

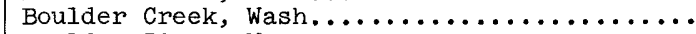

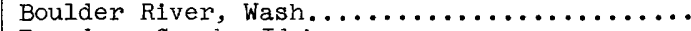

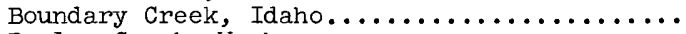

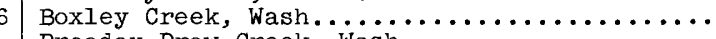

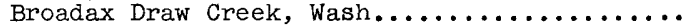

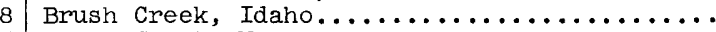

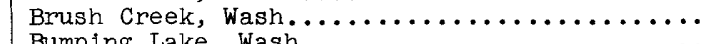

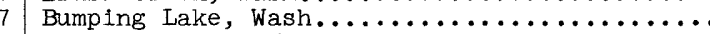

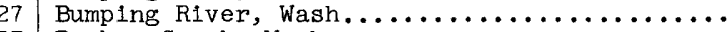

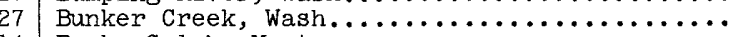

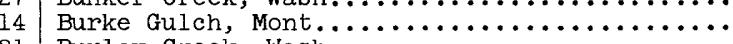

21 Burley Creek, Wash. (tributary to Green River)

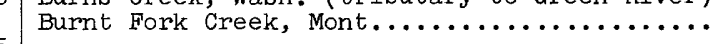

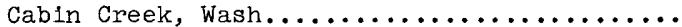

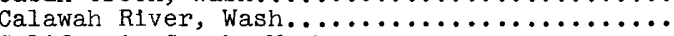

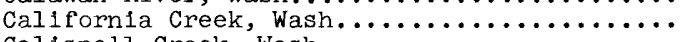
Calispell Creek, Wash.................

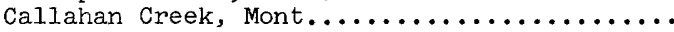

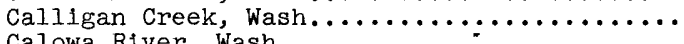

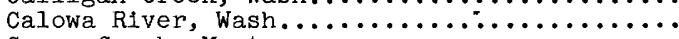

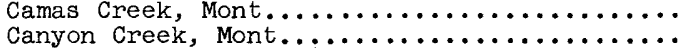
Canyon Creek, Wash. (tributary to

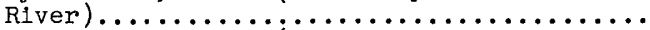

Canyon Creek, Wash. (tributary to Middie

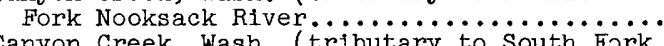

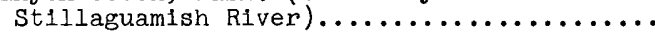

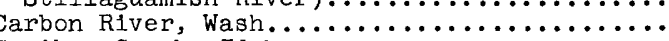

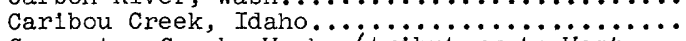
Carpenter Creek, Wash. (tributary to West Fork Woods Creek).................... Carpenter Creek, Wash. (tribüary to sikagit

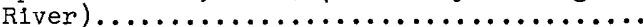

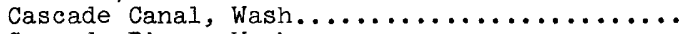

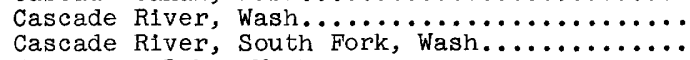
Cavanaugh Lake, Wash.................

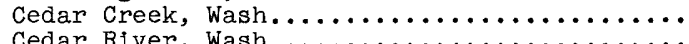

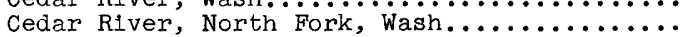
Cedar River, South Fork, Wash..............

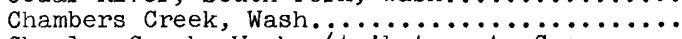

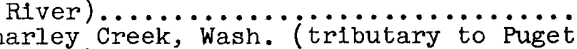

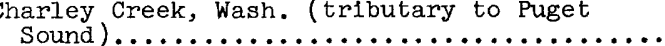

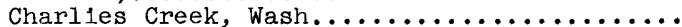

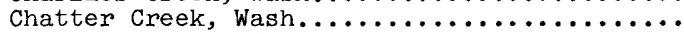

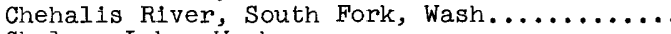

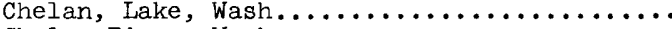

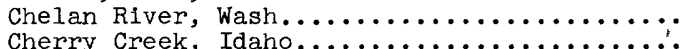

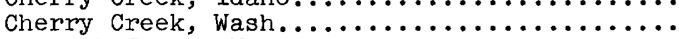
Chewack Creek, Wash..................

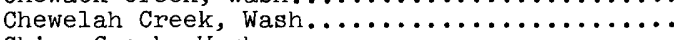

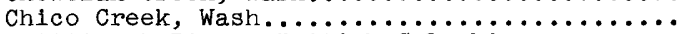
Chilliwack River, British Columbia..........

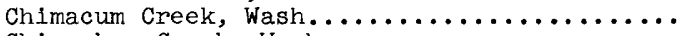

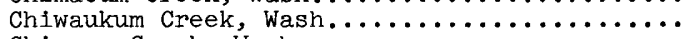

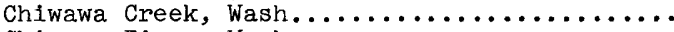

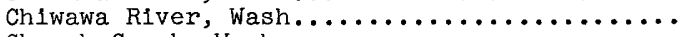
Church Creek, Wash.................................

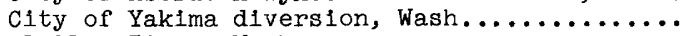

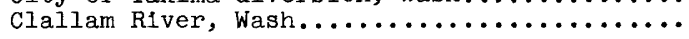
Charley Creek, Wash. (tributary tö Green

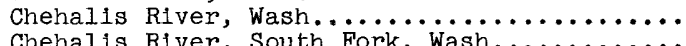

Page 
Clark Creek, Wash. (tributary to Cascade

River......... (tributary to Puyailup

liver

Rlark Fork, Idaho-Mont..............

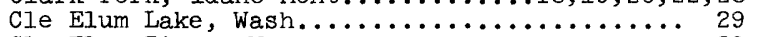

Cle Elum River, Wash................. 29

Cle Elum River, North Fork, Wash............ 29

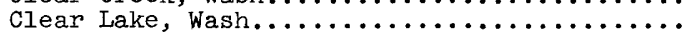

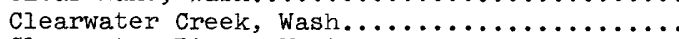

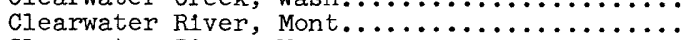

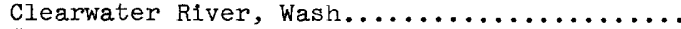

Cloquallum Creek, Wash $\ldots \ldots \ldots \ldots \ldots \ldots \ldots \ldots \ldots$

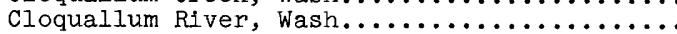

Clover Creek, Wash....

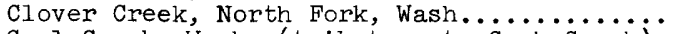

Coal Creek, Wash. (tributary to Crab Creekj)..

Coal Creek, Wash. (tributary to Lake

Washington).

Coal Creek, Wash. (tributary to Nooksack River)

Coal Creek, Wash. (tributary to Skagit River)

Coeur d'Alene Lake, Idaho $\ldots$......................

Coeur d'Alene River, Little North Fork, Idaho.
Coeur d'Alene River, South Fork, Idaho........

Coeur d'Alene River, North Fork, Idaho..........

Coeur d'Alene River, South Fork, Idaho..........

Cold Creek, Wash..

Columbia River, British Columbia-

Wash..............18,23, 26,27,28,29,

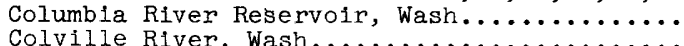

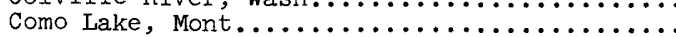

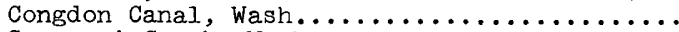

Connawai Creek, Wash.

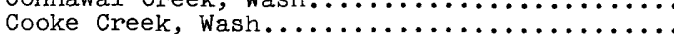

Cool Creek, Wash...

Cottage

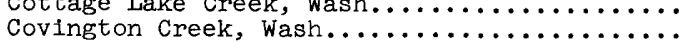

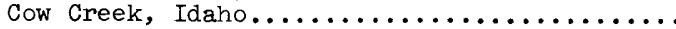

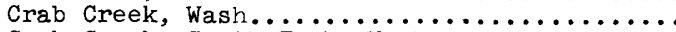

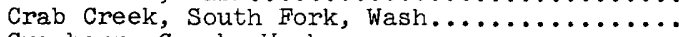

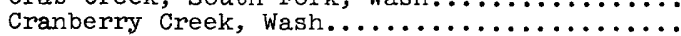

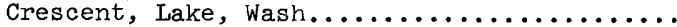

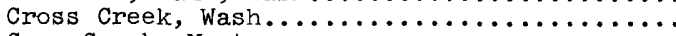

Crow Creek, Mont...

Cub Creek, Wash.

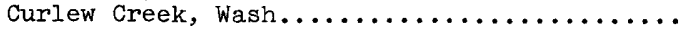

Curlew Lake, Wash.

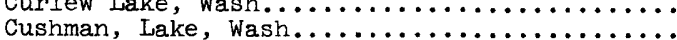

Cyclone Creek, Mont.

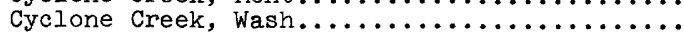

Dakota Creek, Wash.

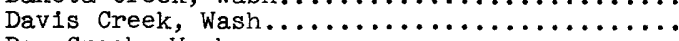

Day Creek, Wash..

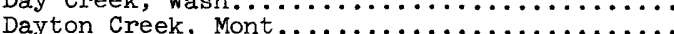

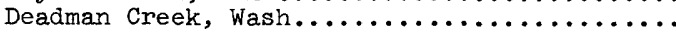

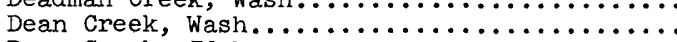

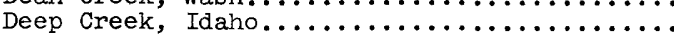

Deep Creek, Mont

Deep Creek, Wash. (tributary to Bumping

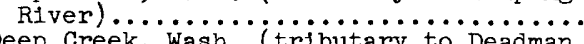

Deep Creek, Wash. (tributary to Deadman

Creek)......... (troßbutary to Green $\ldots$ hiver).

Deep Creek, Wash. ( tributary to Green R

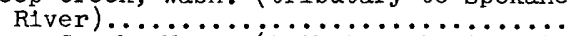

Deer Creek, Wash. (tributary to Colville

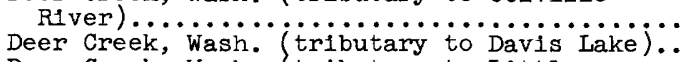

Deer Creek, Wash. (tributary to Little

Spokane River) . (tributary to North Fork

Deer Creek, Wash. (tributary to North Fork

Deer Creek, Wash. (tributary to Puget Sound $)$.

Deer Creek, Wash. (tributary to South Fork

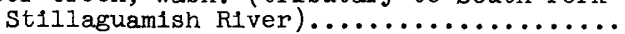

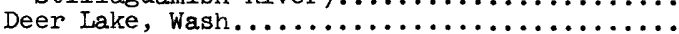

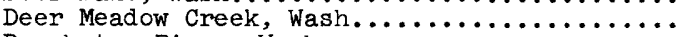

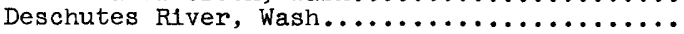

Page

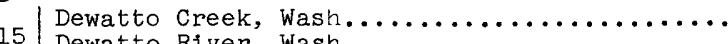

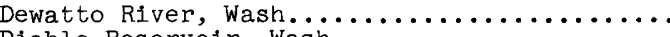

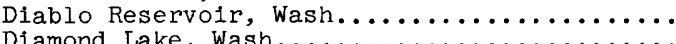

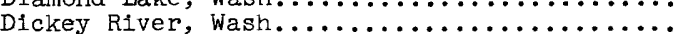

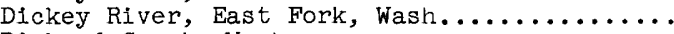

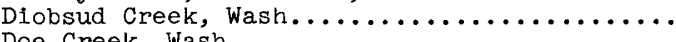

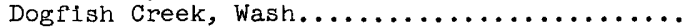

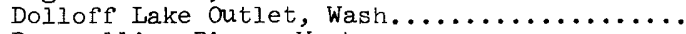

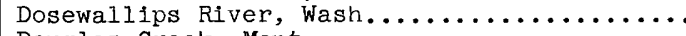

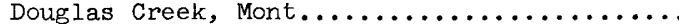

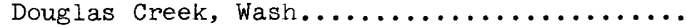

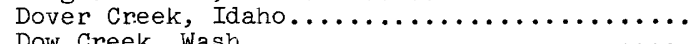

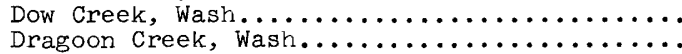

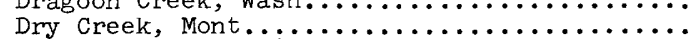

Dry Creek, Wash. (tributary to Tonasket

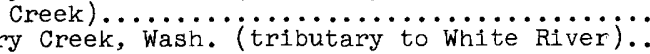

Dry Creek, Wash. (tributary to White River).. Dubuque Creek, Wash. $\ldots \ldots \ldots \ldots \ldots \ldots \ldots$

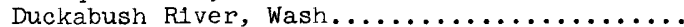

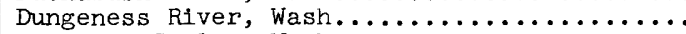

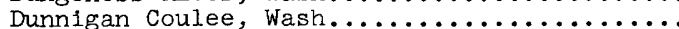

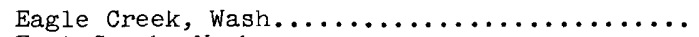

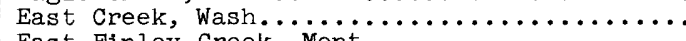

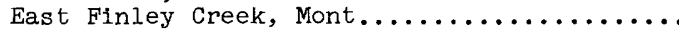

East Fork or Branch. See name of main stream.

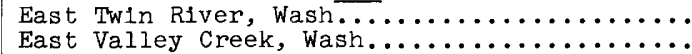

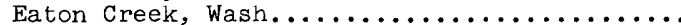

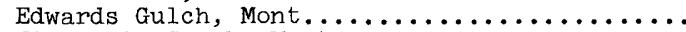

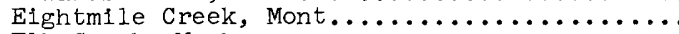

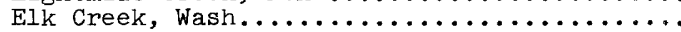

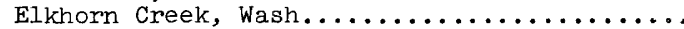

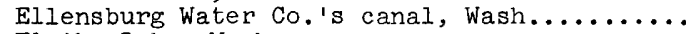

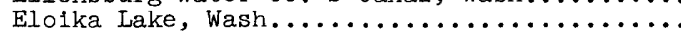

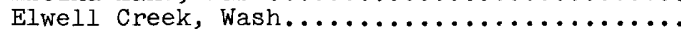

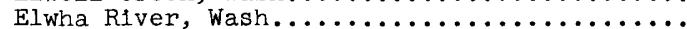

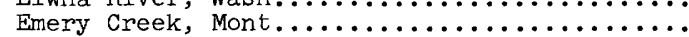

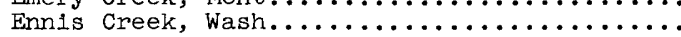

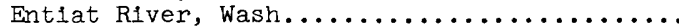

Esquatzel Coulee, Wash.....................

Evans Creek, Wash. (tributary to Bear Creek)

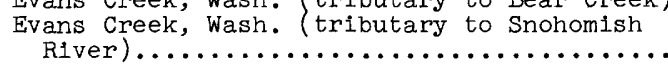

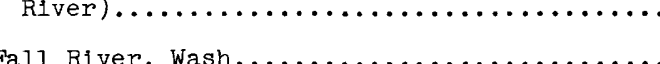

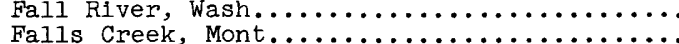

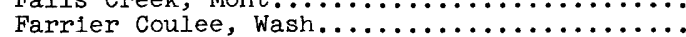

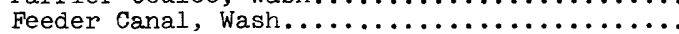

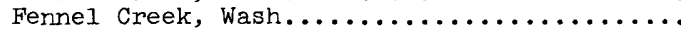

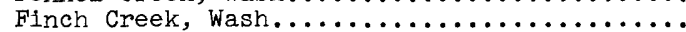

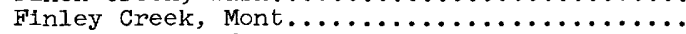

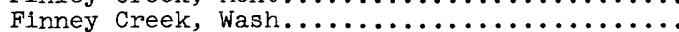

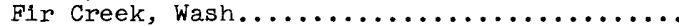

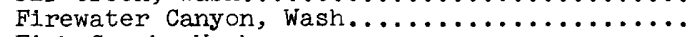

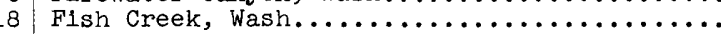

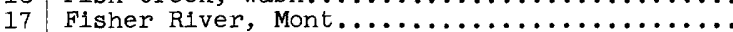

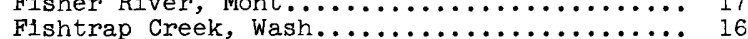

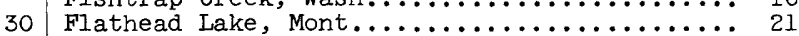

Flathead River, British Coiumbia-Mont.........20, 21

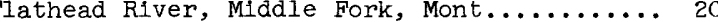

Flathead River, North Fork, Mont.......... 20

Flathead River, South Fork, Mont............. 20

Flett Creek, Wash......................... 9

Flint Creek, Mont....................... 19

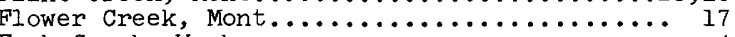

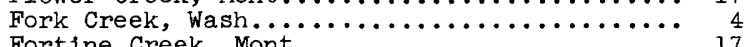

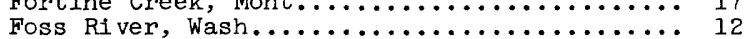

Foss River, East Fork, Wash................

14 Foster Creek, East Fork, Wash.................

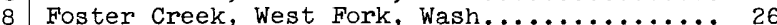

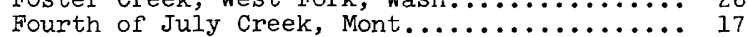

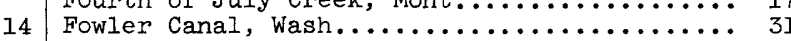

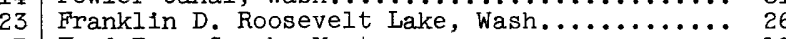

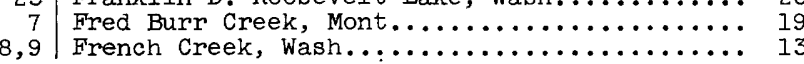
.
8

8

14
25 
Friday Creek, Wash. (tributary to Green River) .................................... (tributary to Samish

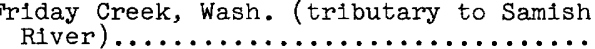

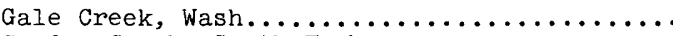

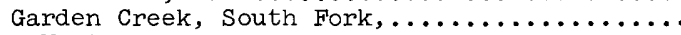

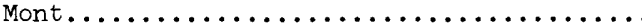

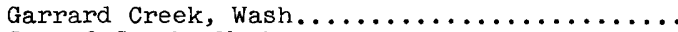

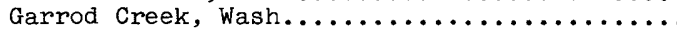

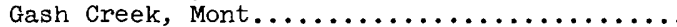

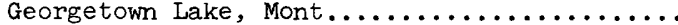
German Gulch Creek, Mont.

Gibson Creek, Wash...

Gilligan Creek, Wash.....

Gleed Canal, Wash. Gold Creek, Mont. (tributary to ciark Fork).. Gold Creek, Mont. (tributary to Kootena1

River)................................... (tributary to Dungeness

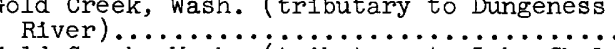

Gold Creek, Wash. (tributary to Lake cheianj. Gold Creek, Wash. (tributary to Tahuya River)

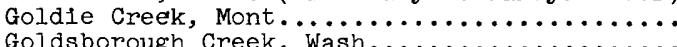

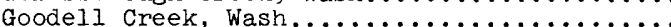

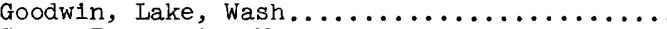

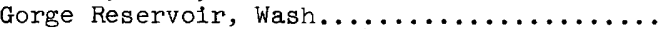

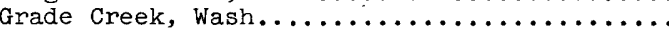

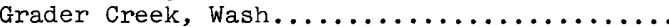
Grand Coulee, Wash.

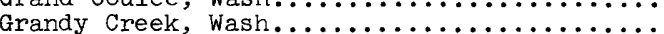

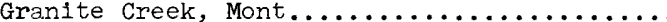

Granite Creek, Wash. (tributary to Ruby

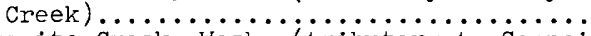

Granite Creek, Wash. (tributary to Sanpoil

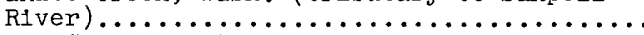

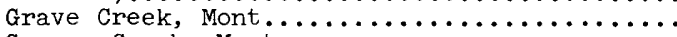

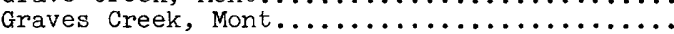

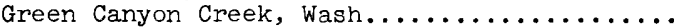

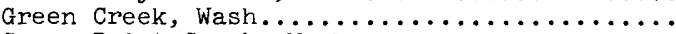

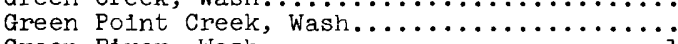

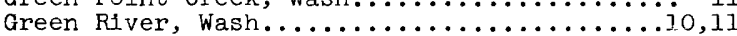

Green River, North Fork, Wash........... 10

Greenwater River, Wash...................

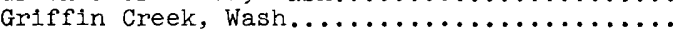

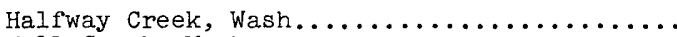

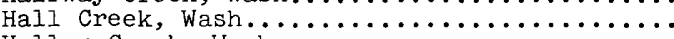

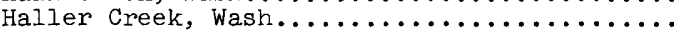

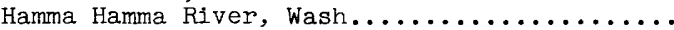

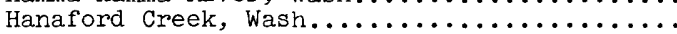

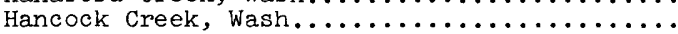

Hangman Creek, Wash...................24,25

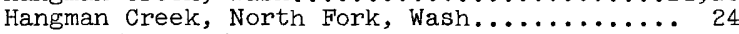

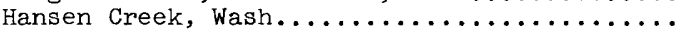

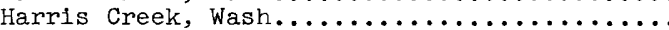

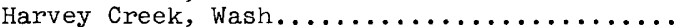

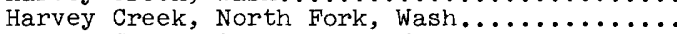

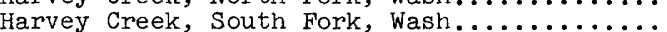

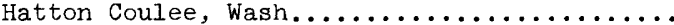

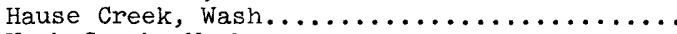

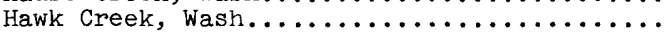

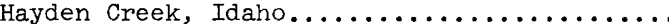

Hayden Lake, Idaho...............................

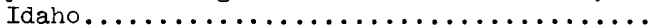

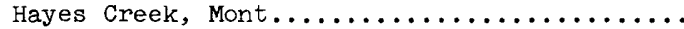

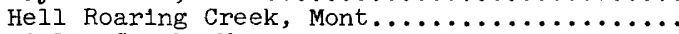

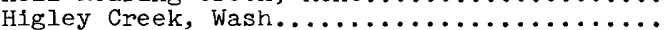

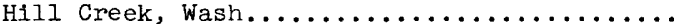

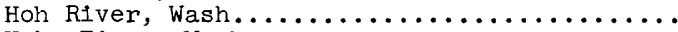

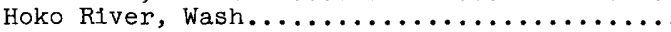

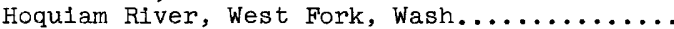

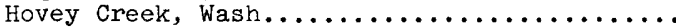

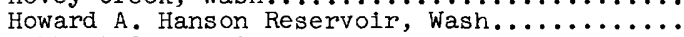

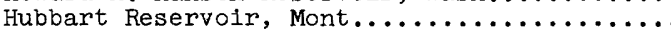

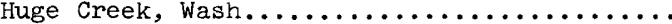

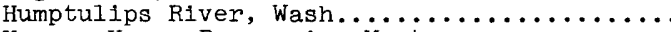

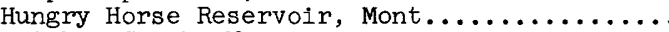

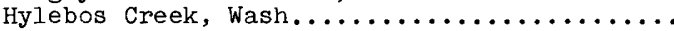

\section{0}

6

Creek, Wash.

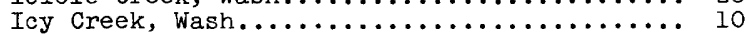

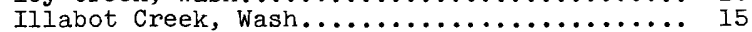

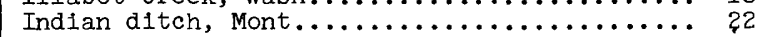

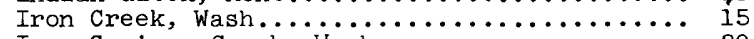

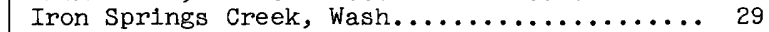

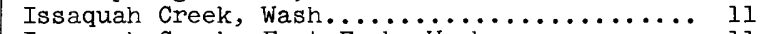

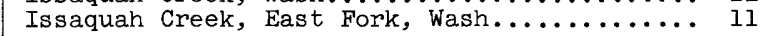

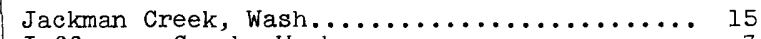

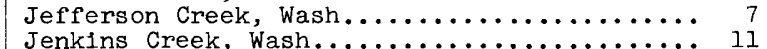

Jim Creek, Wash. (tributary to South Fork:

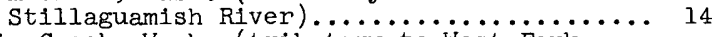

Jim Creek, Wash. (tributary to West Fork

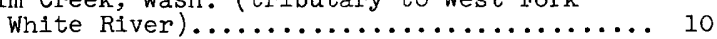

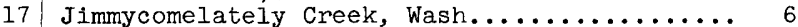

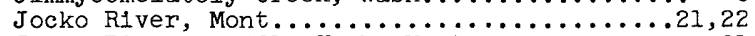

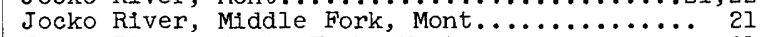

27 Jocko River, North Fork, Mont............... 21

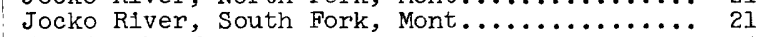

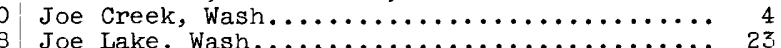

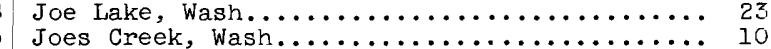

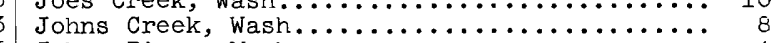

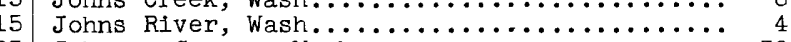

27 Johnson Canyon, Wash.................. 30

Johnson Creek, Wash. (tributary to Okanogan

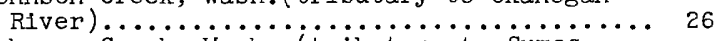

Johnson Creek, wash. (tributary to Sumas

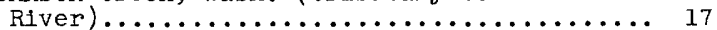

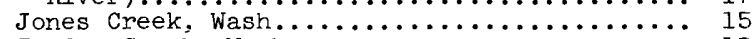

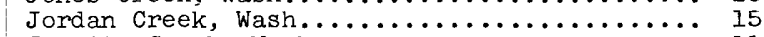

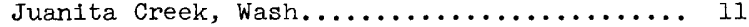

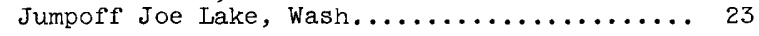

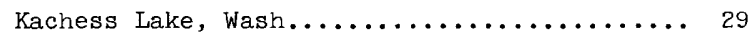

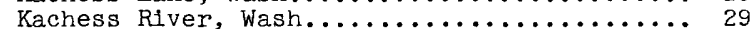

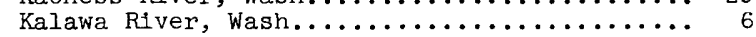

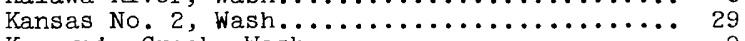

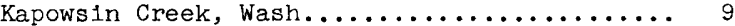

Keechelus Lake, Wash.................. 29

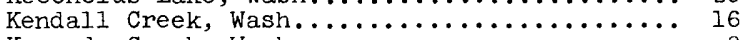

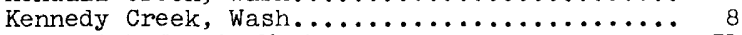

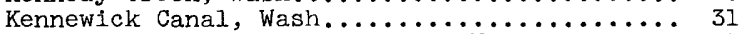

Kettle River, British Columbia-Wash........... 23

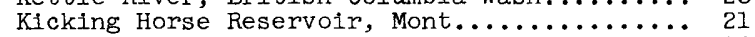

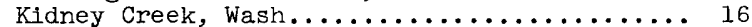

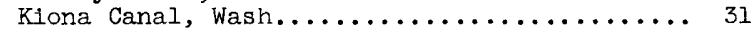

Kitsap Lake, Wash............................ 8

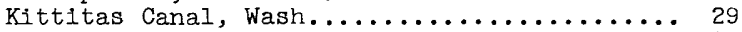

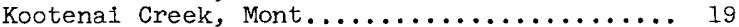

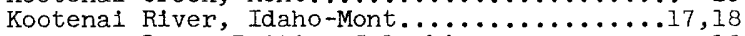

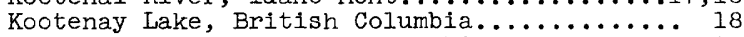

Kootenay River, British Columbia............. 17

La Grande Reservolr, Wash............... 9

Lake. See specific name of lake.

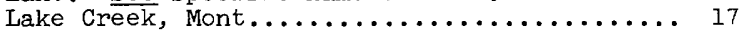

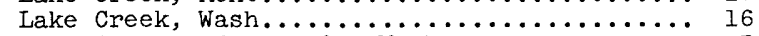

Lake Cushman Reservoir, Wash.................. 7

4 Lake McDonald Outlet, Mont................ 20

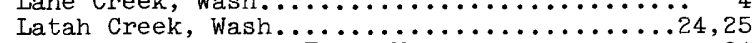

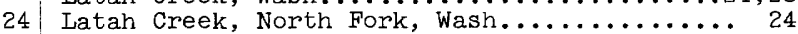

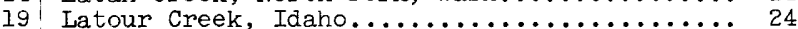

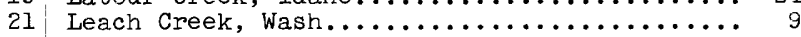

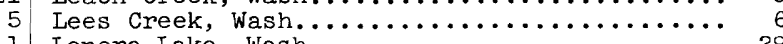

1 Lenore Lake, Wash...................... 29

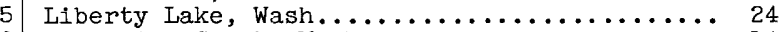

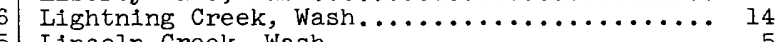

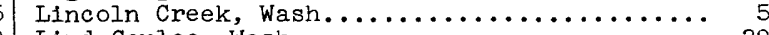

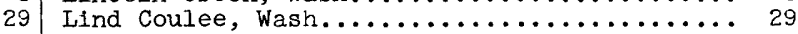

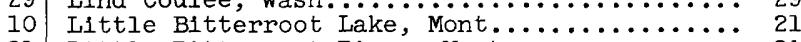

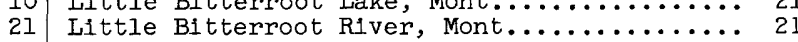

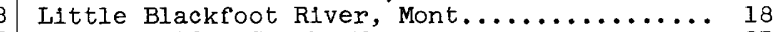

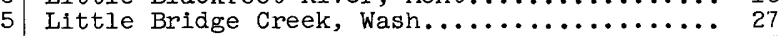

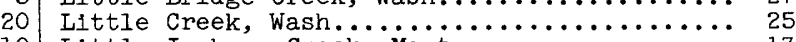

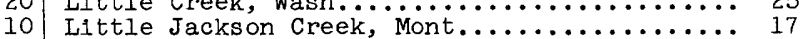


Little Joe Creek, North Fork, Mont......... 20

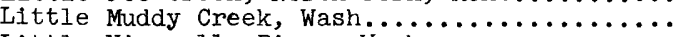

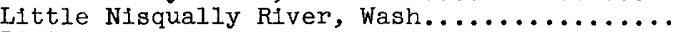

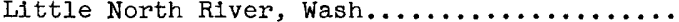

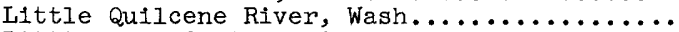

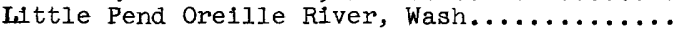

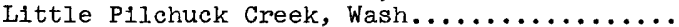

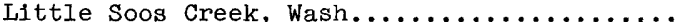

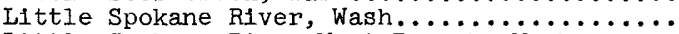
Little Spokane Rive, West Branch, Wash.......

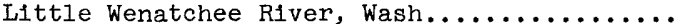

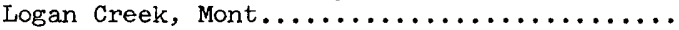

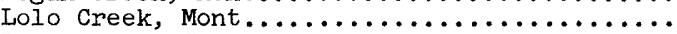

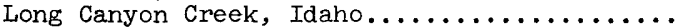

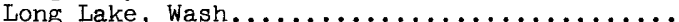
Loon Lake, Wash.

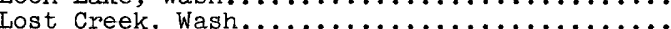

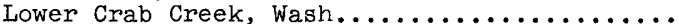

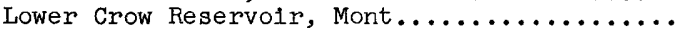

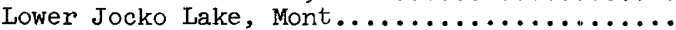

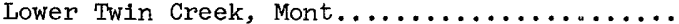

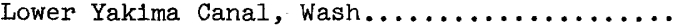

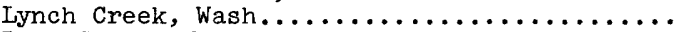

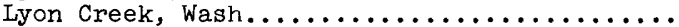

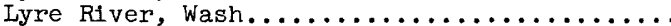

McAleer Creek, Wash.

McAllister Springs, Wash.

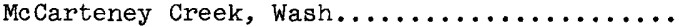

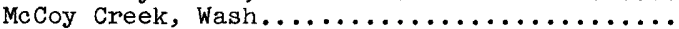

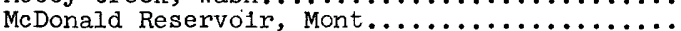

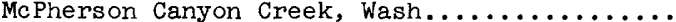

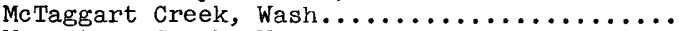

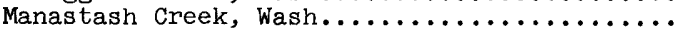

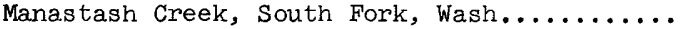

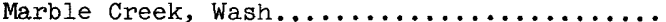
Marshall Creek, Mont. (tributary to Clark Fork).

Marshail Creek, Mont. (tributary to Filint

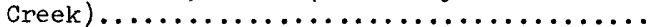

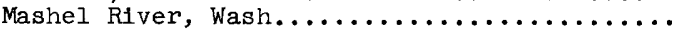

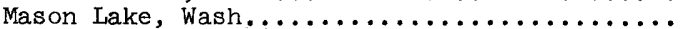

May Creek, Wash. (tributary to Bogachiel

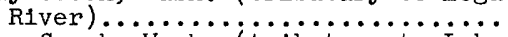

May Creek, Wash. (tributary to Lake

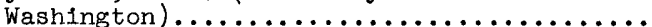

May Creek, Wash. (tributary to Wallace River)

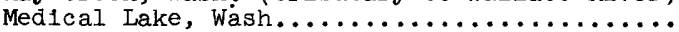

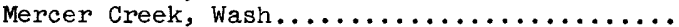

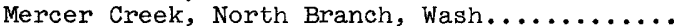

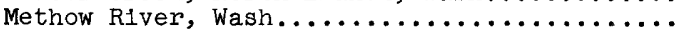

Middle Fork or Branch. See name of main stream.

Mill Creek, Mont. (tributary to Colville

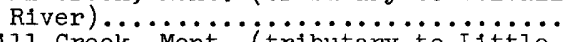

Mill Creek, Mont. (tributary to Iittle

Bitterroot River ..................

Mill Creek, wash. (tributary to Puget

Mill Creek, Wash. (tributary to Willapa

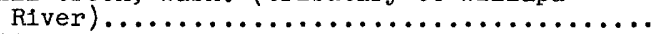

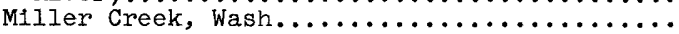

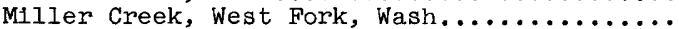

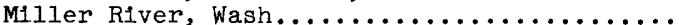

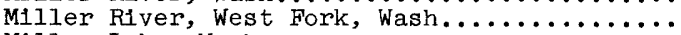

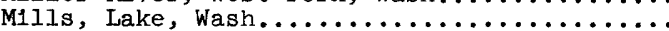

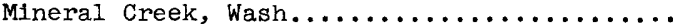

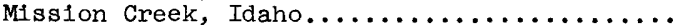

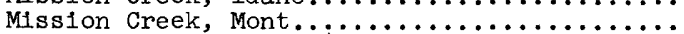

Mission Creek, Wash. (tributary to Puget

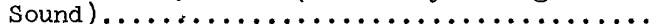
Mission Creek, Wash. (tributary to Wenatche

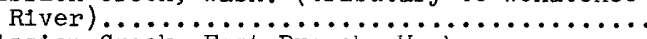

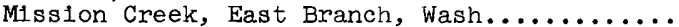

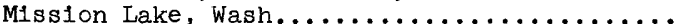

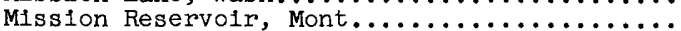

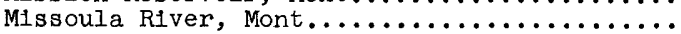

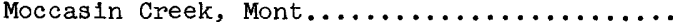

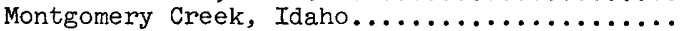

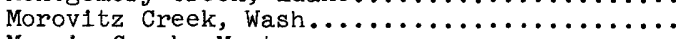

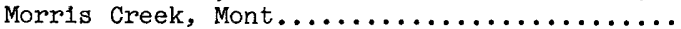

\section{6}

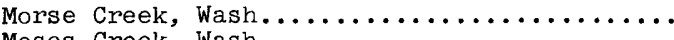
Moses Creek, Wash $\ldots \ldots \ldots \ldots \ldots \ldots \ldots \ldots \ldots \ldots$

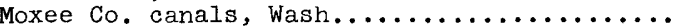

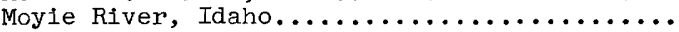

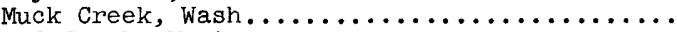

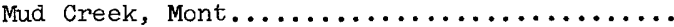

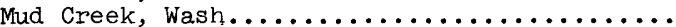

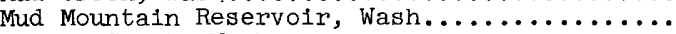

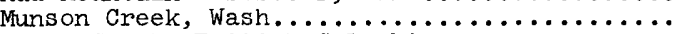

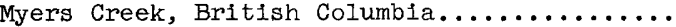

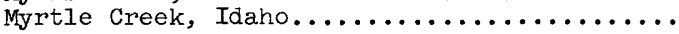

Naches Avenue Union Canal, Wash............

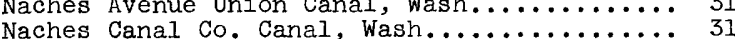

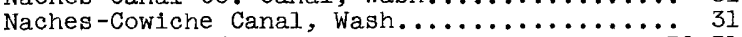

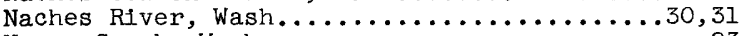

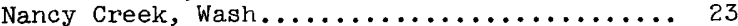
Naneum Creek, Wash.................. 30

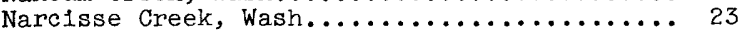
Naselle River, Wash................. 4 Naselle River, South Fork, Wash........... 4

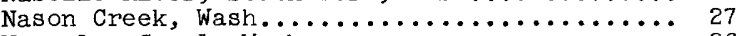

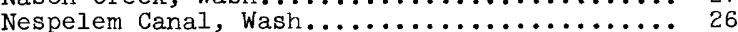

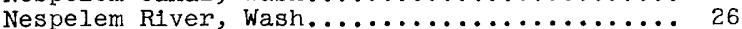

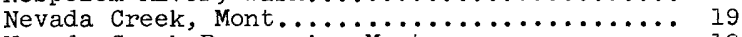
Nevada Creek Reservoir, Mont................. 19 New Reservation Canal, Wash................ 31 Newaukum Creek, Wash................... 10 Newaukum River, Wash $\ldots \ldots \ldots \ldots \ldots \ldots \ldots \ldots \ldots \ldots \ldots{ }_{4}$ Newaukum River, North Fork, Wash......... 4 Newaukum River, South Fork, Wash......... 4 Newhalem Creek, Wash................. 15

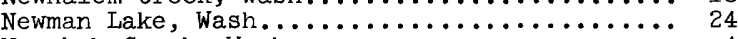

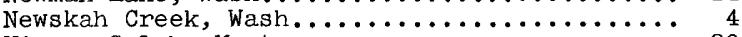
Nigger Gulch, Mont..................... 20 Ninepipe Reservolr, Mont.................. 21

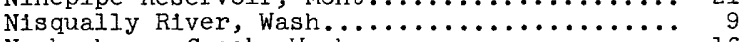
Nookachamps Creek, Wash.................. 16 Nookachamps Creek, East Fork, Wash............ 16 Nooksack River, Wash................... 16 Nooksack River, Middle Fork, Wash........... 16 Nooksack River, North Fork, Wash............ 16 Nooksack River, South Fork, Wash.............. 16 North Creek, Wash...........................

North Fork or Branch. See name of main stream.

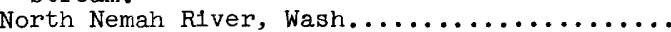

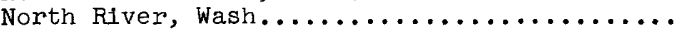
North Yakima Milling Co. waste, Wash............

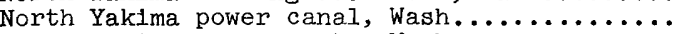

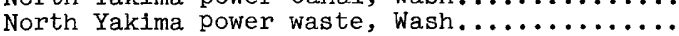

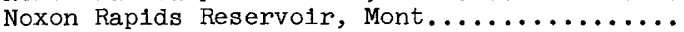

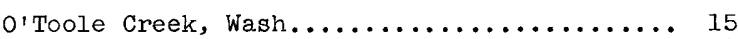
Oak Flat diversion, Wash............... 30 Ohop Creek, Wash.................... 9

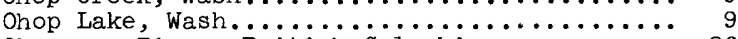
Okanagan River, British Columbia............ 26

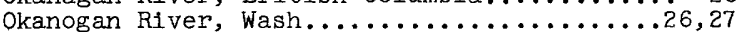

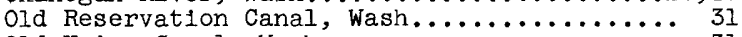
old Union Canal, Wash............................. 31

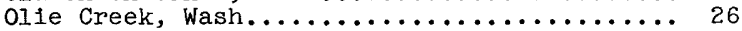

Olney Creek, Wash....................... 12

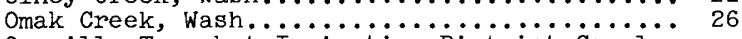
Oroville-Tonasket Irrigation District Canai;

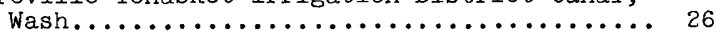

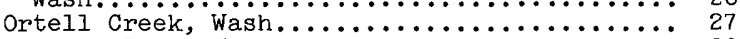

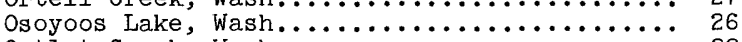

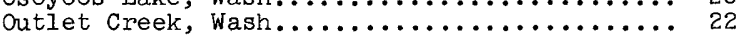

Pablo Reservolr, Mont............... 21

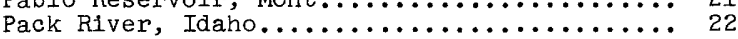

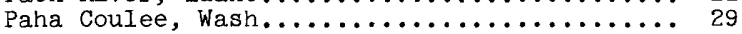

Painted Rocks Lake, Mont.................... 19

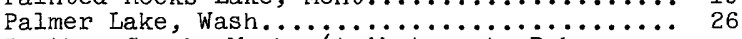
Panther Creek, Wash. (tributary to Dubuque

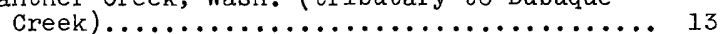
Panther Creek, Wash. (tributary to Tahuya

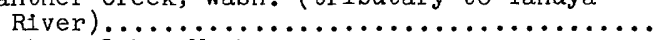

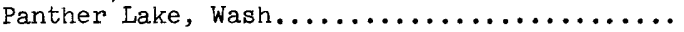
. 10 3 . .

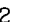
(5) (n) .

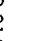

.
. (1) 
Page

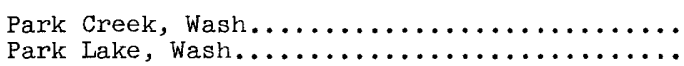

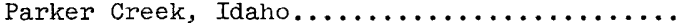

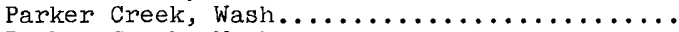
Parkey Creek, Wash.

Patterson Creek, Wash

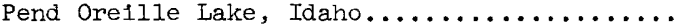

Pend Oreille River, Wash.

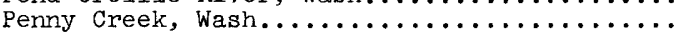

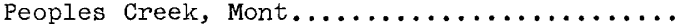

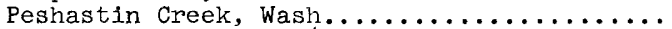

Phelps Creek, Wash. (tributary to Chiwawa

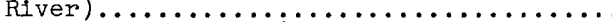

Phelps Creek, Wash. (tributary to South Fork

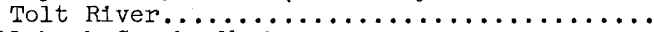

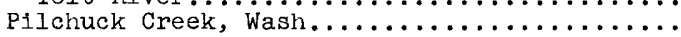

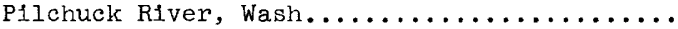

Pine Canyon, Wash....................

Pine Canyon Creek, Wash. (tributary to

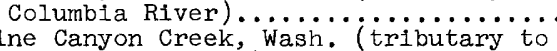

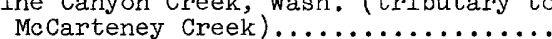

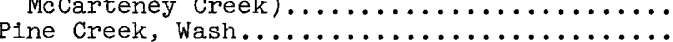

PIne Creek, West Fork, Idaho.............

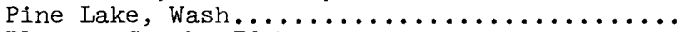

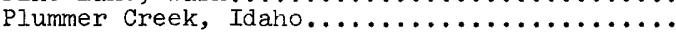

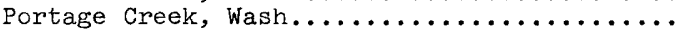

Porter Creek, Wash....................

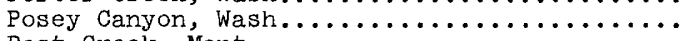

Post Creek, Mont..

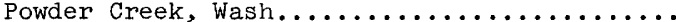

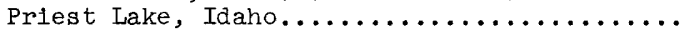

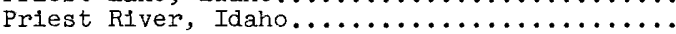

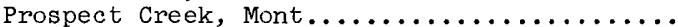

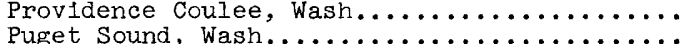

Puget Sound, Wash........................ (tributary

Purdy Creek, Wash. (tributary to Skokomish

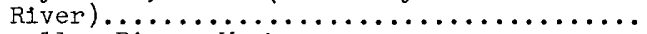

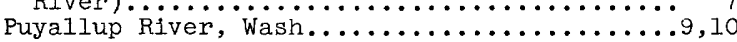

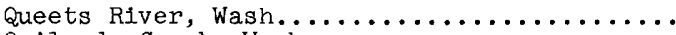
Quilceda Creek, Wash

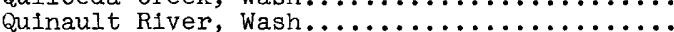

Quinault River, North Fork, Wash...........

Racetrack Creek, Mont.

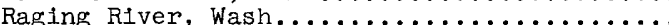

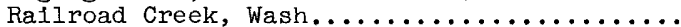

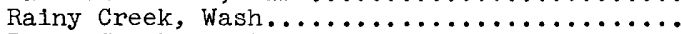

Ranch Creek, Mont.

Rapid Lightning Creek, Idaho.............

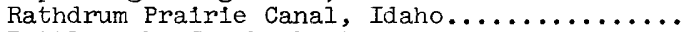

Rattlesnake Creek, Mont.................

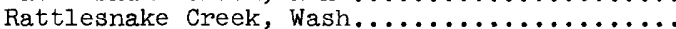

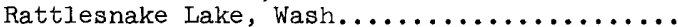

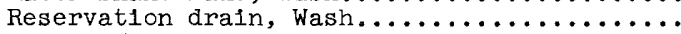

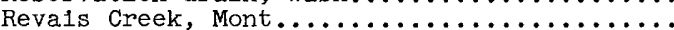

Rex River, Wash.

Rimrock Lake, Wash....................

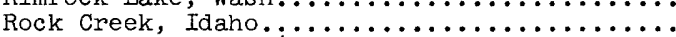

Rock Creek, Mont. (tributary to Bitierroot River).

Rock Creek, Mont. (tributary to

Rock Creek, Mont. (tributary to stillwater River).

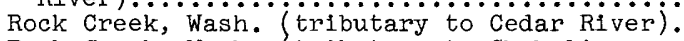

Rock Creek, Wash. (tributary to Chehalis

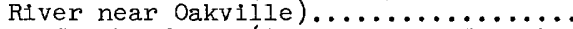

Rock Creek, Wash. (tributary to Chehalis

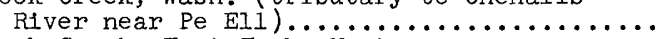

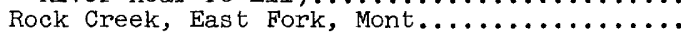

Rock Creek, Middle Fork, Mont..............

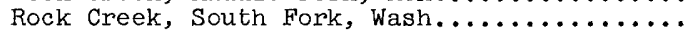

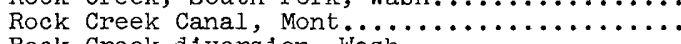

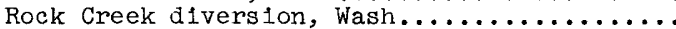

Rock Creek Reservolr, East Fork, Mont.......

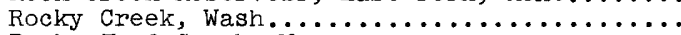

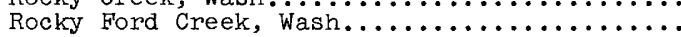

Roesiger Creek, Wash.................

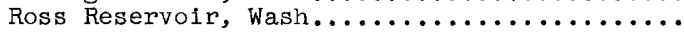

Roza Canal, Wash................... Ruby Creek, Wash...................

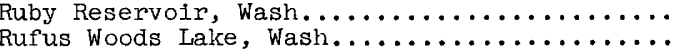
Saar Creek, Wash................... Sacheen Lake, Wash....................

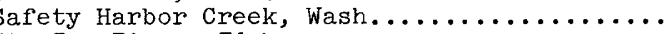

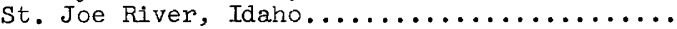

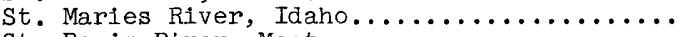
St. Regis River, Mont................

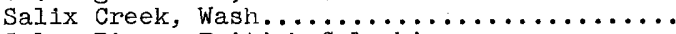
Salmo River, British Columbia............. Salmon Creek, Wash. (tributary to Naselie

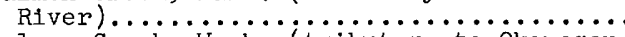
Salmon Creek, Wash. (tributary to Okanogan River $\ldots \ldots \ldots \ldots \ldots \ldots \ldots \ldots \ldots \ldots \ldots \ldots \ldots$ Salmon Creek, Wash. (tributary to Puget Sound )........................ Salmon River, British Columbia............

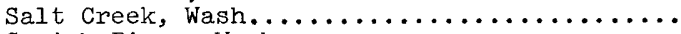

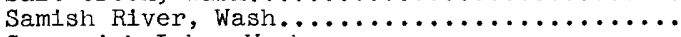

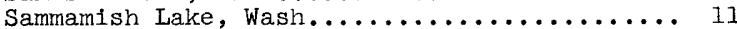

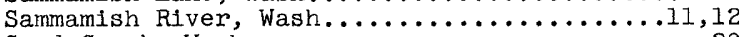

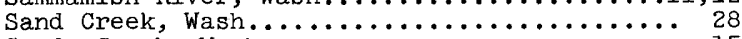

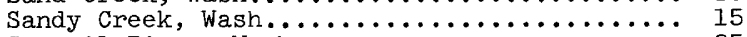

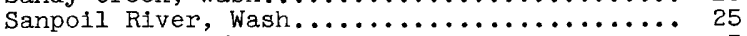

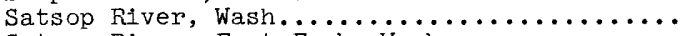

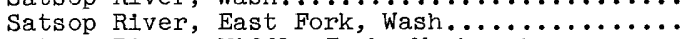

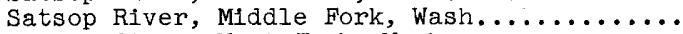

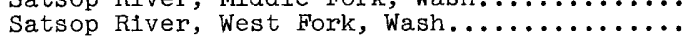

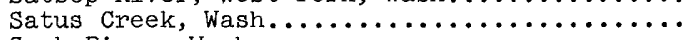

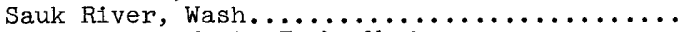

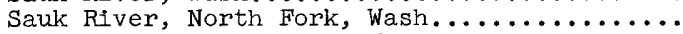

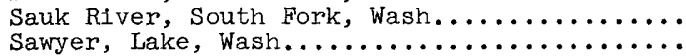
Scatter Creek, Wash...................

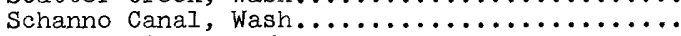

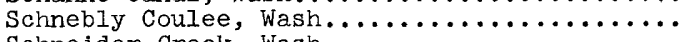

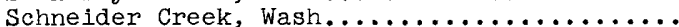

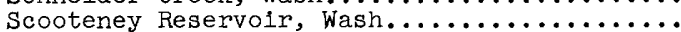

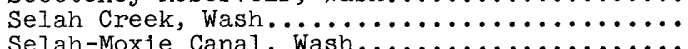

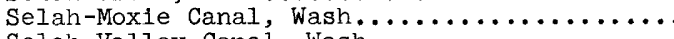

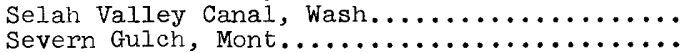

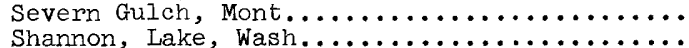

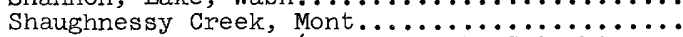
Sheep Creek, Wash. (tributary to Columbia

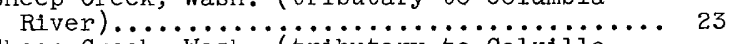
Sheep Creek, Wash. (tributary to Colvilie

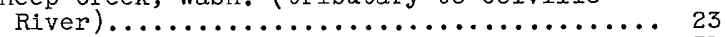

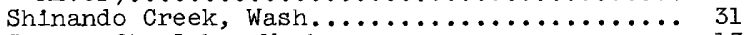

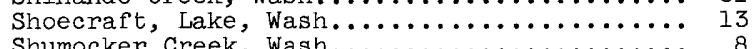

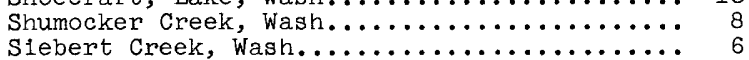

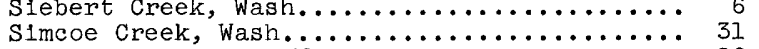

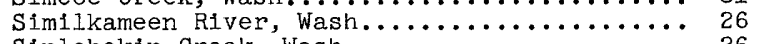

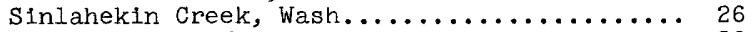

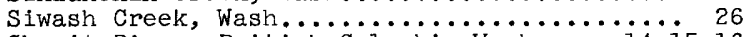
Skagit River, British Columbia-Wash......... 14, is, 16

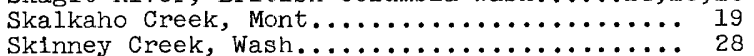

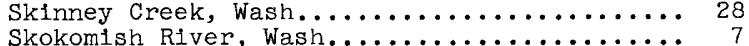
Skokomish River, North Fork, Wash........... 7 Skokomish River, South Fork, Wash.......... 7 Skookum Creek, Wash. (tributary to Puget Scund) Skookum Creek, Wash. (tributary to South

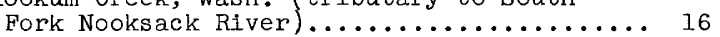

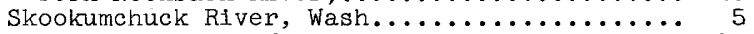

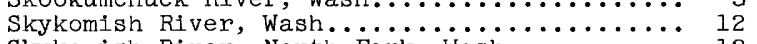

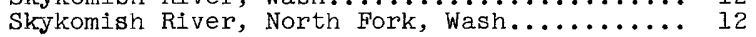

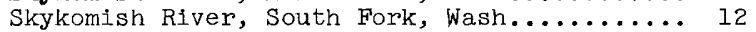

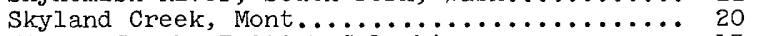
Slesse Creek, British Columbia.................. 17

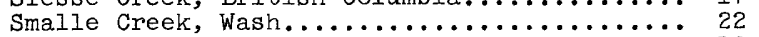

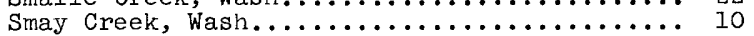

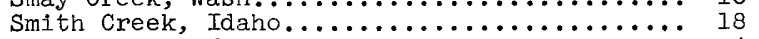

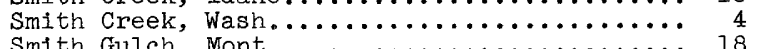

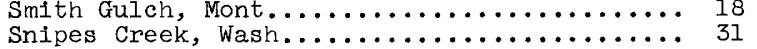

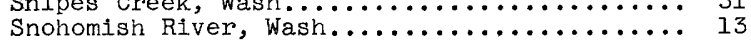




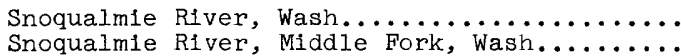
Snoqualmie River, Middle Fork, Wash...........................

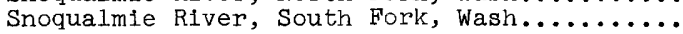
Snow Creek, Idaho $\ldots \ldots \ldots \ldots \ldots \ldots \ldots \ldots \ldots \ldots$. $\ldots \ldots$. $\ldots \ldots$. Snow Creek, Wash. ( tributary to Puget Sound)

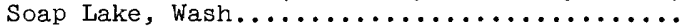

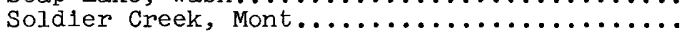

Soleduck River, wash............................

South Fork or Branch. See name of main stream.

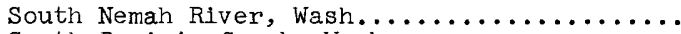

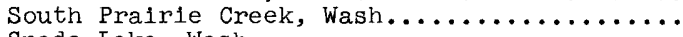

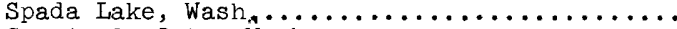

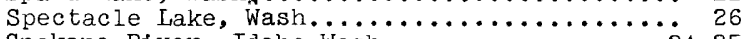

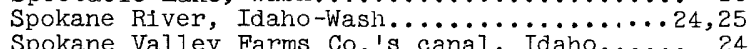

Spokane Valley Land and Water Co.'s canal,

Idaho $\ldots \ldots \ldots \ldots \ldots \ldots \ldots \ldots \ldots \ldots \ldots$

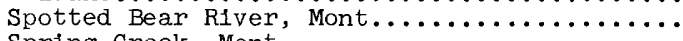

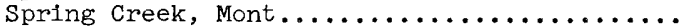

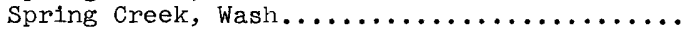

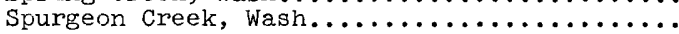

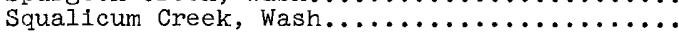

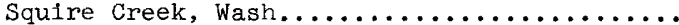

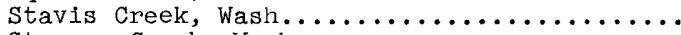

Stearns Creek, Wash.

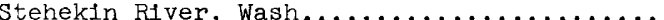

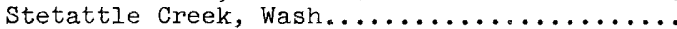

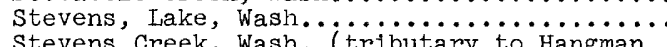

Stevens Creek, Wash. (tributary to Hangman

Creek) ......................... Tributary to ittie

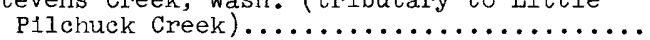

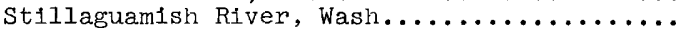

Stillaguamish R1ver, North Fork, Wash.......

Stillaguamish R1ver, South Fork, Wash..........

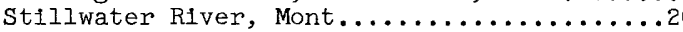

Stossel Creek, Wash. $\ldots \ldots \ldots \ldots \ldots \ldots \ldots \ldots \ldots \ldots \ldots \ldots$
Straight Creek, Wash $\ldots \ldots \ldots \ldots \ldots \ldots \ldots$

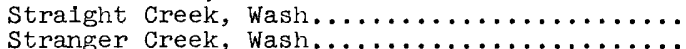

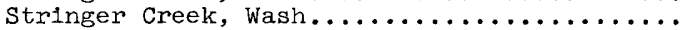

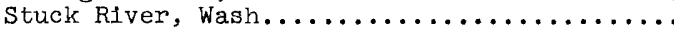

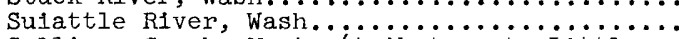

Sullivan Creek, Mont. (tributary to Litile

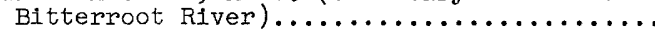

Sullivan Creek, Mont. (tributary to South

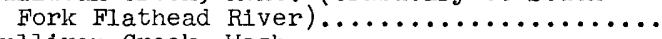

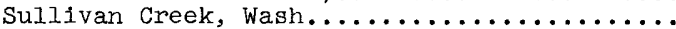

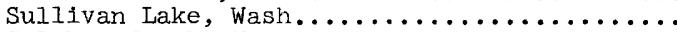

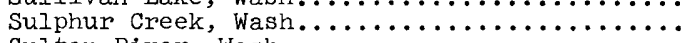

Sultan River, Wash.

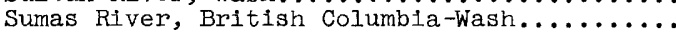

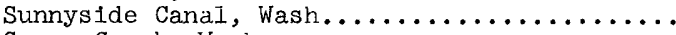

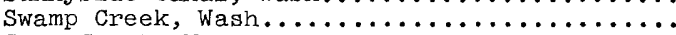

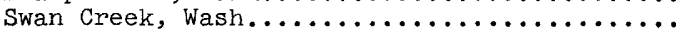

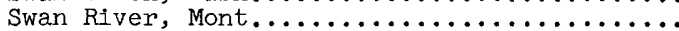

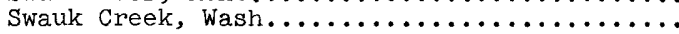

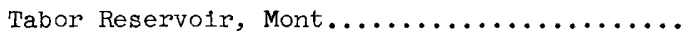

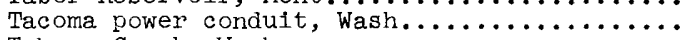

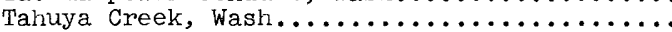

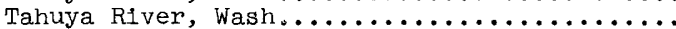

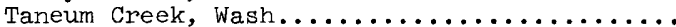

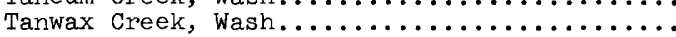

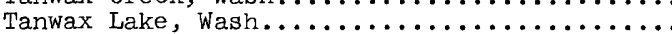

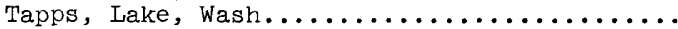

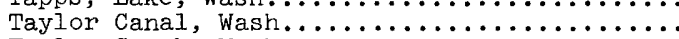

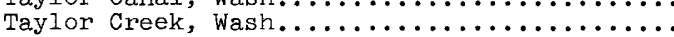

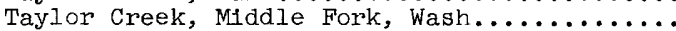

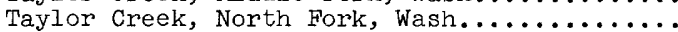

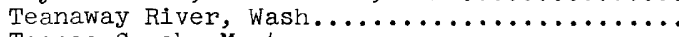

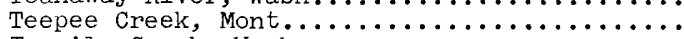

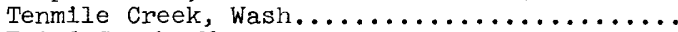

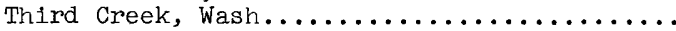

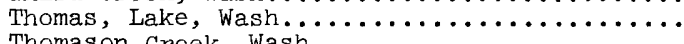

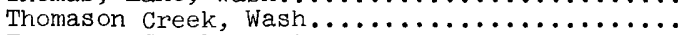

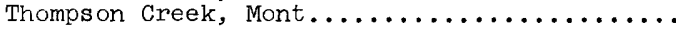

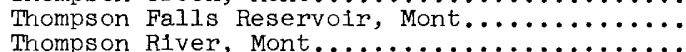

$13 \mid \begin{aligned} & \text { Thornton Creek, Wash } \ldots \ldots \ldots \ldots \ldots \ldots \ldots \ldots \ldots \ldots \ldots \ldots \ldots \\ & 12\end{aligned}$

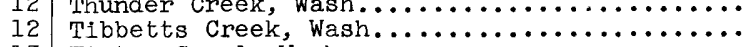

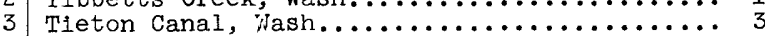

18 Tieton Reservo1r, Wash.................. 30

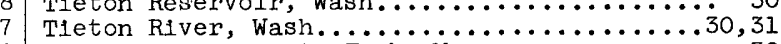

10 Tieton River, North Fork, Wash............. 30

29 Tillicum Creek, Wash................ 27

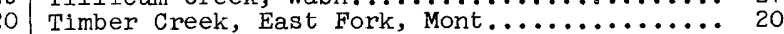

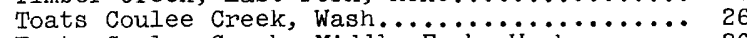

Toats Coulee Creek, Middle Fork, Wash....... 26

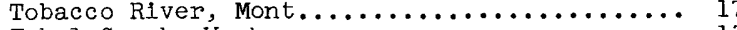

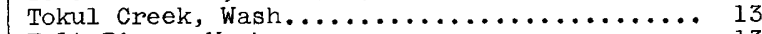

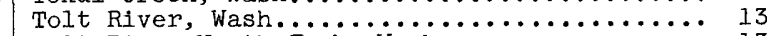

Tolt River North Fork, Wash............ 13

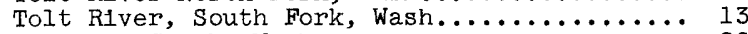

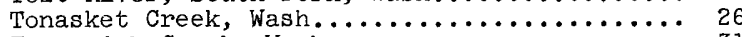

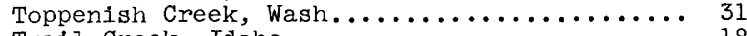

Trail Creek, Idaho................. 18

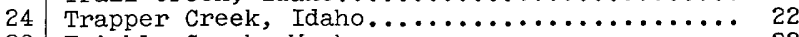

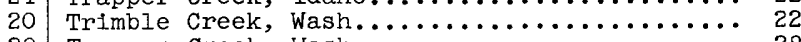

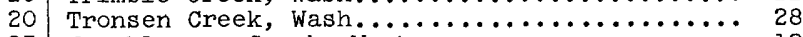

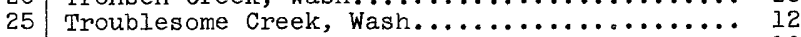

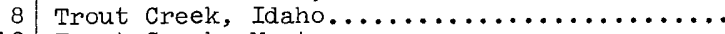

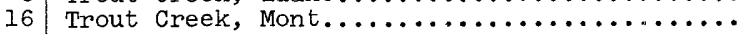

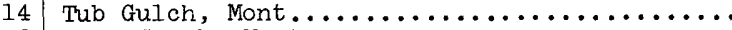

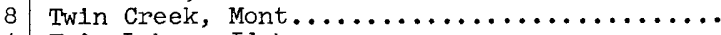

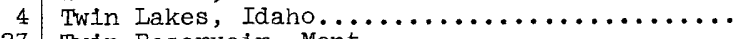

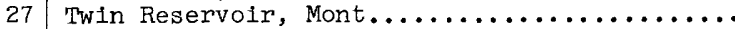

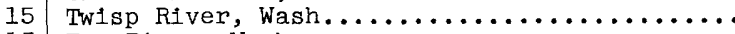

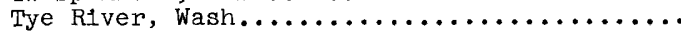

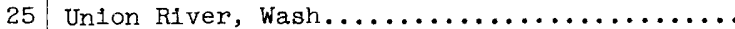

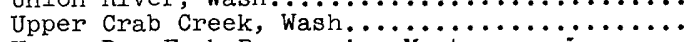

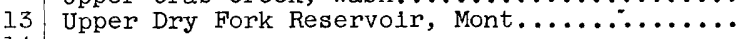

Valley Creek, Mont...................

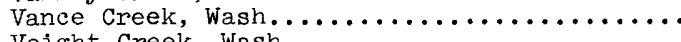

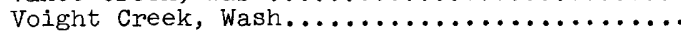

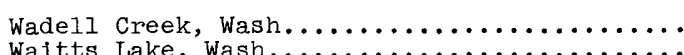

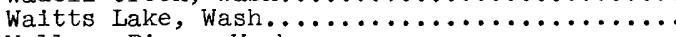

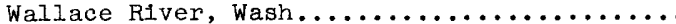
Wandermere Lake Creek, Wash..............

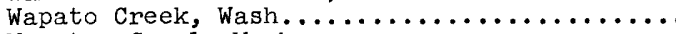

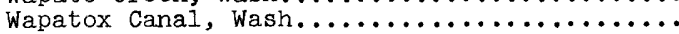

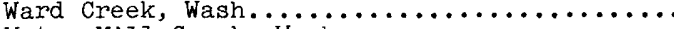

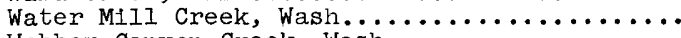

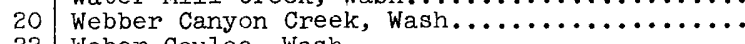

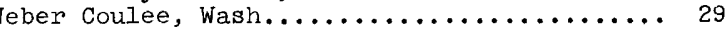

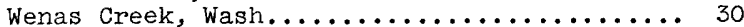

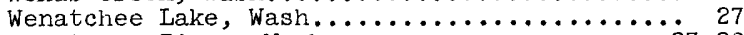

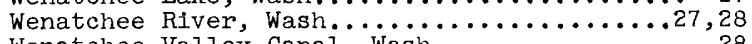

Wenatchee Valley Canal, Wash............. 28

West Fork or Branch. See name of main stream.

West Kittitas Canal, Wash............... 30

West Medical Lake, Wash................. 28

West Okanogan Valley Irrigation District

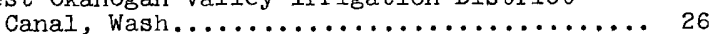

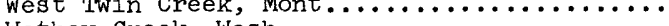

Wethey Creek, Wash...................

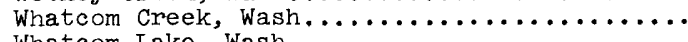

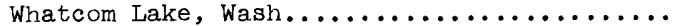

White Mud Lake, Wash.................. (head of Wenatchee River). White River, Wash. (tributary to Puyallup

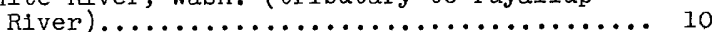

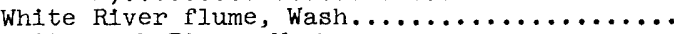

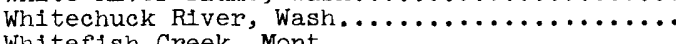

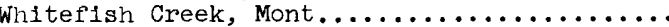

Whitestone Creek, Wash................

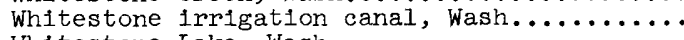

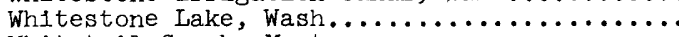

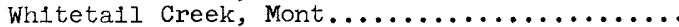

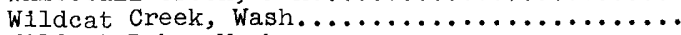

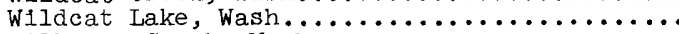

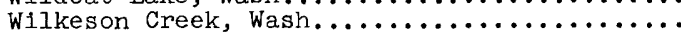

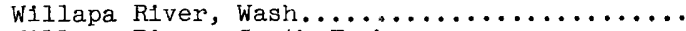
Willapa River, South Fork,

Wash.......................

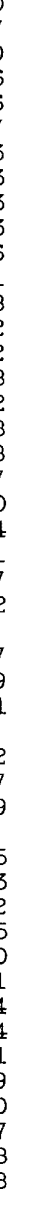
9 21

9 
W11liams Creek, Wash. (tributary to

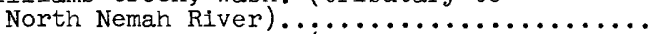

Williams Creek, Wash. (tributary to Twisp

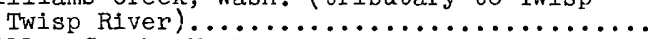

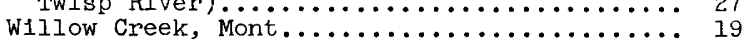

Wilson Creek, Wash. (tributary to Crab Creek) 29

Wilson Creek, Wash. (tributary to Yakima

River)...................... 30

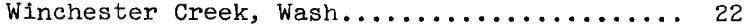

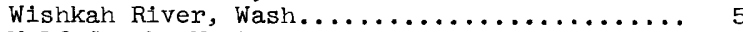

Wolf Creek, Mont......................
Page

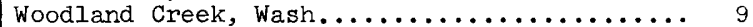

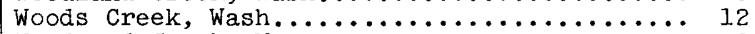

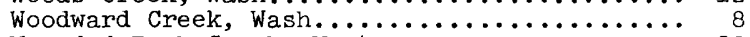

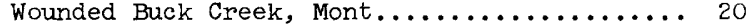

Wynoochee River, Wash................... 5

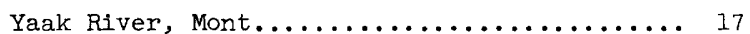

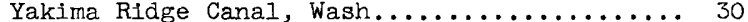

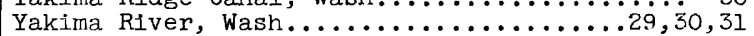

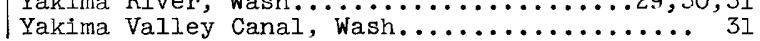




